\title{
XVIII.
}

\section{Beitrag zur Kenntnis der septischen Thrombophlebitis.}

(Aus dem Pathologischen Institut der Universität Berlin.)

Von

\begin{abstract}
Dr. Heinrich Schum,
früherem Assistenten des Instituts, jetzigem Assistenten an der chirurgischen Abteilung des Augusta-Hospitals, Berlin.
\end{abstract}

(Hierzu Taf. IV und 1 Textfigur.)

Bei der mikroskopischen Untersuchung infektiös erkrankter und thrombosierter Venen stößt man nicht allzu selten auf Bilder, die in frappanter Weise an den Anblick erinnern, den eine typische Pseudomembran, z. B. bei der Diphtherie der Trachea, bietet. Das heißt, man sieht ein Maschenwerk von glänzenden, feineren Fäden und dickeren hyalinen Balken auf der Innenfläche des befallenen Organs liegen, das zumeist vollständig seiner inneren Auskleidung (Epithel oder Endothel) beraubt ist. Eingestreut in die Membran finden sich Leukozyten, Kerntrümmer und hauptsächlich an der freien Oberfäche liegende Mikroorganismen, welche natürlich nicht als besonderes Charakteristikum der Pseudomembran zu betrachten sind. Auch makroskopisch sind diese Gebilde bei der Thrombophlebitis septica als ein der Innenfläche der Vene fest anhaftendes, ungefähr millimeterdickes Häutchen wohl wahrnehmbar, das sich nicht wie der übrige, halbfliüssige Inhalt des Gefäßes einfach wegspülen läßt.

Diese Erscheinungsform der „Phlebitis“ war den alten Pathologen auf Grund ihrer vorzüglichen makroskopischen Untersuchungen wohl bekannt, doch ist sie in neuerer Zeit, welche die thrombotischen Prozesse mehr in den Vordergrund gestellt hat, weniger berïcksichtigt worden und auch in den neuesten Lehrbüchern findet sich kaum ein Hinweis darauf. Immerhin schreibt Beneke ${ }^{7^{\mathrm{a}}}$ von Thromben bei lokaler Venenwandinfektion, daß der Gefäßinnenwand nicht sowohl Plättchenhaufen, als vielmehr unmittelbar Fibrinmassen, oft in dichtesten Zügen, sich anlagern. Diese Massen können direkt in das Fibrin zwischen den Wandschichten übergehen und machen dann die Hunter -A ndral -Cr uveilhiersche Anschauung, daß diese Thromben Exsudate der Gefäßwand seien, begreiflich. Allerdings schränkt er sofort die Bedeutung des Exsudates ein, indem er meint, niemand könne sagen, wieviel des umgelagerten Fibrins etwa einer aus der Gefäßwand in den Plasmastrom übergehenden Lymphe entstamme, es aber für erwiesen erklärt, daß das•vorüberfließende Blut die Hauptmasse der Auflagerung liefert. Nur Orth ${ }^{48-50}$ hat in seinen Lehrbüchern, besonders aber in einem kürzlich gehaltenen Vortrage, die exsudativen Vorgänge an der Innenfläche der Venenwand eingehender berücksichtigt. Die Vernachlässigung dieser Kenntnis ist vielleicht zum Teil darauf zurückzuführen, daß man die erwähnten Gebilde nicht als wirkliche Pseudo- 
membranen, d. h. ein entzündliches Produkt der Gefäßwand aufgefaßt hat, sondern als einen Teil des aus dem Blute stammenden Thrombus; in der Tat kann die Unterscheidung unter Umständen schwierig, ja unmöglich sein.

Zweiffellos sind auch den älteren Autoren Irrtümer untergelaufen, wenn sie den gesamten Inhalt des Venenrohrs bei septischer Thrombose als ein Exsudat der Gefäßwand ansprachen. So stellt Hunter ${ }^{21}$ die Entzündung der Venenwand (Phlebitis pseudomembranacea) ganz in den Vordergrund und beschreibt in einem Fall von Entzündung des Arms nach Aderlab, wie die ganze innere Oberfläche der Vene mit geronnener Lymphe bedeckt gewesen sei, welche aus den Vasa vasorum stammen soll ${ }^{1}$ ). Gegenüber der fast dominierenden Stellung, welche auch Cruveil hier für die Phlebitis in Anspruch nimmt, legt Leb ert ${ }^{39}$ doch das Hauptgewicht auf die thrombotischen Vorgänge und spricht nur ganz kurz von pseudomembranösen Bildungen; Rokitansky ${ }^{56}$ betont immerhin noch die Wichtigkeit des Exsudates an der inneren Oberfläche und meint, daß das Blut gerinnt, weil es mit dem Exsudat in Berührung kommt. Unter Exsudat versteht Rokitansky allerdings in erster Linie den vorhandenen Eiter, doch liest man einige Zeilen weiter, daß die zuweilen abgestoßene innere Gefäßhaut leicht mit einem ,,röhrförmigen Exsudat" verwechselt werden könne. Ein vollkommenes Extrem nach der andern Seite hin vertritt wieder Virchow, weleher der Gefäßwand bei erhaltenem Endothel die Möglichkeit einer serösen Aussehwitzung nur in die Substanz des GefäBrohrs, aber nicht àn die freie Oberfäche zugesteht. Wenn er auch in seinen späteren Schriften nicht mehr ganz so schroff an dieser Meinung festhielt und wenigstens für die Eiterkörperchen ein Auswandern aus der Venenwand zugestand, so hat doch diese seine Ansicht lange Zeit absolut geherrscht, und auch Eberth ${ }^{14-17}$ und Schimmelbusch schreiben in ihren bekannten Arbeiten, Virchow ${ }^{63}$ habe nachgewiesen, daß aus der Substanz der Blutaderwand keine Exsudation - im weitesten Sinne gesprochen - zustande kommen könne. Die Hartnäckigkeit, mit der an dieser Theorie festgehalten wurde, erscheint um so weniger erklärlich, als schon eine ganze Anzahl von Jahren vorher Koeste ${ }^{34}$ und Ebeling ${ }^{13}$ auf Grund genauer histologischer Untersuchungen die wichtige Rolle festgestellt hatten, welche das Venenrobr bei der infektiösen Thrombose spielt. Koester beschreibt eingehend die Anordnung der zahlreichen Vasa vasorum und des dichten Netzes von Saftspalten in der GefäBwand, schließlich auch die Prozesse, die hier bei septischen Erkrankungen vor sich gehen, nämlich eine von außen nach innen fortschreitende Lymphangitis und Perilymphangitis der Venenwand (eine Auffassung, die auch durch spätere Arbeiten von Freudweiler ${ }^{21}$, Wlass $0 \mathrm{w}^{6 \overline{5}}$ und Talke ${ }^{62}$ gestützt wird) mit deutlicher Exsudatbildnng zwischen die einzelnen Gewebselemente, ja auch in das Iumen des Gefäßes hinein. Was den letzteren Punkt anlangt, so spricht er allerdings nur davon, daß puriformes Material mit Leukozyten in die Lichtung der Vene übertrete, während Ebeling ausdrücklich betont, daß nicht nur flüssiges, gerinnbares Material, sondern auch weiße und rote Blutkörperchen aus der Wand ins Lumen gelangen könnten, um sich an der Bildung des Thrombus zu beteiligen. Die Tatsache, daß Eiterkörperchen die unverletzte Gefäßwand passieren können, wird nirgends mehr bestritten; abgesehen von der mikroskopischen Untersuchung der Leichenpräparate haben experimentelle Arbeiten diese Erkenntnis unwiderleglich gesichert. Ich nenne hier nur die von Bubn of ${ }^{10}$, welcher den Transport von Zinnoberkörnchen mit Hilfe der Leukozyten durch die ganze Dicke der Gefäßwand von anßen nach innen verfolgen konnte; ähnliches berichtet Merkel ${ }^{35}$ bei experimentell erzengten Pulmonalembolien. Dagegen wird die Ausscheidung von gerinnbarem Exsndat aus der Gefäßwand in den neueren Lehrbüchern der Pathologie kaum erwähnt, höchstens in der Literaturübersicht ganz kurz auf die genannten Arbeiten verwiesen, ebensowenig finde ich in dem Referat Asch off $s^{\star}$ über die Thrombose eine Erörterung dieser Frage, obwohl anch die infektiöse Thrombophlebitis ausführlich abgehandelt wird. Die meisten Autoren sprechen kurzweg von

$\left.{ }^{1}\right) \mathrm{Daß}$ Hunter mit dieser Schilderung ungefähr das meint, was wir unter einem fibrinösen oder serofibrinösen Exsudat verstehen, kann man aus andern Stellen seiner Schriften ohne jeden Zweifel entnehmen. 
einem Exsudat, meinen damit aber, soweit aus dem Zusammenhang ersichtlich ist, vorwiegend ein eitriges Exsudat; allein Orth braucht wieder den alten Namen: Phlebitis pseudomembranacea oder fibrinosa und schildert genan die von ihm oft beobachtete Pseudomembran; er betont auch stets in seinen Vorlesungen die Wichtigkeit, die er diesem entzündlichen Produkt der Venenwand beilegt.

Der Vollständigkeit wegen seien noch einige Einzelbeobachtungen genannt: $O b$ der von Gutsch $y^{23}$ und Laker ${ }^{38}$ geschaffene Begriff der „primären Fibrinmembran" etwas der erwähnten Pseudomembran Analoges ist, kann ich aus der Lektüre ihrer Aufsätze nicht entscheiden; dagegen fand Hauser ${ }^{25}$ die innere Wandfläche eines in phlegmonösen Partien liegenden Gefäßes, das seines Endothels beraubt war, mit einer dünnen Fibrinschicht bedeckt, und von ihr strahlten zarte Fibrinfäden ins Innere aus, also ein Bild, das jedenfalls den Verdacht auf eine Exsudation aus der Substanz der Wand erwecken muB, wenn auch Hauser eine ganz andere Dentung hierfür gibt, die mehr im Sinne Zenkers ${ }^{68}$ und Bizzozeros ${ }^{8}$ liegt. Ähnlich sind vielleicht auch die Beobachtungen v. Bardelebens ${ }^{7}$ aufzufassen, der bei der septischen Thrombophlebitis als erste Veränderung der Gefäßwand parallel angeordnete Fibrinmassen sah, die er allerdings als eine Abscheidung aus dem strömenden Blut betrachtete. Auf zwei andere hierher gehörige Arbeiten, die von Talke ${ }^{62}$ und Stenger ${ }^{61}$, mu.b ich weiter unten genauer eingehen.

Es würde den Rahmen dieser Veröffentlichung überschreiten, wollte ich hier die Vorgänge bei der einfachen, der blanden Thrombose und deren Pathologie in extenso erörtern; ich kann mir das um so eher versagen, als in der großen Literatur über dieses Thema sich eine ganze Anzahl von Aufsätzen findet, in welchen die Entwicklung des Begriffs Thrombose, deren pathologische Anatomie sowie die Theorien ihrer Entstehung übersichtlich zusammengefaßt sind, z. B. die von Schwalbe, Zurhelle, Aschoff, Rost und Yatsushiro. Nur einige Punkte, die für uns von besonderem Interesse sind, müssen kurz hervorgehoben werden; nämlich einmal, daß die Thrombose an sich nichts mit der Gerinnung zu tun hat. Trotz einzelner Stimmen, die sich noch in neuerer Zeit dagegen erhoben haben (Gutschy ${ }^{23}$, Laker ${ }^{38}$, Weigert ${ }^{64}$ und Kelling ${ }^{33}$ ), können wir heute wohl als allgemein gültige Theorie annehmen, daß die ersten Anfänge der Thrombenbildung eine durch vorwiegend mechanische Ursachen bedingte Abscheidung aus dem strömenden Blut sind (Virchow ${ }^{63}, \mathrm{Zahn}^{67}$, Eberth und Schimmelbusch ${ }^{14-17}$, Löwit ${ }^{42}$, Schwalbe ${ }^{59,60}$, Aschoff ${ }^{3-6}$, Loeb ${ }^{41}$, Ribbert ${ }^{51-54}$, Lubarsch ${ }^{44}$, Zurhelle ${ }^{71}$, Hauser ${ }^{25}$, Kusama ${ }^{35}$, Yatsushir. ${ }^{66}$ ), und zwar sind es die Blutplättchen, welche durch Haftenbleiben an der Gefäßwand und Zusammenkleben die allerersten Teile dieser Ablagerung darstellen (Konglutinationsthrombus). Auf dem korallenstockartigen Gerüst (Aschoff) von Blutplättchen siedelt sich ein Mantel von Leukozyten an, während die Erythrozyten, falls sie überhaupt noch Platz finden, in den noch übrig bleibenden Maschen liegen bleiben können. Zu einer Fibringerinnung kommt es zunächst gar nicht, sie kann, muß aber nicht, sich sekundär anschließen, und zwar setzt sie an den Rändern der Balken ein, breitet sich dann nach Aschoff auf das Leukozytenlager aus und kann schließlich auch auf die eventuell vorhandenen Erythrozytenhaufen übergreifen. $\mathrm{Zu}$ vermerken ist immerhin, daß die neueren Arbeiten auf diesem Gebiet das Einsetzen der Koagulationsthrombose schon in jüngeren Stadien annehmen und so die ganze Ansiedelung der roten und weißen Blutkörperchen als 
ihr Werk betrachten. Diese Vorgänge spielen sich im wesentlichen an der Entstehungsstelle des Thrombus (Kopfteil) ab; falls es nun, sei es durch einfache oder septische Blutpfropfbildung zu einem Verschluß des erkrankten Gefäßes kommt, so muß natürlich die stromauf gelegene Flüssigkeitssäule in vollständige Stagnation geraten; hier, im Schwanzteil, kann dann eine gesetzmäßige Abscheidung der einzelnen Elemente, die itio in partes, nicht mehr erfolgen, vielmehr wird eine gewisse Starre und Festigkeit dieser Blutmenge durch gerinnungsartige Vorgänge bewirkt.

Ich habe schon oben mit einigen Worten des zweiten für uns wichtigen Punktes gedacht, nämlich der Ätiologie der einfachen Thrombose; die von Vir eh 0 w zuerst aufgestellte Lehre von der Wichtigkeit der mechanisehen Momente ist mit Erfolg verfochten und neuerdings von A s.ch off weiter ausgebaut und dureh sinnreiche physikalische Experimente gestützt worden. Danach sind die Momente, welche für das Zustandekommen der Abscheidungsthromben, und damit für den Vorgang der Thrombose überhaupt, verantwortlich zu machen sind: die Alteration der Blutströmung (optimale Stromgeschwindigkeit), der qualitative und quantitative Zustand der Blutplättchen und schließlich die Veränderungen der Gefäßwand; es darf nicht unerwähnt bleiben, daß Ribbert gerade diesem letzten Punkt eine hervorragende Wichtigkeit beilegt. Es mag ja sein, daß diese für die Ätiologie der Thrombenbildung als ausschlaggebend beschriebenen Erscheinungen nicht für alle Fälle als vollkommen befriedigend anzusehen sind, wir müssen sie annehmen solange bis eine bessere Erklärung, gefunden ist.

Wäre nun die bakterielle oder toxische Ätiologie, auf welche immer und immer wieder, namentlich von seiten der Kliniker (siehe auch die Arbeiten von Freudweiler ${ }^{21}$, Jakowski ${ }^{36,37}$, Katzenstein ${ }^{31}$ ) hingewiesen wird, in Wahrheit geeigneter, uns das Auftreten blander Thromben zu erklären? Ich für meine Person glaube nicht an diese Theorie, da schon der kleine Prozentsatz positiver Bakterienbefunde bei systematischer Untersuchung von Leichenmaterial durch Lubarsch zu deutliçh dagegen spricht. Auch die Erscheinungen am Krankenbett, der oft fieberlose Verlauf, die Neigung zu Blutaderverstopfungen bei Störungen des. Zirkulationsapparates deuten doch immer wieder auf das Vorwiegen mechanischer Momente hin. Daß zuweilen irgendwelche Spaltpilze in den einfachen geschichteten Thromben vorkommen, kann nicht bestritten werden, doch ist es auf keinen Fall erlaubt, nun ohne weiteres in ihnen auch die Ursache der Blutpfropfbildung zu sehen und aus einzelnen Beobachtungen weittragende Schlüsse auf die Allgemeinheit zu ziehen. Wissen wir doch heutzutage, daß oft genug im menschlichen Kreislauf Mikroorganismen zirkulieren, ohne irgendwelche Erscheinungen zu machen; natürlich können diese, sobald es aus irgendwelchen sonstigen Gründen zu einer Thrombose kommt, einfach passiv in die Ablagerung der korpuskulären Blutelemente eingeschlossen werden (siehe Aschoff). Namentlich möchte ich die Experimente Jakowskis für recht wenig beweisend in dieser Beziehung ansehen, welcher nach Einverleibung von Mikroorganismen unter 
Anwendung erheblicher mechanischer Hilfsmittel Thrombosen erzielte und diese Ergebnisse als Stiitze für die infektiös-toxische Atiologie der Thrombenbildung angesehen wissen will; es ist doch im Prinzip nicht angängig, das, was man beweisen will, gewissermaßen als Voraussetzung bei seinen Experimenten zu benutzen, denn die gefundenen Venenpfröpfe kann man entweder als Folgen der angewendeten mechanischen Hilfsmittel betrachten oder es ist an irgend einer Stelle zu einer lokalisierten Wirkung der Bakterien gekommen, welche dann zu einer Thrombophlebitis septica geführt haben, aber nicht zu einer blanden Thrombose. Endlich steht nicht einmal die Thrombennatur der gefundenen Produkte fest, wie Zurhelle mit Recht betont. Dieser hat in einer größeren Arbeit die ganze bis 1910 bekannte einschlägige Literatur einer genauen Kritik unterworfen. und kommt zu einer. vollständigen Ablehnung der bakteriellen Ätiologie für die gewöhnliche Thrombose.

Wollte man sich wirklich zu dieser Theorie bekennen, so müßte man auch zugeben, daß eine prinzipielle Scheidung der Begriffe: einfache und septische Thrombose oder, wie ich lieber sagen möchte, Thrombophlebitis nicht mehr gestattet ist; der Einwand, daß es sich im einen Falle nur um die Anwesenheit von Mikroorganismen in der Blutbahn, im anderen um eine lokalisierte Ansiedelung und Wirkung der Bakterien handelt, dürfte wenig stichhaltig sein. Angenommen, die kreisenden Kokken hätten wirklich an einer Stelle der Blutbahn zu einer festen Abscheidung geführt, so müssen doch auch einige von ihnen hier mit eingeschlossen sein und haben nun in dem guten Nährboden die günstigsten Bedingungen für lokalisierte und unter dem Mikroskop nachweisbare Lebensäußerungen; man könnte nun wieder einwenden, für derartige Erscheinungen seien die gerade vorliegenden Bakterien nicht virulent genug, aber dann kann ich mir nicht vorstellen, daß derartig geschwächte Lebewesen ganz allein eine Thrombose hervorgerufen haben sollen. Finde ich also in einem solchen - vorausgesetzt, daß er nicht ganz frisch ist - typisch gebauten Thrombus Kokken ohne irgendwelche Reaktion der Umgebung, wie Nekrose, Fiterung und dergleichen, so kann ich mich nicht zu der Anschauung entschließen, daß die Bakterien die Bildung des Blutpfropfs verschuldet haben, und andererseits kann es sich nicht um eine Thrombophlebitis septica handeln, die sich makroskopisch und histologisch durch die oben kurz skizzierten Reaktionen des mensehlichen Körpers auf die Einwirkungen der Spaltpilze und ihrer Stoffwechselprodukte unterscheidet. Eine andere Frage ist es, ob die Anwesenheit von Mikroorganismen im Blut ein begünstigendes Moment für das Auftreten von Thrombosen darstellt, die nicht ohne weiteres mit nein beantwortet werden kann.

Aus dieser kurzen Darstellung ergibt sich, daß auch heute die Vorgänge bei der Thrombenbildung noch keineswegs endgültig geklärt sind, weder was ihr Wesen noch was die Ursachen anlangt. Es kann daher nicht wundernehmen, daß bei der septischen Thrombophlebitis noch manche Frage auf Antwort harrt; denn außer der Ablagerung von Blutelementen, welehe, wie oben kurz entwickelt, 
schon recht komplizierte und schwer zu deutende Erscheinungen darstellt, machen sich bei der Thrombophlebitis septica noch mancherlei Vorgänge bemerkbar, welche das Verstehen der mikroskopischen Bilder wesentlich erschweren. Dazu kommt, daß die Untersuchung des Leichenmaterials für ein genaueres Studium insofern sehr undankbar ist, als man die Fälle zuweilen in den ungünstigsten Stadien bekommt. So habe ich zum Beispiel mehrere Objekte ganz von meinen Untersuchungen ausschalten müssen, da die Zerstörungserscheinungen zu weit fortgeschritten waren, um noch einigermaßen den Ablauf der einzelnen Prozesse rekonstruieren zu können. Die genaue makroskopische Betrachtung ließ mich öfters im Stich, wenn es sich darum handelte, geeignete Stellen für die mikroskopische Untersuchung zu gewinnen; so fielen wieder manche Objekte weg, weil an dem gerade konservierten Stück sich nur ein roter oder ein gemischter Thrombus fand, entweder ganz ohne Mikroorganismen, oder auch mit solchen, aber ohne jede Entzündungserscheinung, also Veränderungen der Venen, die an dieser Stelle jedenfalls nicht sicher durch die Kokken geschaffen waren; streng genommen, ist eben nur die Partie geeignet, unsere Kenntnis der Thrombophlebitis septica zu bereichern, wo der Prozeß eingesetzt hat und als solcher fortschreitet, im wesentlichen also die, welche bei der gewöhnlichen Thrombose dem Kopfteil entspricht, während die übrigen Stellen ein ganz indifferentes Verhalten zèigen können. Endlich erwies es sich als sehr störend, daß ich oft nicht in der Lage war, bei der Sektion mit Sicherheit festzustellen, ob im vorliegenden Falle die Infektionserreger die zu untersuchende Vene vom Lumen oder der Peripherie aus angegriffen hatten. Auch die mikroskopische Untersuchung bietet gerade in diesem Punkte, wie der Verlauf der Arbeit zeigte, große Schwierigkeiten; z. B. ist es mitunter ganz unmöglich, hierüber eine Entscheidung zu treffen bei der Betrachtung von Schnitten eines Ligamentum latum, das vollkommen eitrig infiltriert ist und eine Anzahl von Venen mit septischen Thromben enthält. Um wenigstens in einigen Fällen vielleicht einen Anhalt zu bekommen, habe ich durchweg jeder Beobachtung einen kurzen Bericht über den klinischen Verlauf beigefügt, der auch für manche andere Frage wünschenswerte Fingerzeige bieten sollte.

Diese mancherlei erschwerenden Umstände mögen das ihrige dazu getan haben, daß systematische Untersuchungen über die Thrombophlebitis septica an Leichenmaterial in der neueren mir zugänglichen Literatur wenig zahlreich sind und stets nur eine relativ kleine Anzahl von Einzelbeobachtungen zum Gegenstand haben. Schließlich ist nicht zu vergessen, daß bei dem heutigen. Stande der Asepsis das Material der pathologischen Institute an infektiösen Venenerkrankungen absolut genommen, gar nicht mehr sehr groß ist, während den Autoren der vorantiseptischen Zeit vielleicht mehr Beobachtungen von septischen als von einfachen Thrombosen zur Verfügung standen $\left(0 \mathrm{rth}{ }^{50}\right)$.

Ich habe nun bei sämtlichen im Laufe von $21 / 2$ Jahren am hiesigen pathologischen Institut zur Sektion gekommenen Thrombophlebitiden mikroskopische Untersuchungen angestellt; nach Ausscheidung einiger Fälle, die mir aus den 
oben erwähnten Gründen nicht geeignet erschienen, bleibt noch immer eine Reihe von 29 Beobachtungen. Da ich mir keinen Augenblick darüber im Unklaren bin, daß eine so kleine Zahl keine weitgehenden Folgerungen gestattet, habe ich schließlich auch das Experiment zu Hilfe nehmen müssen, um nach Möglichkeit die Bedingungen festzulegen, unter denen es bei der Thrombophlebitis septica zur Pseudomembranbildung kommt.

Über diese selbst noch einige Worte: die in den einleitenden Zeilen gegebene Beschreibung bringt ein Bild von dem, was Orth eine oberflächliche pseudomembranöse Entzündung nennt; während dieses Exsudathäutchen an der Oberfläche der Tonsillen oder der Trachea z. B. abgestoßen werden, und, da nur das Epithel zerstört ist, die Heilung ohne Narbenbildung erfolgen kann, tritt bei der tiefen pseudomembranösen Entzündung auch eine Ausschwitzung gerinnbarer Massen in die Saftspalten der darunter gelegenen Gewebe ein, welche von einer wenigstens teilweisen Nekrose dieser Partien gefolgt ist. Zu einer Heilung kann es also nur dadurch kommen, daß das tote Material abgestoßen und der eintretende Substanzdefekt durch eine bindegewebige Narbe ersetzt wird. Hier steht also im Vordergrund das Absterben von Körpergewebe, die Geschwürsbildung, und in diesem Sinne hat Orth die Endocarditis ulcerosa auch als diphtheroide Entzündung bezeichnet. Als Analogon hierzu spricht Benda ${ }^{2}$ in Aschoffs Lehrbuch von einer Endophlebitis diphtheroides, trifft also mit diesem Namen nicht ganz das, was mich vor allem zu der vorliegenden. Arbeit führte, nämlich die oberflächliche Pseudomembranbildung; das heißt die Exsudation einer gerinnbaren Flüssigkeit an die Innenfläche der mit Ausnahme des Endothels erhaltenen Venenwand. Da nun beide Formen der Erkrankung mehr quantitativ als qualitativ versehieden sind, so leuchtet es wohl ein, daß bei Fortdauer der bakteriellen oder toxischen Reize der oberflächliche in den tieferreichenden, nekrotisierenden Prozeß übergehen, daß auch beide nebeneinander vorkommen, ja daß bei einer von außen wirkenden Infektion die Entziundung nach dem Lumen zu fortschreiten und so unter gewissen Umständen die oberflächliche Exsudatbildung der in den tieferen Wandschichten folgen kann. Gerade aber die Häutchen an der inneren Oberfläche sind es, die wir relativ häufig bei der septischen Thrombose antreffen, und sie spielen meiner Ansicht nach eine nicht unwichtige Rolle bei dieser Erkrankung. Es ist in gewissem Grade auffallend, daß bisher auf diesen Befund so wenig hingewiesen ist. Manche Autoren mögen ihn für nebensächlich, nicht erwähnenswert gehalten haben; zum Teil sind sicher, wie oben angedeutet, Verwechselungen mit Thrombenteilen untergelaufen, denn bei den gewöhnlichen Färbemethoden sind die Pseudomembranen von Resten körnig degenerierter Plättchenthromben, in welche vielleicht noch Leukozyten eingewandert und dort zerfallen sind, nicht immer mit Sicherheit zu unterscheiden.

An und für sich sollte man meinen, daß gerade das Hautartige, die Eigenschaft als Auskleidung der inneren Venenfläche, makroskopisch und histologisch als gutes Differentialdiagnostikum der Pseudomembran gegenüber dem Thrombus 
dienen müßte; wenn ein solches Häutchen schön ausgebildet vorhanden ist und in ziemlich gleichmäßiger Dicke mit einer der Gefäßwand parallelen Oberfläehe das Venenrohr überzieht, so ist die Entscheidung auf den ersten Blick scheinbar ganz leicht. Aber wie nun, wenn man sich vorstellt, daß im Zentrum eines fest haftenden Thrombus (und wir werden sehen, daß diese Pfröpfe recht fest sitzen können) mit wenig ausgesprochener Schichtung eine eitrige Einschmelzung stattgefunden hat, und dab bei der Entnahme und Konservierung der Venenstücke diese erweichte Masse ausgeflossen ist? Wird jetzt nicht die noch vorhandene Randzone des Blutpfropfs der Gestalt einer Pseudomembran gleichen müssen? Andererseits finden wir hie und da Stellen, wo sich einer pseudomembranartigen Schicht ein wohl ausgebildeter Thrombus aufgelagert hat. Eine scharfe Grenze läßt sich an solchen Stellen zwischen beiden gar nicht konstruieren, man weiß nicht, wo hört die Ablagerung von Blutbestandteilen auf, wo fängt das Exsudat an, ja ist nicht vielleicht das ganze Gebilde nur ein Konglomerat von zusammengesinterten Blutplättchen mit eingesprengten Leukozyten? Ich zitiere hier einen Passus aus der Talke schen Arbeit; bei seinem 8. Versuch schreibt er: Die Trennung von Thrombus und Gefäßwand, welche in ihren inneren Schichten von geronnenem, fibrinreichem Exsudat durchsetzt ist, ist einwandsfrei nicht möglich und kann nur willkürlich gemacht werden.

Es reicht also die Form und das Aussehen des Gefäßinhalts bei den gewöhnlichen Tinktionen nicht immer aus, um eine sichere Differentialdiagnose stellen zu können; auch die Weigertsche Fibrinmethode kann nicht alles klären, denn einmal zerfallen die Blutplättehen sehr bald in eine körnige Masse, die im Gegensatz zu dẹm bei Gerinnung sich bildenden fädigen Fibrin als körniges Fibrin bezeichnet wird (Dietrich $\left.{ }^{1}\right)$ ). Auch A sch off meint, daß die feinkörnig gewordenen Plättchenbalken und die körnig zerfallenen Léukozyten durch Fibrin ersetzt würden, sei es durch Auflösung oder durch direkte Umwandlung. Nun spielt aber die Fibringerinnung bei der septischen Thrombophlebitis überhaupt eine sehr viel wichtigere Rolle als bei der einfachen Thrombose, wenigstens sehen wir bei der ersteren fast stets eine sehr viel größere und unregelmäßiger angeordnete Menge von Substanzen, die sich nach der Weigertschen Methode blau färben; ich will hier nicht auf die Frage eingehen, ob diese vermehrte Fibrinausscheidung nur auf einer durch die Stoffwechselprodukte der Mikroorganismen erhöhten Gerinnungsfähigkeit des Blutes beruht, die in ähnlicher Weise auch bei den toxischen Thrombosen zu beobachten ist, oder ob sie in einem gewissen Zusammenhang steht mit der größeren Zahl von Leukozyten, die sich bei der infektiösen Thrombose ansammeln; daß die Eiterkörperchen nicht ohne Einfluß sind, steht heute wohl außerhalb jeder Diskussion, und auch in meinen Präparaten findet sich manche Stelle, welche diese Ansicht zu stïtzen geeignet ist. Ich möchte meinen, daß wohl beide Umstände das ihrige zu einer gesteigerten Fibrinausscheidung tun, die wir

1) Zitiert nach Aschoffs Lehrbuch. 
mit Schwalbe als das Kriterium der Gerinnung betrachten müssen. Wenn also das Vorhandensein von reichlichem Fibrin in einem seiner Natur nach zweifelhaften Gebilde bei der Thrombophlebitis nicht gegen die Diagnose Thrombusreste spricht, in welche die Gerinnungsprodukte sich sekundär abgelagert haben, so läßt andererseits nicht einmal das Fehlen von Fibrin das Vorliegen einer Pseudomembran mit Sicherheit ausschließen, denn wir müssen uns stets vor Augen halten, daß das längere Bestehen eines eitrigen Prozesses auch wieder zum Verschwinden des Fibrins oder wenigstens seiner färberischen Eigenart führen kann.

Es käme sonach nur noch das Auftreten der dickeren, sogenannten hyalinen Balken in den Pseudomembranen als differentialdiagnostisches Hilfsmittel in Betracht, doch müssen ja solche stärkeren, knorrigen Bestandteile nicht in jeder Pseudomembran vorhanden sein, auch sind die Übergänge zu den gewöhnlichen Fibrinfasern größeren Kalibers derartig fließend, daß mir die Entscheidung allzusehr vom subjektiven Urteil des Untersuchers abhängig zu sein scheint, ob es sich dabei überhaupt um zwei verschiedene Körper handelt. Ich werde daher im folgenden stets einfach von Fibrin sprechen. Da nun auch dieser Punkt für meine Untersuchungen ausscheidet, habe ich mir, um einen einigermaßen bestimmten Anhalt für die Diagnose: Pseudomembran den Nachweis zur Bedingung gestellt, daß der Körper, den ich als Exsudat betrachten will, auch wirklich aus der Gefäßwand stammt, von ihr ausgeschwitzt ist.

Um nun die Grenze zwischen Substanz des Venenrohrs, von dessen Endothel an den untersuchten Stellen fast niemals mehr etwas zu sehen war, und der Pseudomembran nach Möglichkeit deutlich hervortreten zu lassen, erschien es mir wünschenswert, die Färbung der elastischen Fasern mit der Weigert schen Fibrinmethode zu kombinieren, doch sollte natürlich die gleichzeitige Tinktion der Zellkerne nicht fehlen. Nach mehrfachen Versuchen, die ich unternommen hatte, um alle drei Elemente in verschiedenen Farbtönen darzustellen - z. B. Lithionkarmin, braune Elastika (Vesuvelin) und Fibrinfärbung -, hat sich mir als einfachstes und sicherstes Verfahren die Zusammenstellung: Hämatoxylin, rote Elastika (Saffranelin) und Weigerts Methode recht gut bewährt. Ein leichtes Abblassen der Elastikafärbung durch die spätere Nachbehandlung mit Anilinxylol mußte freilich in Kauf genommen werden, doch blieb sie für unsere Zwecke ausreichend scharf; die ähnliche Färbung der Kerne und des Fibrins machte sich kaum je störend bemerkbar.

Selbstverständlich wurden an den nach Alkoholfixation in Paraffin eingebetteten und möglichst in Serienschnitte zerlegten Präparaten auch die gewöhnlichen Färbungen (Hämatoxylin, van Gies on, Elastika - van Gies on, Methylenblau, nach Gram und die einfache Fibrinfärbung mit Kerntinktion durch Lithionkarmin) vorgenommen. Ich lasse die einzelnen Fälle der Reihe nach, wie sie zur Sektion kamen, hier folgen.

Fall 1. S.-Nr. 1200 (1909). Ida H., 27 Jahre. Aufnahme 5. 10. 1909.

Krankengeschichte: Pat. blutet seit 1. 10. 1909. Am 5. 10. kam die Frucht, dto. Plazenta. Am 6. 10. geringe Deziduareste festgestellt. Am 9.10. Sehüttelfrost. 10.10. Entfernung geringer 
Deziduareste. 11. 10. Stiche in der rechten Brust, Exsudat. 13. 10. Punktion desselben. 14. 10. Schüttelfrost.' Ikterus (seit dem 11. 10. bestehend) nimmt zu. 15. 10. kapilläre Blutungen unterhalb beider Schulterblätter sowie in der Axillargegend hinten. 16. 10. Exitus.

Klinische Diagnose und Notizen: Abort und septische Thrombose.

Anatomische Diagnose: Septische Endometritis; Metritis thrombophlebitica; Thrombophlebitis spermatica, links geringer, rechts ausgedehnter, bis nahe an die Kava reichend. Peritonitis mit mäßigem Exsudat; mehrfache kleine metastatische eitrig-hämorrhagische Herde in den Lungen; Milzschwellung mit Infarktbildung, kleine Infarkte in beiden Nieren. Starker allgemeiner Ikterus bei freiem Hepatikus und Choledochus, deren Wand gallig imbibiert ist; gallige, wenn auch ungleichmäßig gefärbte, breiige Faeces. Starkes doppelseitiges Lungenödem, Hydrothorax. Multiple kleine Blutungen in den verschiedensten Organen. (Hämorrhagische Diathese.) Gallenblase mit wenig trübem, gallenfreiem Inhalt, Schleimhaut nicht gallig imbibiert, mit zahlreichen kleinen Blutungen; Leber kaum ikterisch gefärbt, überhaupt nicht wesentlich makroskopisch verändert.

Bakteriologische Diagnose: Sehwankte zwischen Pneumokokkus und Streptokokkus mitior, doch wird der erstere als wahrscheinlich betrachtet.

Mikroskopischer Befund: In diesem Fall handelt es sich um eine ganz ausgesprochene Psendomembranbildung, welche in allen untersuchten Schnitten das ganze Gefäßrohr fest auskleidet bis auf eine kleine Partie, wo die Membran frei in das Lumen der Vene hineinhängt. Es fällt auf, daß an dieser Partie die Gefäßwand relativ wenig verändert ist. Man erkennt noch hier und da Endothelzellen, die Elastika ist gut färbbar, nur wenig aufgefasert usw., und das alles, obwohl hier Kokken gefunden werden, welche der der Venenwand zunächst liegenden Seite der Pseudomembran, ja der Gefäßwand selbst, unmittelbar anhaften. Die Membran selbst besteht aus einem Gewirr von bei van Gieson - Färbung gelbtingierten dicken Balken und feineren. Fasern von leuchtendem Glanz, durchsetzt von zahlreichen polynukleären Leukozyten, einigen mehr runden Kernen und zahllosen Kerntrïmmern. Die Weiger tsche Fibrinmethode läßt das erwähnte Netzwerk aufs deutlichste hervortreten und drei verschiedene Systeme in dessen Anordnung erkennen. Da, wo die Membran frei ins Lumen hängt, finden sich in ziemlich regelmäßiger Anordnung größere blaue Klumpen, von denen strahlenförmig feine Fasern ausgehen und sich mit den Ausläufern der benachbarten Klumpen zu einem äußerst zierlichen Gitterwerk verflechten. Ein anderes Bild bietet sich ganz besonders da, wo dieser Zipfel der Pseudomembram der Gefäßwand noch fest anhaftet, welche hier am schwersten verändert ist (starke Auffaserung der Elastika, Ödem der von zahlreichen Lenkozyten durchsetzten Gefäßwand, Quellung und starker Zerfall der Bindegewebs- und Muskelkerne). Das Fibrin nimmt mit feinsten, senkrecht zur Gefäbachse gestellten Fäserchen seinen Ursprung von der Gefäßwand her, ja direkt aus dieser, um nach dem Lumen zu in ein gröberes, dichteres Geflecht überzugehen, in welchem die parallel zur Achse gestellten Züge vorherrschen. Umgekehrt an der dritten Stelle: grobe, dicke Balken an der Gefäßwand, hauptsächlich dieser entlang verlaufend, nach dem Lumen zu löst sich dies Balkenwerk in feinere Netze auf, deren Fasern keine bestimmte Richtung erkennen lassen; dies dritte System findet sich da, wo die Pseudomembran der Gefäßwand fest aufliegt, wo diese jedoch weniger stark verändert ist, als an der zweiten Stelle. Auch in der Tiefe der Venenwand finden sich isolierte Fibrinnetze, namentlich in der Adventitia, die sich des ferneren durch reichlichen Gehalt an Leukozyten auszeichnet; ganz vereinzelt sieht man hier Kokken liegen, während sonst die Wand des Gefäßes frei davon ist; abgesehen von der oben erwähnten Stelle. Da die oberflächlichsten Partien der Pseudomembran von Kokken wimmelt, hat man geradezu den Eindruck, als hätte sich die Membran wie eine Schutzwehr zwisehen die vordringenden Mikroorganismen und die gefährdete Wand geschoben. Es handelt sich um grampositive Kokken, meist Diplokokken von länglicher Gestalt, ähnlich den Pneumokokken; stellenweise ist eine ziemlich deutliche, helle Kapsel zu erkennen; daneben finden sich, wohl als Verunreinigung, plumpe, kurze, grampositive Stäbchen.

Fall 2. S.-Nr. 1256 (1909). Bruno M., 53/4 Jahre. Aufnahme 28. 10. 1909, gestorben am 30. 10. 1909 . 
Krankengeschichte: Es besteht eine chronische Otitis media rechts; Nackensteifigkeit. 28. 10. Radikaloperation; ein großes Cholesteatom hat die Dura der mittleren Schädelgrube und den Sinus freigelegt. Der Sinus selbst ist verdickt, braunot schmierig belegt und scheint Blut zu führen. 30. 10. Exitus.

Klinische Diagnose und Notizen: Cholesteatom. Sepsis.

Anatomische Diagnose: Radikaloperationswunde im rechten Felsenbein. Jauchige Phlegmone in der Umgebung des Bulbus venae jugularis. Septische Thrombophlebitis im rechten Sinus transversus und Vena jugularis. Multiple verjauchte Lungeninfarkte. Doppelseitige fibrinöseitrige Pleuritis. Beginnende serös-eitrige Perikarditis. Bronchitis. Milzschwellung.

Bakteriologischer Befund: Pneumokokken.

Protokoll: Nach Abziehen der Dura von der Schädelbasis zeigt sich die Gegend des rechten Sulcus sigmoideus sowie die Außenseite des zugehörigen Sinus von schwarzbrärnnlichen Massen bedeckt; an der Innenfläche des Sinus findet sich nur eine geringe, bis $1 \mathrm{~mm}$ dicke graugrünliche, ziemlich fest haftende Auflagerung. Die an der Außenfläche liegenden erwähnten schwarzbräunlichen Massen umscheiden den Bulbus venae jugularis dextrae und setzen sich an der Schädelunterfläche in die dortige Muskulatur fort. Die rechte Vena jugularis ist bis drei Querfinger oberhalb ihrer Einmündung in die Anonyma von olivbraunen, bis $1 \mathrm{~mm}$ dicken, festhaftenden Massen ausgekleidet, ihre Wand ist in diesem Bereich verdickt, ihr Lumen klafft.

Mikroskopisch bietet dieser Fall viele Ähnlichkeiten mit dem vorhergehenden. Stärkere Veränderungen der Venenwand, Zerstörung des Endothels dort, wo die ganz typischen Pseudomembranen dem Gefäßrohr fest anhaften, geringere dort, wo nur eine lockere oder gar keine Verbindung besteht; im ganzen betrachtet, liegt übrigens keine so schwere Erkrankung vor, wie in Fall 1, namentlich ist die Elastika überall gut exhalten und färbbar, das Ödem ist geringer, auch läßt sich kein so starker Kernzerfall nachweisen. Die Zusammensetzung der Pseudomembran wechselt so ungemein, daß sich keine einigermaßen klare Schilderung geben läßt, nur ganz allgemein kann man aussagen, daß der Fibrinreichtum von der Wand des Gefäßes nach der Achse zu abnimmt; die in diesen Häutchen liegenden Kerne zeigen etwas Zerfall, nach der Mitte der Vene $\mathrm{zu}$ am stärksten. An einigen Stellen ist das Fibrin klumpig zerfallen und nicht mehr ganz so intensiv färbbar. Besonders interessant ist eine ziemlich ausgedehnte Partie, in der man ganz oberflächlich dicht unter den ersten Lamellen der Elastika int. der noch einigermaßen gut erhaltenen Wand feinste Fibrinnetze findet, welche unmittelbar in das Fibrin der Pseudomembran übergehen. Femer finden sich feine Fibrinnetze ganz in der Tiefe ohne Zusammenhang mit den eben erwähnten, schließlich anch in den zum Teil thrombosierten Vasa nutritiva. Die Kokken, grampositive Mikroorganismen von sehr wechselnder Gestalt und Größe, liegen teils auf der freien Fläche der Membran, teils auf der GefäBwand, soweit sie unbedeckt ist, auch an Stellen, wo das Endothel noch gut erhalten ist; in der Tiefe der Membran finden sich Kokken nur da, wo sie ein lockeres Gefüge hat und nicht innig mit der Intima zusammenhängt, hier sind scheinbar die Kokken zwischen Gefäßwand und Häutchen entlanggewandert.

Fall 3. S.-Nr. 1391 (1909). F., 42 Jahre alter Mann. Aufnahme 4. 12. 1909, gestorben am 8. 12. 1909.

Krankengeschichte: Seit 1893 offene Unterschenkelgeschwüre links, am 30. 11. 1909 Schmerzen im Hals mit Anschwellung, namentlich der rechten Seite. Seit 3. 12. Benommenheit, Delirium tremens. Puls 120. 6. 12. Cheyne-Stokessches Atmen. Schmerzhaftigkeit des linken Schultergelenks. Phlegmonöse Schwellung des linken Ellenbogengelenks, Inzision ergibt eitrige Flüssigkeit, mikroskopisch Streptokokken. 8. 12. 1909 Exitus.

Klinische Diagnose und Notizen: Delirium tremens und allgemeine Blutvergiftung.

Anatomische Diagnose: Multiple Eiterherde in den Halsmuskeln und der Gelenkkapsel des rechten Humerus und um die linke Ellbogengegend. Septische Thrombose der Vena jugularis links. Septische Milz. Lungenemphysem; verkalkte Bronehialdrüse links; Bronchitis. Chronisches Ulcus cruris, Periostitis und chronisehe Phlebitis. Varices oesophagi. Cystitis granularis et cystica. Prostatahypertrophie, geringe Balkenblase, Arthritis deformans des Kniegelenks. 
Mikroskop: Gelapptkernige Leukozyten in Haufen unter der Gelenkkapsel und in dem perikapsulären Bindegewebe.

Bakteriologische Diagnose: Verunreinigungen.

Protokoll: Beim Herausnehmen der Halsorgane quillt beim Durchschneiden des linken Sternokleidomastoideus in der Höhe des Kehlkopfes aus dem Muskel dicke, gelbe, rahmige Flüssigkeit; er ist größtenteils eitrig eingeschmolzen. Diese eitrige Einschmelzung hängt zusammen mit einem kleinaprikosengroßen Eiterherd in der Halsmuskulatur um den Kehlkopf. Die Wand dieser Eiterhöhle graurötlich bis gelblich, leicht höckerig. Vor diesem Herd verläuft die Vena jugularis, deren Wand verdickt ist und deren Oberfläche von graugelblicher Beschaffenheit ist. Diese Veränderung in der Vena jugularis hört nach oben etwa $1 \mathrm{~cm}$ unterhalb des Bulbus jugularis auf. Der Sinus transversus ist vollständig frei. Nach unten reicht die Veränderung bis nahezu an das untere Ende der Vena jugularis und endigt oberhalb einer Venenklappe.

Mikroskopischer Befund: Das untersuchte Venenstück stammt von einer Stelle, welche außerhalb der oben beschriebenen Eiterung liegt; die an der Außenseite der Vene haftende Muskulatur zeigt nur eine geringe Infiltration mit Rundzellen, nirgends gelapptkernige Leukozyten. Ein Überblick über die Präparate läßt erkennen, daß auf der rechten Seite des Bildes eine geringe, doch deutliche Pseudomembranbildung vorliegt, welche nach links zu allmählich abnimmt, so daß schließlich die Gefäßwand frei zutage liegt. Eine mächtige kleinzellige Infiltration findet sich in der Adventitia, ganz besonders stark auf der einen Seite des Präparats. Im selben Sinne machen sich Unterschiede in der Verteilung der mehr nach der Oberfläche zu liegenden Leukozyten bemerkbar; links zahlreiche Eiterkörperchen, die dem Gefäßlumen am nächsten liegenden schon stark zerfallen, rechts zwar auch erhebliche Eiterung, aber hier werden zahlreiche Leukozyten in Wanderform gefunden, unmittelbar unter der Obexfläche meist parallel zu dieser, etwasoweiter in der Tiefe streben sie dem-Lumen der Vene zu. Was nun die Elemente der Gefäßwand selbst angeht, so kann man unter dex Pseudomembran die gewöhnlichen Vexänderungen feststellen, an den unbedeckten Partien jedoch ist das Gewebe fast vollständig nekrotisch; kaum noch gefärbte Kerne, zahlreiche Kerntrümmer, ausgedehnte Zerstörung der Elastica interna, während die Bindegewebsfasern mit Säurefuchsin noch einigermaßen färbbar sind. Die Eitererreger - es handelt sich um gràmpositive Kokken mit schöner Kettenbildung - liegen hier in dichtem Rasen auf den Resten der Venenwand und sind teilweise schon etwas in die Tiefe gedrungen, während sie im übrigen auf und in der Pseudomembran sitzen, ohne die Wand erreichen zu können. Besonders interessant sind die Weigert-Fibrinpräparate; die Pseudomembran besteht aus einem ganz plumpen Balkenwerk, das stellenweise fast homogen geworden ist; in der Tiefe findet sich bier kein Fibrin. Je dünner und zarter nun aber das Häutchen auf der Oberfläche wird, desto weiter reichen die Netze in die Gefäßwand und schlieBlich ist diese an den Partien ohne Membran - auch in den nelkrotischen Stellen - ganz von blaugefärbten Massen durchsetzt, welche im allgemeinen ein grobes Netz bilden, in dessen Maschen sich wieder ein feineres Geflecht findet. Gerade unter dieser Seite der Präparate liegt die fast unveränderte Muskulatur, so daß man einen direkten Einfluß der oben erwähnten Muskelabszesse auf die Vene hier ausschließen kann.

Fall 4. S.-Nr. 29 (1910). Martha N., 19 Jahre. Aufnabme 31. 12. 1909, gestorben am. 8. 1. 1910.

Krankengeschichte: Am 14. 12. 1909 normale Entbindung, bald darauf Fieber und AusfluB. Charité.

Befund: An der vorderen Scheidenwand Schleimhautnekrosen, blutig schmieriger Ausfluß.

Links neben dem Uterus ein dreifingerbreiter, leicht druckempfindlicher, bis an die Beckenschaufel gehender Strang. 3. 1. Links im Scheidengewölbe walnußgroßer AbszeB, Inzision, Eiter. 5. 1. über der Lunge rechts hinten unten Dämpfung. 7. 1. Pleurapunktion: eitrige Flüssigkeit. Rippenresektion. Temperatur $38,6^{\circ}$. 8. 1. Exitus.

Klinische Diagnose und Notizen: Pyämie, Empyem rechts, Pleuritis links. Myocarditis parenchymatosa acuta. 
Anatomische Diagnose: Janchige Endometritis puerperalis mit jauchiger Thrombophlebitis der gesamten Beckenvenen. Multiple jauchige Beckenabszesse mit beginnendem Einbruch in die Blase. Multiple metastatische, zum Teil jauchige Lungenabszesse. Starke Milzschwellung, kleiner septischer Milzinfarkt. Parenchymatöse Degeneration von Myokard, Leber und Nieren. Infarktnarbe der rechten Niere. Tuberkulose der rechten tracheobronchialen und supraklavikularen Lymphdrüsen. Angina pseudomembranacea.

Bakteriologische Diagnose: Streptolrokken im Blut, Milz steril.

Protokoll: Beide Vv. spermaticae und iliacae communes enthalten Speckhautgerinnsel und flüssiges Blut, ihre Wandung ist hellgrau und glatt. Das die Urethra umgebende Bindegewebe ist derb infiltriert, die dort verlaufenden Venen sind von graugelben, teils schmierigen, teils etwas derberen Massen erfüllt, ihre Wand ist schwärzlich. Die grünlich-grau gefärbte Uterusmuskulatur ist durchsetzt von zahlreichen, weitklaffenden GefäBen mit etwas grünlicher. Wandung, aus deren Lumen sich gelbliche, schmierige Massen ergießen. Die beiden Parametrien, sowie der ganze unter dem Levator ani gelegene Teil des Beckenbindegewebes sind derb; beim Finschneiden finden sich sämtliche Venen der Parametrien in gleicher Weise verändert wie die Venen des Uterus und um die Urethra. Die Veränderung der Beckenvenen reicht nur bis in die größeren Äste der Hypogastrika hinein, der Stamm der Hypogastrika ist beiderseits frei.

Mikroskopischer Befund: Die Deutung der sich in diesem Fall darbietenden Bilder ist dadurch etwas komplizierter, daf eine ältere aseptische Thrombose bestanden hatte, welche an den Randpartien schon zahlreiche kleine Gefäße und Bindegewebsfäserchen zeigt. Nach dem Gesamteindruck, den die Präparate von versehiedenen Gefäßen (es wurden mehrere Stücken der kleineren Beckenvenen untersucht) gewähren, sind diese Thrombusmassen vom. Zentrum her eitrig zerfallen, anwielen Stellen ist die Zerstörung schon tief in die Gefäßwand bis in die Adventitia vorgedrungen. Größeres Interesse bietet nur eine weniger veränderte Stelle dar. Der von der Mitte her eitrig eingeschmolzene Thrombus hat sich zum Teil von der Venenwand losgelöst, und zwar in der Zone, wo die meisten und größten neugebildeten Gefäßchen liegen, während eine schmale Randpartie noch an der Wand haftet; zwischen beiden Stïcken liegen zahlreiche Kokken — grampositive, ziemlich uncharakteristisch geformte und gelagerte rundliche Mikroorganismen —, wohl ein Beweis, daß dieser Riß kein Kunstprodukt ist. Nun bietet dieser losgelöste Thrombusteil, abgesehen von den deutlichen Zeichen der in den peripherischen Sehichten erfolgten Organisation, ein der typischen Pseudomembran sehr ähnliches Bild, das namentlich in den van GiesonSchnitten ganz deutlich zutage tritt. Der mächtige Gehalt an Fibrinmassen in einem plumpen Netzwerk stimmt mit den Bildern anderer Fälle überein. In dex Venenwand, sowie im Lumen der neugebildeten Gefäße finden sich feine Netze von Fibrin, welche zum Teil mit dem Gitterwerk in dem noch haftenden Teil des GefäBinhalts durch die aufgefaserte Elastika hindurch mit Hilfe feiner Fäserchen kommunizieren. Die Gefäßwand ist im Vergleich zu den anderen untersuchten Partien wenig geschädigt, am meisten jedoch an der Stelle, wo der Thrombus abgehoben ist. Auch in den Präparaten von anderen Stücken fällt die große Menge des Fibrins in den besser erhaltenen Thromben auf, das manchmal große, fast homogene Flecken bildet, während sich in den zerfallenen Partien nur noch ein feines Netzwerk findet.

Fall 5. S.-Nr. 69 (1910). Walther T., 25 Tage alt. Aufnahme 15. 1. 1910, gestorben am 19. 1.1910.

Krankengeschichte: Alter bei der Aufnahme: 21 Tage. Das Kind wurde in der Augenklinik vom 6. 1. bis 15. 1. wegen Blenorrhoe behandelt. Dort stellte sich am 14. 1. plötzlich Fieber ein, Erbrechen. 16. 1. Der Nabel ist vorgewölbt, von hochroter Farbe. Die Wunde ist schmierig belegt und sezerniert. Umgebung gerötet. Die eingeführte Sonde läßt sich tief in die Wunde vorschieben. Geringer Nabelbruch beim Schreien feststellbar. Parotis rechts geschwollen, bis über den Kieferwinkel hinaus. Eitriger Ausfluß aus dem Duct. Stenon., Streptokokken. 17. 1. Inzision der Parotis. 19. 1. Exitus.

Klinische Diagnose und Notizen: Blenorrhoe, Sepsis, Parotitis septica. 
Anatomisehe Diagn ose: Nabelsepsis. Pleuritis serofibrinosa rechts, bronchopneumonische Herde im rechten Oberlappen. Ikterus der Haut, ikterische Leber und Nieren. Operationswunde an der rechten Parotis.

Bakteriologische Diagnose: Bacterium coli in Blut und Milz.

Protokoll: Der Nabel ist mit einem rötlichen Schorf bedeckt, die Nabelvene ist frei und von weißlicher Farbe. Die Nabelarterien dagegen erscheinen erweitert und sind von dunkelviolettroter Farbe mit gelblichem durchschimmernden Inhalt, der ziemlich eingedickt ist; an der Wand haften gelblich-bräunliche Massen.

Mikroskopisch finden sich hier im Lumen der Arterien nur ganz geringe, fädige Massen, welche bei Giesonfärbung gelb erscheinen und positive Fibrinreaktion geben; die Fäden ragen etwas zwisehen die ganz aufgefaserte Elastika hinein. Die Arterienwand ist im Zentrum voliständig nekrotisch, am Rand reichlich von Leukozyten durchsetzt, welche zum großen Teil in. Wanderform auftreten. Nirgends zeigt sich eine Spur von Pseudomembran. Neben einigen gramnegativen, plumpen Stäbchen, welche wohl als Bacterium coli anzusprechen sind, findet sich eine größere Menge grampositiver Kokken, welche an manchen Stellen tief in die Gefäßwand eingedrungen sind, während die Stäbchen sich mehr an der Oberfläche aufhalten.

Fall 6. S.-Nr. 114 (1910). Gertrud M., 20 Jahre. Aufnahme 31. 12. 1909.

Krankengeschichte: Am 30. 12. Blutung ohne äußere Ursaehe, Schmerzen. Condylomata acuminata. 2. 1. Ausräumung. Links hinten unter Skapula pleuritisches Reiben. 10. 1. Zyanose, Dyspnoe. Punktion des Exsudats. Reichlicher stinkender gelblich-rötlicher Eiter aus Uterus. Am 14. 1. Punktion einer seit etwa dem 2. 1. am linken Hinterbacken entstandenen ödematösen Schwellung: dicker, rahmiger Eiter. Punktion eines gänseeigroßen Tumors links unter dem Uterus: dünnflüssiger Eiter. Tamponade. 26. 1. Leib aufgetrieben, Erbrechea. Punktion der rechten Bauchseite. 29. 1. Schmerzhaftigkeit in der linken Nierengegend. 30. 1. Atemnot, Exitus.

Klinische Diagnose und Notizen: Peritonitis post abortum. (Klinisch erst Gonokokken gefunden, später Staphylokokken.)

Anatomische Diagnose: Schwere eitrige Peritonitis anschlieBend an Abort. Septische Endometritis, eitrige Peri- und Parametritis, links Pyoophoron mit Durchbruch in den hinteren Douglas. Phlegmone des retroperitonealen Bindegewebes und des linken M. ileopsoas. Eröffneter Abszeß in linken Labium majus. Eitrige Thrombophlebitis der Vv. uterinae sinistrae. Embolien in beiden Lungen und in der rechten Niere. Vereiternde Infarkte in Lunge and Milz. Eitrige Pleuritis links. Eitrige Perisplenitis und Perihepatitis. Geringe Hydronephrose beiderseits, besonders links. Pleuritische Stränge rechts. Geringe Fettleber. Aspiration von Mageninhalt.

Bakteriologische Diagnose: Bac. pyocyaneus.

Protokolk: Die Venen im kleinen Becken, besonders die linksseitigen Vv. uterinae enthalten gxüngelbe, zum Teil feste, zum Teil bereits erweichte Pfröpfe. Rechts ist ein Ast der V. renalis. mit festhaftendem Blutgerinnsel verschlossen.

Mikroskopischer Befund: Mancherlei Umstände tragen dazu bei, die Beurteilung dieses Falles sehr zu erschweren. Einmal finden sich die weiter unten noch zu besprechenden Mikroorganismen nicht nur im Lumen der Venen, vielmehr liegen sie auch im umliegenden Gewebe, teils verstrent, teils in größeren Haufen, so daß gar nicht zu entscheiden ist, ob ihre Einwirkung auf die Venenwand mehr vom Lumen oder von der Umgebung aus erfolgt ist. Sodann sind in allen untersuchten Stücken die.Zeichen einer älteren Thrombose zu fimden, an mehreren Stellen hat eine deutliche Oxganisation begonnen; gerade im Bereich der Organisationen nun finden sich auch ältere Veränderungen der Venenwand, Verdickung der Intima und Neubildung feiner elastischer Fasern. Die Thromben sind zum Teil zentral erweicht, zum Teil beim Vordringen der Entzündungserreger eitrig eingeschmolzen, an anderen Stellen wieder hat sich der Pfropf von der Venenwand gelöst; indem die Eiterung zwischen beiden fortgekrochen ist. Eine sicher als solche anzusprechende Pseudomembran findet sich nirgends, nur einzelne der losgelösten Thrombusstücke bieten eine gewisse Ähnlichkeit mit solchen, wie durch den ziemlich reichlichen Fibrin- 
gehalt noch mehr hervorgehoben wird; doch läßt namentlich die van Gieson-Färbung noch einigermaßen die Thrombusstruktur erkennen. Daß sich in der Tiefe des Gewebes hier und da Fibrinnetze finden, erklärt sich leicht aus der vorhandenen Phlegmone. Interessant in diesem Fall ist die Mannigfaltigkeit der beteiligten Mikroorganismen. An Zahl bei weitem überwiegen grampositive, runde Kokken, die jedoch nicht so charakteristisch gelagert sind, um eine Differentialdiagnose zwischen Streptokokken und Staphylokokken stellen zu können. Dazwisehen eingestreut. finden sich gramnegative, mit Methylenblau sehwach gefärbte Stäbchen, wohl die bakteriologisch festgestellten Pyozyaneusbazillen, und schließlich noch grampositive, etwas längliche Kokken, welche oft genug deutliche Lanzettform und Kapselbildung erkennen lassen, um den Verdacht auf Pneumokokken zu erwecken.

Fall 7. S.-Nr. 141 (1910). Johannes S., 2 Jahre. Aufnahme 23. 1. 1910, gestorben am 4. 2. 1910 .

Krankengeschichte: Vor 14 Tagen Windpocken, vor 10 Tagen Halsschmerzen. 21. 1. Schwellung am linken Unterarm und rechten Oberschenkel.

Aufnahmebefund: Am Unterarm, Volarseite, fluktuierende Schwellung. Temperatur abends $40,0^{\circ}$.

24. 1. Inzision am Unterarm, Eiter, gleichfalls am Oberschenkel. 25.1. 40,8 ${ }^{\circ}$. Mikroskopisch Eiter: Staphylokokken. 26. 1. 40,4 ${ }^{\circ}$. Eröffnung des Femur selbst und Freilegen des Markraums. 27. 1. $37,8^{\circ}$, nachher abends $38,5^{\circ}$. 2. 2. Temperatur normal. 4. 2. Dyspnoe. Rasseln über Lunge, Exitus.

Klinische Diagnose und Notizen: Osteomyelitis acuta und Bronchopneumonie. Zweimal operiert. (Inzisionen am Oberschenkel, das zweite Mal vor 10 Tagen mit Aufmeißelung des Femur.)

Anatomische Diagnose: Osteomyelitis purulenta apostematosa im rechten Femur. Endophlebitis septica der rechten Vena femoralis und iliaca. Eitrige Perikarditis, ulzeröse Endocarditis parietalis im rechten Ventrikel mit Thrombenbildung. Multiple Lungenabszesse mit Durchbruch in die Pleurahöhle und abgekapselten Empyemherden beiderseits. Geschwollene Bronchialdrüsen, besonders rechts, eitrige Bronchitis. Schwere parenchymatöse Degeneration beider Nieren mit Schrumpfherden, Markherde beiderseits. Septischer Infarkt in der rechten Niere. Amygdalitis apostematosa dextra et lacunaris sinistra. Lymphdrüse in der Gallenblasenwand. Glottisödem, Hämatom an der Mitralis.

Bakteriologische Diagnose: Staphylococcus aureus im Herzblut, Milz und perikarditischem Exsudat, daneben Streptokokken.

Protokoll: Die rechte Vena femoralis und iliaca enthält gelbliche, derbe Pfröpfe, die der Wand stellenweise ziemlich fest aufsitzen.

Mikroskopischer Befund: Das erste der beiden untersuchten Stücke bietet wenig Interesse. Zwei darin enthaltene Venen zeigen ältere Thromben mit Pigment neben Zeichen von Organisation, die bis zur Bildung von Fasergewebe fortgeschritten ist. Der eine, nicht gànz das Venenlumen erfüllende Thrombus zeigt an der Innenseite neugebildetes Endothel. Trotzdem ähneln die zentral gelegenen Partien sehr einer Pseudomembran, auch die Fibrinreaktion fällt zum Teil positiv aus. Auffälligerweise finden sich einige grampositive Kokken in diesen sonst ganz aseptischen Thromben. Eine leichte zellige Infiltration der umgebenden quergestreiften Muskulatur zeigt, daf auch hier nux geringe entzündliche Reize wirken. Anders bei dem zweiten Block. Der auch hier vorbandene, schon ziemlich weit organisierte Thrombus ist eitrig zerfallen, gerade an der Stelle, wo die Organisation schon am weitesten vorgeschritten war. Fibrin ist hier kaum noch färbbar, während auf der anderen Seite des Thrombus ein sehr dichtes Netzwerk von gröberen und feineren Fasern zu tage tritt; eine Verbindung mit den in der Gefäßwand liegenden Fibrinnetzen findet sich nicht. In den zerfallenen Partien sieht man eine ganze Anzahl grampositiver Mikroorganismen, anscheinend Staphylokokken.

Fa.11 8. S.-Nr. 153 (1910). Margarethe S., 16 Jahre. Aufuahme 3. 2. 1910, gestorben 9. 2. 1910. 
Krankengeschichte: Mit 9 Jahren Scharlach, im Anschluß daran Nephritis. Vor 4 Wochen Blasenkatarrh; vor 14 'Tagen hohes Fieber und Schmerzen in der rechten Seite und Rücken, Atemnot.

Befund: Über den Lungen rechts hinten unten Dämpfung. Puls 130. Milz nicht vergrößert. $\mathrm{Alb}+$ + 5. 2. $40^{\circ}$, Puls 160 , geringe Spannung. 6. 2. Milz palpabel. 7. 2. Leukozyten 12500 , Diazo +. 8. 2. Puls 190. 9. 2. Exitus.

Klinische Diagnose und Notizen: Lungenentzündung.

Anatomische Diagnose: Pyämie, ausgehend von doppelseitiger jauchiger Otitis media. Septische Thrombophlebitis der Vena jugularis dextra. Multiple, zum Teil verjauchte Lungenmetastasen mit frischer Pleuritis beiderseits, besonders links. Geringe Milzschwellung; parenchymatöse Degeneration der Nieren. Kleines Ösophagusdivertikel, perihepatitische Verwachsungen, Nebenmilz, Corpus haemorrhagicum und Hydrosalpinx beiderseits.

Bakteriologische Diagnose: Kulturen steril.

Protokoll: Im absteigenden Teil des rechten Sinus transversus graurötliche, mäßig feste Massen, die gegen den Bulbus Venae jugularis zu eine grünliche Farbe und schmierig-weiche Konsistenz annehmen.

Da die thrombosierte Vene dem Museum überwiesen wurde, konnte nur der Sinus transversus untersucht werden.

Mikroskopischer Befund: Dieser Fall bietet fast die gleichen Bilder wie der vorige, nur ist die Organisation des Thrombus nicht so weit vorgeschritten; dieser zeigt an manchen Stellen große Xhnlichkeit mit einer Pseudomembran, der Fibringehalt ist auch hier am geringsten an den eitrig eingeschmolzenen Partien. Es finden sich Haufen von sehr feinen, grampositiven Mikroorganismen, deren Natur sich nicht näher analysieren läßt.

Fall 9. S.-Nr. 159 (1910). Frau G., 33 Jahre. Aufnahme 2. 2. 1910, gestorben am 11. 2. 1910.

Krankengeschichte: Mitte Januar 1910 Fehlgeburt, im Anschluß daran Venenthrombose und Sepsis. Seit dem 29. 1. 1910 Abklingen dieser Vorgänge. Wegen maniakalischer Zustände Charité. (Bis dahin Angaben des behandelnden Arztes.) Ergänzungen: Am 25. 1. schwoll das rechte Bein stark an. Puls bei der Aufnahme 86. 4. 2. Kampher. Gynäkologisch: Spannung der Parametrien. 11. 2. rechtes Bein ist hochrot, etwas bläulich. Exitus.

Klinische Diagnose und Notizen: Saprogenes Begleitdelirium, Venenthrombose, Lungenembolie.

Anatomische Diagnose: Thrombus im Sinus longitudinalis sup. Anämie im oberen Teil des Rückenmarks. Chronische Endometritis, chronische rechtsseitige Parametritis mit Abszeß im rechten M. psoas.

Thrombose der Vena iliaca und ihrer sämtlichen Äste, Thrombose der linken V. spermatica, multiple Embolien der linken Lungenarterie. Bronchitis, geringes Lungenemphysem, mäBige Trübung der Magenschleimhaut.

Protokoll: Das rechte Bein ist doppelt so dick wie das linke, Hant gespannt, alle kleinen oberflächlichen Venen der Haut stark gefïllt. Im Sinus longitudinalis ist ein derber, halb das Lumen ausfüllender, grauroter Pfropf; er reicht bis in die seitlichen Hirnvenen hinein. In den übrigen großen Blutleitern nur wenig flüssiges Blut. Rechte Vena spermatica dünn und zart, enthält nur flüssiges Blut, linke Vena spermatica bleistiftstark, ist bis zur Einmündung in die Vena renalis mit grauroten, ziemlich festen, der Wand anhaftenden Massen gefüllt. Das rechte Parametrium fühlt sich etwas derber an als das linke, die gesamten Verzweigungen der Vena hypogastrica dextra sind gleichfalls durch graurote Pfröpfe verschlossen. Vena cava inferior teilweise, Vena iliaca dextra mit ihren gesamten Verzweigungen völlig durch dunkel-graurote, der Wand der Vene fest anhaftende Massen verschlossen. Beim Herauslösen der BauchgefäBe stößt man auf eine taubeneigroße mit bräunlichen, schmierigen Massen gefïllte, nicht scharf begrenzte Höhle im rechten M. psoas unmittelbar unter der thrombosierten V. iliaca communis gelegen. Die Höhlung hat mit der Wirbelsäule keinerlei Verbindung, dagegen steht ihre derb infiltrierte Ungebung in 
unmittelbarem Zusammenhang mit dem gleichfalls infiltrierten rechten Parametrium, in dem die Venen gleichfalls wie erwähnt versehlossen sind.

Mikroskopischer Befund: Wie schon nach der Krankengeschichte zu erwarten war, finden sich in der V. femoralis Zeichen einer älteren Thrombose mit weit fortgeschrittener Organisation des Pfropfes, der im allgemeinen zellarm ist und noch Spuren von Schichtung zeigt. In diesem, primär anscheinend blanden Thrombus sind mehrere, teils zentral, teils peripher zwischen Pfropf und Gefäßwand gelegene Erweichungsherde nachweisbar mit größeren Haufen von Leukozyten, zwischen denen Schwärme von grampositiven, rundlichen Kokken liegen. In gewissem Abstand von diesen Herden, aber fast gar nicht in noch ganz unveränderten Thrombusmassen sind ziemlich zarte Fibrinnetze sichtbar; die Venenwand, die abgesehen von einigen Infiltraten um Vasa vasorum, sich wenig an dem EntzündungsprozeB beteiligt hat, enthält kein Fibrin.

Fall 10. S.-Nr. 367 (1910). Frau W., 24 Jahre. Aufnahme 29. 3. 1910.

Krankengeschichte: Früher gesund, am 23. 3. plötzlich mehrere Schüttelfröste, nachdem die Regel 14 Tage ausgeblieben war. Am 25. 3. Schmerzen im rechten Bein, die anf Krampfadern bezogen wurden. Uterusaussehabung. Schüttelfröste. Leichte Benommenheit. 1. 4. Exitus.

Klinische Diagnose und Notizen: Thrombophlebitis septica. (Vor 8 Tagen Schüttelfrost, vermutlich krimineller Abort.)

Anatomische Diagnose: Septische Endometritis puerperalis, beginnende eitrige Paraund Perimetritis, Corpus luteum verum links, akute Oophoritis und Salpingitis. Beginnende Phlegmone an der rechten Wade mit schwerer Phlebitis der V. saphena und Lymphadenitis inguinalis. Milzschwellung. Schwere parenchymatöse Degeneration der Nieren, eitrige Bronchitis; pleuritische Verwachsungen rechts. Soor im Ösophagus.

Bazteriologische Diagnose: Im Herzblut und Milz Streptococeus pyogenes.

Protokoll: Venae spermaticae dünn, kollabiert, enthalten nur sehr wenig dunkles, flüssiges Blut; ebenso die $V_{v}$. iliacae communes, externae und der Anfangsteil der Vena hypogastrica. Dagegen ist dieVena saphena dextra auffallend dick, an ihrerEinmündungsstelle in dieV.femoralis fast kleinfingerdick; sie enthält hier außer einigen Kruorgerinnseln einen etwa federkieldicken, $1-1 \frac{1}{2} \mathrm{~cm}$ langen rötlich-grauen, opaken, etwas derberen Pfropf, in ihrem weiteren Verlanf nur flüssiges Blut. Je mehr man beim Aufschneiden in die Gegend der Kniekehle kommt, desto dicker wird die Wand; sie ist schließlich in der Kniekehle etwa $1 \mathrm{~mm}$ dick, in Längsfalten gelegt, von grauer bis rötlich-graner Farbe; ihre Innenfläche ist rauh, stellenweise deutlich mit zarten, grauen Auflagerungen versehen. Der Inhalt des Gefäßes ist hier eine graurötliche, trübe Flüssigkeit; diese Beschaffenheit reicht noch etwa handbreit nach abwärts fort. In die Verästelungen der Vene sind verschiedene variköse Knoten eingeschaltet, deren Wand etwas dünner, deren Inhalt der gleiche, wie oben beschrieben ist. Das umgebende Gewebe ist in dieser Gegend auffallend derb und feucht. Noch mehr abwärts im Bereich der Wade und darunter ist das Gewebe von graurötlicher bis gelbrötlicher Flüssigkeit durchtränkt. Der Inhalt der Venen ist ein dünner, gelbrötlicher Brei, ihre Wand ist noch stärker verdickt und gefaltet als weiter oben. Erst in der Gegend des Fußgelenkes nimmt die Veränderung allmählich wieder ab.

Beim Einschneiden in die Parametrien quellen aus einzelnen größeren Lymphgefäßen gelbe rahmige Tröpfchen; die Venen enthalten flüssiges Blut, ihre Wand ist leicht verdiekt, sonst $0 . \mathrm{V}$.

Mikroskopischer Befund: Da nach dem makroskopischen Anblick die Veränderungen der V. saphena stark wechselten, wurden vier verschiedene Abschnitte dieses Gefäßes untersucht; dabei zeigte sich, daß die Verdickungen der Venenwand zum Teil durch ältere produktive Vorgänge an der Intima bedingt waren, in denen sich feine neugebildete elastische Fasern vorfinden. Diese Intimawucherungen nehmen nicht die ganze Peripherie der Venenwand ein, sondern ragen wie flache Buckel in das Gefäßrohr hinein, ähnlich wie z. B. sklerotische Herde in einer Koronararterie, so daß der Rest des Lumen ganz exzentriseh liegt (Varizen). Diese Bildungen fallen um so mehr ins Auge, als sie nun wieder sekundär durch ein starkes Ödem mit wenigen Leukozyten verdickt sind. Die ödematöse Durchtränkung erstreckt sich über die ganze Vena saphena, hier 
stärker, dort etwas weniger; die Gewebselemente der Gefäßwand sind durch die Flüssigkeit weit auseinandergedrängt, so daß die Venenwand mächtig verdickt erscheint und, da die peripheren Teile des Gefäßrohrs nicht nachgegeben haben, gezwungen ist, sich in den inneren Partien in Iängsfalten zu legen. Inhaltsmassen finden sich nur ganz spärlich; sie bestehen aus amorphen Massen, anscheinend geronnener Flüssigkeit und Resten von Blutkörperchen, das ganze ist durchsetzt von zahllosen Kokken, die sich in besonders dicken Haufen im Grunde der Falten angesiedelt haben. An manchen Stellen sind sie tief in die Venenwand eingedrungen, die zuweilen bis auf die Media zerstört ist. Fibrin findet sich weder im Lumen noch in der Venenwand in nennenswerten Mengen, nur in den Lymphräumen der Adventitia finden sich einige feine Netze.

Fall 11. S.-Nr. 380 (1910). Selma L., 22 Jahre. Aufnahme 17. 3. 1910, gestorben am 4.4.1910.

Krankengeschichte: Empfängnis: Anfang August 1909; Temperatur bei Aufnahme $37,8^{\circ}$, letzte Kohabitation: vor 36 Stunden. Placenta praevia totalis, Hydramnion. Kombinierte Wendung, Austastung wegen Retentionen. 20. 3. Schüttelfrost, Uterus sehr druckempfindlich; leiehter Ikterus. 25. 3. Streptokokken im Blut. 27. 3. Laparotomie und Totalexstirpation. Mehrere Schüttelfröste. 4. 4. Exitus.

Klinische Diagnose und Notizen: Sepsis post abortum.

Anatomische Diagnose: Sepsis post abortum. Thrombophlebitis septica der kleinen Venen des Beckens und beider Vv. spermaticae internae bis zur Mündung in die V. cava bzw. renalis. Laparatomiewunde, operativer Defekt des Uterus. Janchige Pelveoperitonitis, beginnende allgemeine Peritonitis. Schlaffes Herz. Septische Infarkte in Iungen, Milz und Nieren. Verfettung und parenchymatöse Trübung der Leber und Nieren. Alveoläres Emphysem und Ödem der Lungen. Bronchitis. Struma colloides.

Bakteriologische Diagnose: Im Herzblut und Milz Bacillus pyocyaneus (und Bact. coli, als Verunreinigung angesehen).

Mikroskopischer Befund: Abgesehen von einzelnen Stellen, wo in den die Venen verschließenden Pfröpfen weder Kokken noch Eiter gefunden werden, wo auch die Gefäßwand keine erheblichen Veränderungen zeigt, bieten die meisten der untersuchten Stücke Bilder, deren Deutung zuerst große Schwierigkeiten macht. Scheinbar handelt es sich um Thromben, die erst sekundär in der Mitte eitrig erweicht sind; die noch an der Gefäßwand haftenden Teile erinnern wohl so z. B. namentlich in den van Gieson-Präparaten - an eine Pseudomembran mit relativ wenig Kernen, andererseits ist eine große Ähnlichkeit mit den Randpartien der oben erwähnten Pfröpfe nicht abzuleugnen. Diese nun enthalten, wie die nach Weigert behandelten Schnitte dartun, ganz erhebliche Mengen von Fibrin, das in hauptsächlich konzentrischen, ziemlich starken Balken angeordnet ist, die durch ein feineres Netzwerk in Zusammenhang stehen. Analog ist auch der Aufbau der Fibrinmassen am Rande der eingeschmolzenen Thromben, doch sind diese durch ganz feine Fäden innig mit den Elementen der Venenwand verbunden, ja teilweise erscheinen diese Fasern tiefer in das Gewebe hineinzureichen und mit den in der Media liegenden Netzen zu kommunizieren. Die Entscheidung über diesen Punkt ist nicht ganz leicht zu treffen, da die innersten Partien des Gefäßrohrs schwer verändert ist; namentlich ist auch die Färbbarkeit der elastischẹn Fasern erheblich herabgesetzt. Die anderen Elemente der Gefä.Bwand sind weniger stark an den Entzündungsprozessen beteiligt, doch finden sich stellenweise reichliche Leukozyten, zum Teil in Wanderform nach dem Lumen des Gefäßes zu strebend. Die mittelsten Partien des Pfropfes endlich enthalten neben den Eiterkörperchen nur zahllose grampositive Kokken, kein Fibrin; endlich in der Zone, die zwischen der Eiterung und den pseudomembranähnlichen Bildungen liegt, finden sich spärliche, meist radial angeordnete, baumförmig verästelte Balken von Fibrin.

Fall 12. S.-Nr. 391 (1910). Maria Sch., 29 Jahre. Aufnahme 9. 2. 1910, gestorben am 6. 4. 1910 .

Krankengeschichte: Seit dem 2. Lebensjahr zirkumskripte Wucherungen am linken Oberschenkel und FuB.

Befund: Am linken Oberschenkel bis zu den Labien eine starke elephantiastische Wucherung der Haut. 17. 2. Operation. Eröffnung des Talokruralgelenks bei der Entfernung der Wuche- 
rangen, gleichfalls eines Teils der Sehnenscheiden. Radikale Entfernung des Tumors nicht möglich. 10. 3. Die Wunde am Fuß ist fast geschlossen. 11. 3. zweite Operation. Weitere Abpräparierung der Tumormassen. Starker Blatverlust. Drainage. 14. 3. Entfernung des Drains. Wunde sieht gut aus. 17. 3. Die Wunde am Mons pubis eitert. 21. 3. Eröffnung der Naht am Darmbeinkamm, da in der Tiefe Eiterung. Feuchter Verband. 27. 3. Am rechten Oberarm hat sich eine Infiltration gebildet, Fieber bis $41^{\circ}$. Am Arm kleine sezernierende Wunde (Kochsalzinfusion). 2. 4. Stiche in der Brust. Unterbindung der Vena cephaliea, es quillt aus der Vene dicker Eiter. 4. 4. Über der rechten Lunge ist Reiben zu hören. Puls schlecht. 6. 4. Exitus.

Klinische Diagnose und Notizen: Herzschwäche infolge eitriger Venenentzündung und eitriger Lungen- und Brustfellentzündung. (Vor 3 Wochen Entfernung eines großen Neuroms. Kochsalzinfusion in die rechte Ellenbogenbeuge.)

Anatomische Diagnose: Eitrige Thrombophlebitis der Vena cephalica dextra, ausgehend von einer vereiterten Einstichstelle in der rechten Ellenbogenbenge; verjauchter Infarkt im rechten Mittellappen, fibrinös-eitrige Pleuritis rechts; Lungenödem; Bronchitis; pleuritische Verwachsungen. Milzschwellung. Geringe parenchymatöse Degeneration von Nieren und Herz. Magenschleimhautinseln im Ösophagus. Frische Operationswunde am rechten Oberarm; alte granulierende Operationswunden in der linken Seite und am linken Malleolus internus.

Bakteriologische Diagnose: Im Herzblut Streptococcus pyogenes.

Protokoll: In der rechten Ellenbogenbeuge eine Einstichöffinung mit geröteter Umgebung; auf Druck quillt aus der Öffnung etwas trïbe, gelbe Flüssigkeit.

Die Operationswunde am rechten Arm wird nach oben und unten erweitert; dabei zeigt sich, daß ein etwa $4 \mathrm{~cm}$ langes Stijek der V. cephalica fehlt. Oberhalb und unterhalb ist die Venenwand verdickt, das Lumen von gelblichen, sehmierigen Massen exfüllt. Diese Veränderung reicht nach abwärts bis in die Gegend der Ellenbogenbeuge dicht an die beschriebene Einstichöffnung; hier findet sich eine mandelgroße, ebenfalls mit gelblichen, schmierigen Massen erfüllte Wundhöhle im subkutanen Gewebe. An den beiden Stümpfen der V. cephalica finden sich Unterbindungen.

Mikroskopischer Befund: Die ganz herauspräparierte Vena cephalica wird in mehrere Teile zerlegt, von jedem dieser Stückchen wird ein Abschnitt untersucht. Leider sind durch das Aufschneiden der immerhin engen Vene bei der Sektion mechanische Veränderungen gesetzt worden, namentlich ist natürlich der Inhalt, soweit er fliussig war, verloren gegangen. Auch die vorhandene, stellenweise sehr schön ausgebildete Pseudomembran zeigt an ihrer Oberfläche Defekte, die höchstwahrscheinlich durch das eingeführte Scheerenblatt hervorgerufen sind. Um eine Pseudomembran handelt es sich hier ganz unzweifelhaft, wie namentlich die nach Weigert behandelten Schnitte sehr schön demonstrieren. Nach dem Lumen zu finden sich etwas gröbere Balken von Fibrin, nach der Gefäßwand zu lösen sie sich in ein ziemlich großmaschiges Netz von feinen Fasern auf, das unmittelbar in ein in den aufgelockerten Elementen des Venenrohrs liegendes Fadenwerk übergeht. Da an solchen Stellen nekrotische Bezirke in der Venenwand nicht fehlen, so könnte man wohl von einer oberflächlichen pseudomembranösen Entzündung sprechen mit einzelnen Partien von tiefer pseudomembranöser Phlebitis. An der Oberfläche der Pseudomembran liegen, wie gewöhnlich, amorphe Massen mit Kerntrümmern und grampositiven Kokken, welche sich da, wo die Gefäßwand ganz frei liegt, auf dieser angesiedelt haben. Die einzelnen Bestandteile der Venenwand sind von blasigen HohIräumen auseinandergedrängt, offenbar wird dieses Bild durch kleine Tropfen von Flüssigkeit erzeugt, die in den Gewebsmaschen liegen; möglicherweise handelt es sich hier um eine Art Stauungsödem in der Gefäßwand, jedenfalls bietet sich kein Anhalt dafür, diese Flüssigkeit als entzündliches Exsudat aufzufassen. Zahlreiche Leukozyten sind in die einzelnen Gewebsschichten eingestreut, die meisten zeigen die sogenannte Wanderform und zwar ist die Längsachse der gestreckten Kerne oft radiär zur Vene gestellt. Einer von ihnen liegt zur Hälfte noch in der Intima, zum andern Teil schon in der Pseudomembran. Erhebliche Veränderungen in der weiteren Umgebung lassen sich nicht feststellen, schon die Beteiligung der Adventitia ist sehr gering. 
Fall 13. S.-Nr. 398 (1910). Pauline H., 28 Jahre. Aufnahme 26. 3. 1910, gestorben am 7. 4. 1911.

Krankengeschichte: Blutungen seit Weihnachten 1909. Am 26. 2. 1911 normale Entbindung, seitdem Fieber. Bei Aufnahme starke Schwellung und Druckempfindlichkeit der Oberund Unterschenkel. 28. 3. Schüttelfrost. 7. 4. Exitus.

Klinische Diagnose und Notizen: Phlegmasia alba dolens.

Anatomische Diagnose: Puerperale Sepsis. Septische Metritis, septische Thrombophlebitis sämtlicher Beckenvenen, beider VV. femorales, VV. spermaticae und der ganzen V. cava inf. bis zur Einmündung der Vena hepatica. Endocarditis ulcerosa mitralis. Septische Infarkte in Lunge, Milz und Nieren. Subphrenischer AbszeB links infolge Durchbruchs eines vereiterten Milzinfarktes. Puerperaler Uterus mit Verlagerung nach rechts infolge Verkürzung des Lig. latum. Beginnende Fettleber. Pankreaszirrhose. Ödem beider Beine. Dilatation der Blase.

Mikroskopischer Befund: Die von den Vv. spermaticae entnommenen Präparate zeigen, daß es sich hier um eine ältere, ursprünglich aseptische Thrombose handelt; zahlreiche junge GefäBe und Bildung von Fasern, die sich mit der van Gies on-Methode stellenweise deutlich rot färben, lassen die schon ziemlich weit fortgeschrittene Organisation erkennen. In den ganz alten Partien findet sich wenig Fibrin, das an den anderen Stellen, wo noch wenig Bindegewebe vorhanden ist, in großen Massen - teils in dichten, feinen Netzen, teils in dicken, plumpen Balken nachweisbar ist; sogar die schon vaskularisierte Zone ist von reichlichem Fibrin durchsetzt. In der Peripherie ist es in konzentrischen Schichten, nach dem Zentrum zu etwas unregelmäßiger angeordnet. Ganz in der Mitte, die im eitrigen Zerfall begriffen ist, fehlt es vollkommen; zwischen den Eiterkörperchen finden sich diffus verstreute Kokken, anscheinend Streptokokken, in derartigen Massen, daß die Grampräparate bei schwacher Vergrößerung ganz bläılich erscheinen.

Fall 14. S.-Nr. 413 (1910). Frau Sch., 62 Jahre. Aufnahme 29. 4. 1909, gestorben am 10. 4. 1910 .

Krankengeschichte: Im Herbst 1907 am rechten äußeren Knöchel ein erbsengroßes Geschwür. Wachstum, Eiter (Kankroid).

Befund: An der Ferse fast handtellergroßes unregelmäßig begrenztes Ulcns. Leistendrüsenmetastasen.

2. 5. 1909 Grittische Amputation, Exstirpation der Inguinaldrüsen. 10. 5. In rechter Leistenbeuge stark eitrige Sekretion. 18. 6. Granulationen sehen gut aus. 25. 6. Erysipelatöse Rötung der Haut in der Umgebung der Wunde. 5. 8. Wunden gut geschlossen. 18. 8. gebessert entlassen. 9. 11. wieder aufgenommen: Fistelmündung am Amputationsstumpf, harter Rand; Rezidiv? 30.11. Operation, y-förmiger Schnitt, Ca-ähnliche Massen. 21. 12. Noch diffuse Rötung des Amputationsstumpfes. 10. 1. Noch starke Eiterung am Stumpf, ebenso an der Wunde in der Leistenbenge. 15. 2. große ulzerierende Fläche am Stumpf. 6. 3. Die starke Eiterung beider Wunden besteht unverändert fort. 31. 3. Eiterung, Abstoßung nekrotischer Gewebspartien nimmt immer mehr zu. 10. 4. Exitus.

Klinische Diagnose und Notizen: Karzinom des Unterschenkels.

Anatomische Diagnose: Verjauchter Amputationsstumpf am rechten Obersehenkel, verjauchte Operationswunde in der rechten Leistengegend. Septische Thrombophlebitis und Arteriitis femoralis und iliacalis. Janchende Phlegmone auf der rechten Beckenschaufel. Milzschwellung. Bronchopneumonische Herde mit frischer fibrinös-eitriger Pleuritis im linken Unterlappen. Narben in beiden Spitzen. Pleuritische Verwachsungen rechts. Harngries. Submuköses Lipom des Ileum. Fettgewebsnekrosen im Pankreasschwanz.

Mikroskopischer Befund: Der Hauptstamm der V. femoralis ist durch einen blanden Thrombus verschlossen, dessen Zentrum die ersten Anzeichen eines eitrigen Zerfalls aufweist; Fibrin ist nur hier und da in geringen Mengen vorhanden, entsprechend dem noch erkennbaren schichtweisen Aufbau des Piropfs. Mehrere kleine Venenäste, die vom Amputationsstumpf entnommen wurden, liegen in einem von zahlreichen Leukozyten durchsetzten Gewebe. Die Intima 
ist mächtig verdickt, im Lumen findet sich neben amorphen Massen und etwas Eiter eine ganze Menge grampositiver Kokken. Fibrin fehlt vollständig, die eigentliche Gefäßwand ist an den Entzündungserscheinungen auffällig wenig beteiligt.

Fall 15. S.-Nr. 436 (1910). Ida R, 11 Jahre. Aufnahme 6. 4. 1910, gestorben am 14. 4. 1910.

Krankengeschichte: Am 7. 4. schmerzhafte fluktuierende Schwellung an der Nasenwurzel, Inzision. Am 11. 4. starke Schmerzhaftigkeit und Schwellung hinter dem rechten Ohr, Nackensteifigkeit.

Befund bei Aufnahme: Temperatur 40,9 . 11. 4. Operation: Eröffnung der rechten Stirnhöhle, Eiter, Drainage. Ferner Bogensehnitt hinter dem rechten Ohr, es zeigen sich viel thrombosierte Venen. 12. 4. 39,9 ${ }^{\circ}$, später $41,2^{\circ}, 13.4 .39^{\circ}$. Durchfall. Collargol intravenös. Das entnommene Blut ist steril geblieben. 14. 4. $36^{\circ}$. 14. 4. Exitus.

Klinische Diagnose und Notizen: Stimhöhleneiterung, Faszienphlegmone, Herzschwäche.

Anatomische Diagnose: Doppelseitiges Stimhöhlenempyem (rechts operativ eröfnet). Phlegmone der rechten Orbita (eröffinet). Epiduraler Abszeß. Septische Thrombose des Sinus longitudinalis und des rechten Sinus transversus. Beginnende Phlegmone an der rechten Halsseite. Septische Lungeninfarkte. Subpleurale und subperikardiale Hämorrhagien. Milzschwellung. Katarrhalische Enteritis. Ödem und Hyperämie der Pia und des Gehirns.

Protokoll: Im Längssinus finden sich im vordersten Abschnitt, der der soeben beschriebenen Stelle (dem epiduralen AbszeB) unmittelbar benachbart ist, gelblich-graue, weiche, teils zerfließ.liche, teils der Wand fest anhaftende Massen. Weiter nach hinten enthält der Sinus teils schmutzigrote Kruorgerinnsel, teils opake graue bis rötlich-graue, zum Teil mehr gallertige, zum Teil mehr zerfließliche Massen. Linker Sinus transversus enthält Kruorgerinnsel, der rechte bis zum Bulbus herab teils Kruor, teils graugelbliche, mehr oder weniger konsistente, dex Wand teilweise fest anhaftende Massen.

Mikroskopischer Befund: Die ganz charakteristische Pseudomembran enthält meist parallel zur Innenfläche des Sinus angeordnete Fibrinbalken, welche durch ein Netz feiner Fäden deutlich tief im Gewebe der Sinuswand wurzeln. Sonst findet sich in dieser nur wenig Fibrin. Stellenweise ist die Pseudomembran durch eine Schicht von Leukozyten von ihrer Unterlage abgehoben; kleine Herde von diesen Zellen finden sich anch in der Wand des Sinus und in der Mitte des Lumens. Mikroorganismen finden sich nur im Lumen des Gefäßes, und zwar zentral von der Pseudomembran, soweit sie fest haftet; an den Stellen jedoch, wo sie sich abgelöst hat, sind die Kokken auch in dem entstandenen Spalt zu finden. Soweit sich aus dem mikroskopischen Bild allein schließen läßt, handelt es sich um eine Mischinfektion mit Pneumokokken und Staphylokokken. Außer etwas Ödem und den schon erwähnten kleinen Eiterherden bietet die Sinuswand keine schwereren Veränderungen.

Fall 16. S. Nr. 583 (1910). Louise P., 24 Jahre. Aufnahme 23. 4. 1910, gestorben am 17. 5. 1910.

Krankengeschichte: Entbindung am 29. 4. (enges Becken) durch suprasymphysüren Kaiserschnitt. 2. 5. Schüttelfrost, Drainage. 8. 5. Katarrh über Lungen, besonders rechts. 12. 5 . linkes Bein schwillt an. 16. 5. Halluzinationen und Erregungszustände. 17. 5. rechts Knöchelödem. 17. 5. Exitus.

Klinische Diagnose und Notizen: Beckenphlegmone und Thrombose der Beckenvenen links.

Anatomische Diagnose: Uterus puerperalis. Septische Thrombose der Vena femoralis, iliaca externa, interna und der V. cava inferior (unterster Teil). Wandständige Thromben in der V. spermatica links. Multiple Lungenabszesse beiderseits. Rechtsseitiges Pleuraempyem und Kollaps der rechten Lunge. Leichtes Lungenödem. Beiderseits pleuritische Verwachsungen und frische fibrinöse Pleuritis. Alveoläres Randemphysem, starke eitrige Tracheobronchitis. Schwellung und Anthrakose der Hilusdrüsen. Septische Milz. Gastritis. NierenabszeB links. Frische Pyelitis 
und Ureteritis. Schwere hämorrhagische Zystitis. Operationswunde in der linken Unterbauchgegend mit Drainage in die Scheide. Mäbige Phlegmone der Umgebung der Operationsöffnung. Intimaverfettung der Aorta. Verkalkte Mesenterialdrüsen. Kleines Dermoid am Kleinhirnbrückenwinkel links. (Mikroskopisch: Fettgewebe, Cholesterintafeln, Kömchenkugeln und Faserbündel.)

Bakteriologische Diagnose: Im Herzblut Streptokokkus und Staphylococcus albus und citreus.

Protokoll: In der Mitte der hinteren Uteruswand findet sich eine fast fünfmarkstückgroße Stelle, wo graurötliche, buckelige Erhabenheiten stehen. Beim Einschneiden findet man unter ihnen breitklaffende, von Pfröpfen verschlossene Gefäßlumina. Vena uterina und Vena spermatica in der Nähe des Uterus auf weite Strecken hin vollständig unverändert. In der linken Vena spermatica finden sich ungefähr in der Mitte ihres Verlaufs zwei bohnengroße graurötliche derbe Pfröpfe, die der Wand fest anhaften in der Nähe der Klappentaschen. Vom untersten Teil der Vena cava übergehend in die liaca communis, den obersten Teil der interna, die externa und weit hinab in die Femoralis findet sich ein, die Gefäße fast völlig ausfüllender, graurötlicher, bröckliger Pfropf, der an manchen Stellen graugrünliche, rahmige Massen einschließt. Die Innenfläche der Venen erscheint nach Fortnahme der Pfröpfe fast überall graugrünlich bis graugelblich verfärbt, schmierig und bröcklig.

Mikroskopischer Befund: Während in einigen der untersuchten Venenäste sich ältere aseptische Thromben mit Pigment in weit fortgeschrittener Organisation, zum Teil mit eitriger Einschmelzung im Zentrum finden, bietet ein Teil der Präparate die typischen Bilder der Pseudomembran, die in dicker Schicht die ganze Innenfiäche des Gefäßes auskleidet. Die Veränderungen der Gefäßwand treten besonders stark in den Vordergrund, namentlich die Ausdehnung der Lymphspalten, die Zerstörung des elastischen Gewebes und der Reichtum an Leukozyten, welche, soweit man aus ihrer Anordnung einen Schluß machen darf, dem Lumen der Vena zustreben; im Gewebe findet sich nur wenig Fibrin. Wenn schon das ganze Aussehen der Pseudomembran kaum einen Zweifel an ihrer Natur aufkommen läßt, so sind die W eigertschen Fibrinpräparate wohl geeignet, die Diagnose noch erheblich zu sichern. Erleichtert wird dies durch die Veränderungen des elastischen Gewebes, das aufgefasert und weit anseinandergedrängt, vielfach blasser oder gar nicht mehr gefärbt, stellenweise ganz unterbrochen ist; während nun gewöhnlich die dichte Lamina elastica int. eine scharfe Grenze zieht zwischen Gefä.Bwand und Inhalt - das Endothel ist meist zerstört und fehlt - und das Hineinreichen von Fibrinfäden zwischen die elastischen Elemente nur schwer und selten aufzufinden ist, läßt sich diese Tatsache hier sehr deutlich feststellen. Weit hinein zwischen die stark auseinandergezerrten elastischen Fasern läßt sich das Fibrinnetzwerk verfolgen. Ganz besonders wichtig erscheint mir jedoch der Umstand, daß sich in der Pseudomembran Teile von losgelösten elastischen Fasern finden, welche über ihr ursprüngliches Niveau nach dem Zentrum des GefäBrohrs verlagert erscheinen; haften sie noch an einem Ende fest, so ist der gewissermaßen frei flottierende, abgehobene Teil in radiärer Richtung nach dem Lumen der Vene zu umgebogen. Diese Erscheinungen kann ich nur aus dem Umstande erklären, daß sich wirklich aus der Wand ins Lumen eine Exsudatströmung vollzieht und die beschriebenen Bilder hervorruft. Kokken sind nur in minimaler Menge nachweisbar, und zwar liegen sie in der Zerfallshöhle im Lumen der Vene.

Fall 17. S.-Nr. 634 (1910). Bertha F., 37 Jahre. Aufnahme 5. 5. 1910, gestorben am 31. 5. 1910.

Krankengeschichte: Entbunden am 25. April 1910, Placenta praevia partialis. Wendung auf den FuB, Extraktion. Stärkere Blutung am 1. 5. Fieber, Abgang übelriechender Blutkoagula aus Uterus. Zervixriß rechts wurde konstatiert. Bei Aufnahme über $\mathrm{r}$. Lig. Pouparti $8 \mathrm{~cm}$ lange schräge Geschwulst. 10.5. Eröffnung der erwähnten Hämatozele rechts. 12. 5. linker Oberschenkel geschwollen, schmerzhaft. Über Lunge rechts hinten Dämpfung. 28. 5. Punktion ergibt in Pleurahöhle blutig seröse Flüssigkeit. Rippenresektion. 31. 5. Exitus.

Klinische Diagnose und Notizen: Venenentzündung nach Entbindung. 
Anatomische Diagnose: Puerperale Pyämie. Uterus puerperalis mit fast geheiltem rechtsseitigem Zervixriß. Doppelseitige Parametritis, rechts operativ eröffnet. Ausgedehnte Thrombose der rechten Schenkel-, Becken-, spermatischen und Nierenvenen. Multiple Lungenembolien. Zwei embolisehe, in Organisation begriffene Lungeninfarkte. Rechts fibrinös-eitrige Pleuritis mit Kollaps des Unterlappens und Thorakotomiewunde. Starkes Ödem der Nieren und der unteren Extremitäten. Milzschwellung. Soor im Ösophagus. Pentastomum denticulatum der Leber. Allgemeine Anämie. Rotes Knochenmark. Mikroskopisch: In den Lungeninfarkten nur spärliche, gut erhaltene Lenkozyten, keine Bakterienhaufen. Ausgedehnte nekrotische Zonen und zahlreiche thrombosierte Gefäße.

Protokoll: Die linken parametranen Venen sind sämtlich, die rechten nur zum Teil durch gelblichrote ziemlich derbe Pfröpfe verschlossen. Ähnliche, aber mehr graurote bis braunrote Pfröpfe verschließen sämtliche Äste beider Vv. lemorales sowie diese selbst. In den Iliacae communes finden sich graugelbe, zum Teil breiig erweichte Massen. Rechte Vena spermatica daumendick, linke kleinfingerdick. In der linken gelbrote, ziemlich feste Pfröpfe, die bis in die Vena renalis hineinreichen; in der rechten graugelbe, weiche, bröckelige, zum Teil dickbreiige Massen, die sich bis dicht an die Leber in den Stamm der Vena cava hineinerstrecken.

Bakteriologische Diagnose: Kulturen steril.

Mikroskopischer Befund: Vena iliaca und spermatica zeigen auf ihrer Innenfläche eine dicke Auskleidung mit alten, organisierten, in Längsstreifen angeordneten Thrombusmassen mit Blutpigment, die sich bei der van Gieson-Methode deutlich rot färben. Auf dieser Schicht haben sich in der Iliaca amorphe Massen, einige Leukozyten, kleine Kokkenhaufen und ganz geringe Fibrinmassen niedergeschlagen; das restierende Lumen der Spermatika dagegen wird fast vollständig verschlossen durch eine frische Thrombusmasse, die zwar nicht gerade als typischer, geschichteter Thrombus anzusprechen ist, aber doch eine deutliche Separation der einzelnen Blutelemente erkennen läßt. Sie enthält mehr Fibrin als ein gewöhnlicher blander Blutpfropf, in die Leukozytenherde finden sich einige Kokkenhaufen eingestreut. Überall jedenfalls sind die Reaktionen auf die Einwirkung dieser Mikroorganismen änßerst geringfügig, nach dem Protokoll konnte man ja auch annehmen, daß ihre Virulenz nur gering sein konnte. Von einer Pseudomembranbildung findet sich nirgends eine Andeutung.

Fall 18. S.-Nr. 1412 (1910). Frau R., 34 Jahre. Aufnahme 28. 11. 1910, gestorben am 14. 12. 1910 .

Krankengeschichte: Am 25. November von der Poliklinik aus wegen Fiebers mit Zange entbunden. Am 27. 11. Fieber, Unterleibsschmerzen, profuse Durchfälle, geringe Benommenheit, Eitriger Ausfluß aus Gebärmutter. 28. 11. Punktion im rechten Hypogastrium: kein Eiter. 29.11. Thrombose am ganzen linken Bein und linken Labinm maj. mit geröteter Haut. Blatkultur: Streptokokken. 3. 12. Zurückgehen der Thrombose. 7. 12. Inzision eines kleinen Infiltrats am linken Oberschenkel, dicker gelber Eiter. 9. 12. Am linken Bein Thrombose der Schenkelvenen. 12. 12. Dämpfung über beiden Lungen. 13. 12. Inzision eines periphlebitischen Abszesses. 14. 12. Delirien. Exitus.

Klinische Diagnose und Notizen: Sepsis puerperalis.

Anatomische Diagnose:' Sepsis. Endometritis septica. Septische Thrombophlebitis der linken Vena iliaca, iliaca externa und hypogastrica, der femoralis und der parametranen Venen. Septische Lungeninfarkte, partielle fibrinös-eitrige Pleuritis, diffuse fibrinös-eitrige Peritonitis. Ausscheidungsherde in beiden Nieren. Hämorrhagische Nephritis (?). Septischer Milztumor mit Nebenmilzschwellung. Geschwüre, stellenweise mit Pseudomembranen an der hinteren Pharynxwand. Schwellung der linksseitigen Halslymphdrüsen. Hypertrophie und Dilatation des linken Ventrikels. Alte Geschwürsnarbe an der hinteren Magenwand. Rechtsseitiger Zervixriß. Ovula Nabothi. Struma colloides. Hypertrophischer Knoten in der Leber. Puerperaler Uterus. Ödem des linken Beins.

Bakteriologische Diagnose: Im Herzblut Streptococcus longus und Staphylococeus albus. Milz: Streptococcus longus. 
Protokoll: Die beiden Vv. spermaticae erscheinen etwas weit, enthalten jedoch außer einigen Blatgerinnseln keinen Inhalt; ihre Wandungen sind unverändert. Beim Abtrennen der Blase von der Vorderwand der Scheide tritt aus dem linksseitigen Douglasgewebe dickex, gelbgrüner Eiter vor, der sich offenbar im Lumen der dort liegenden venösen Gefäße befindet. Die linke Vena femoralis sowie die linke Mliaca bis zur Einmündungsstelle in die Cava inferior sind vollständig ausgefüllt mit erweichten, teils mehr braungelben, teils mehr gelbroten, der Wand fest anhaftenden schmierigen Massen. Rechte femoralis frei.

Mikroskopischer Befund: Das untersuchte Stück der Vena femoralis enthält einen Thrombus mit typischer Schichtung; nur der beginnende Zerfall der Leukozyten und die Anwesenheit von Kokken deuten darauf hin, daß auch infektiöse Vorgänge mit im Spiel sind. Die Fibrinmengen sind etwas reichlicher als in wirklich ganz aseptischen Thromben, doch haftet das Fibrin nie ganz fest an der Venenwand.

Fall 19. S.-Nr. 334 (1911). Frau K., 44 Jahre. Aufnahme 8. 2. 1911.

Krankengeschichte: Am 8. 2. nach Zervixerweiterung Entbindung. 13. 2. entzündete Krampfadern rechts. 16. 2. zirkumskripte Schwellung am Bein. Zyanose. R. H. U. Dämpfung. 18. 2. Inzision am Bein, blatiger Eiter. 20. 2. Giemen über r. O-Lappen. 21. 2. Auch am linken Bein thrombophlebitische Herde. 23. 2. Inzision am rechten Bein. 25. 2. Inzision am rechten Bein sowie eines Herdes zwischen Nabel und Symphyse. 4. 3. Inzision eines Abszesses am linken Oberschenkel. 10. 3. Erguß im reehten Kniegelenk. 18. 3. Dekubitus über der Raute des Michaelis. 19. 3. Auf Sternum in Höhe der zweiten Rippe Vorwölbung, Inzision, kein Eiter. 24. 3. Oberschenkel und linker Arm sind stark geschwollen. 26. 3. Schüttelfrost. 29. 3. Herzschwäche, Exitus.

Klinische Diagnose und Notizen: Thrombose beider Schenkelvenen, Lungen- und Nierenentzündung; Frühgeburt (angeblich im 6. bis 7. Monat).

Anatomische Diagnose: Septische Endometritis. Thrombophlebitis der Vv. uterinae, vesicales, haemorrhoidales und femorales. Abszesse und Ausscheidungsherde in beiden Nieren. Ältere Abszesse in beiden Lungen. Durchbruch eines Abszesses durch das Brustbein in die Brustmuskulatur und das subkutane Gewebe oberhalb der rechten Mamma. Multiple inzidierte Abszesse an beiden Beinen. Abszesse in der rechten Herzmuskulatur. Frische Embolien in gröBeren Pulmonalästen beiderseits. Schlaffes Herz mit Dilatation beider Ventrikel und Hypertrophie des linken Ventrikels. Gallensteine. Starkes Ödem beider Unterschenkel. Kleine Geschwüre im Dickdarm. Bronchopneumonische Herde in der rechten Lunge. Bronchitis beiderseits. Parenchymatöse Trübung der Leber.

Bakteriologische Diagnose: Staphylococcus aureus in Milz und Herzblut.

Mikroskopischer Befund: Die Vena femoralis enthält einen obturierenden Pfropf, der auf einer Seite den typischen, geschichteten Thrombenaufbau noch erkennen Iäßt, auf der andern Seite nur aus Erythrozyten zusammengesetzt ist. In den zentral gelegenen, erweichten Partien finden sich kleine Haufen grampositiver Kokken. Fibrin ist in mäßjger Menge vorhanden. Der Zusammenhang des Pfropfs mit der Venenwand ist nur lose, diese selbst ist gar nicht verändert.

Fall 20. S.-Nr. 662 (1911). Emma K., 16 Jahre. Aufnahme 17. 6. 1911, gestorben am 20. 6. 1911.

Krankengeschichte: Im Jahre 1909 Radikaloperation wegen Schwellung hinter dem linken Ohr. Seit $1 / 2$ Jahr rechts Ohrlaufen. Seit dem 7. 6. starke Kopfschmerzen, seit dem 9. 6. täglich Erbrechen, Fieber, Nackensteifigkeit. Am 17. 6. r. Radikaloperation. Der Sinus transversus ist schmutzig grau verfärbt, Thrombus!, schmutziges Aussehen. Entfernung des Thrombus mit dem Löffel. 18. 6. Schüttelfrost, Unterbindung der Vena jugularis am Halse. 19. 6. Nachoperation der alten Radikaloperation links, der Sinus wird freigelegt. 20.6. Exitus.

Klinische Diagnose und Notizen: Eitrige Meningitis nach Sinusthrombose infolge chronischer Mittelohreiterung.

Anatomische Diagnose: Doppelseitige Otitis media purulenta. Septische Sinusthrom- 
bose und Thrombophlebitis jugularis (operiert). Doppelseitiger Operationsdefekt des Processus mastoideus. Fibrinös-eitrige Pleuritis links. Multiple metastatische septische Lungeninfarkte mit teilweiser Erweichung, teils eitriger Demarkation und Pleuranekrose. Septisch-hämorrhagische Nephritis. Frische Milzschwellung. Haselnußgroße Nebenmilz. Nekrotisierende bämorrhagische Urozystitis. Langgestielte Morgagnische Hydatide an den rechten Fimbrien. Weiche, schlaffe Ovarien mit pigmentierten Resten von Corpora haemorrhagica beiderseits. Links mehrere Gra afsche Follikel (?). Kalkherd in einem der stark geschwollenen Lymphknoten.

Bakteriologische Diagnose: Pneumokokken oder Streptokokken, wegen bald eintretender Verunreinigungen nicht sicher gestellt; nicht mäusepathogen.

Mikroskopischer Befund: Die Veränderungen sind schon weit fortgeschritten; eigentliche Thrombusmassen oder auch eine Auflagerung auf der Innenfläche der Venenwand fehlt vollkommen. Diese ist in ihren zentralen Partien von großen Leukozytenschwärmen durchsetzt, zwischen denen sich hyaline Massen finden, die in ihrem ganzen Aussehen und auch in ihrem Verhalten der van Gieson -Färbung gegenüber ganz dem gleichen, was wir in den Pseudomembranen zu sehen gewohnt sind; die Fibrinreaktion fällt jedoch, abgesehen von einigen kleinen Partien mit schwacher Tingierung nirgends mehr positiv aus. Ebensowenig färben sich die Gewebskerne im Bereich der Eiterung, dagegen lassen sich noch Teile von bindegewebigen und elastischen Fasern deutlich nachweisen, dabei überwiegt wieder die Zerstörung der elastischen Fasern. Sehr hübsch lälit sich verfolgen, wis Teile von ihnen nach dem Lumen der Vene zu verlagert sind; entweder sind sie parallel zu sich versehoben oder auch, wenn ihr eines Ende noch fest sa $B_{\text {, nur mit dem }}$ andern nach der Mitte zu umgebogen, so daß die ursprünglich zur Venenachse konzentrische Lage in eine mehr radiäre verwandelt ist. Zahllose feine Kokken finden sich als dichter Rasen an der freien Oberfläche, zum Teil auch als feine Wolke in der Eiterschicht.

Fall 21. S.-Nr. 927 (1911). Frieda W., 20 Jahre. Aufnahme 21. 7. 1911, gestorben am 23. 8. 1911.

Krankengeschichte: Letzte Menses 2. 5., am 12. 7. (angeblich!) Fall von Leiter, rittlings auf eine Sprosse. Am 16. 7. Blutung, Abgang größerer Stücke, Fieber, Schüttelfrost.

Befund: In Scheide markstückgroße frische Rißwunde in Nähe der Portio, rechts parametranes Infiltrat. 26. 7. öfters Schüttelfrost. 29. 7. Ribwunde gut geheilt. Puls weich. 31. 7. trockener Husten, Schmerzen r. h. u. 2. 8. Schüttelfrost, rostfarbenes Sputum. 6. 8. rechter Lungenbefund: abgeschwächtes Atmen rom Skapulawinkel ab. 14. 7. Dämpfung im Bereich beider U-Lappen. 17. 8. schleimig-eitr:ger Auswurf, seit 4 Tagen leichte Durchfälle. Schüttelfröste öfters. 19. 8. Puls sehr frequent, bis 130. 20. 8. Dyspnoe. 22. 8. Sensorium völlig getrübt. 23. 8 . Exitus unter den Erscheinungen plötzlicher Dyspnoe.

Anatomische Diagnose: Sepsis; Endometritis septica, parametritischer abgekapselter AbszeB. Thrombose der Vena hypogastrica dextra. Septische Milz. Fast kirschgroßer, oberflächlicher, perforierter Abszeß der linken Lunge. Fibrinös-hämorrhagische Pleuritis links. Eitrige Pleuritis rechts. Kollaps des unteren und mittleren Lungenlappens rechts. Starkes Lungenödem beiderseits. Fettleber, Fettnieren, schlaffes Herz.

Bakteriologische Diagnose: Im Herzblut Staphylococcus aureus und albus. Milz steril.

Mikroskopischer Befund: Von der verschlossenen Vena hypogastrica wurden mehrere Stücke untersucht. Die das Lumen fast vollständig verschließenden Pfröpfe zeigen auf der einen Seite deutlichen Aufbau eines gemischten Thrombus mit wenig Fibrin; die entsprechenden Stellen der Gefäßwand sind kaum verändert. Nach der Mitte zu ist eitriger Zerfall eingetreten, hier haben sich Massen von grampositiven Kokken angesiedelt. Auf der andern Seite der Vene läßt sich keine Schichting in der Verschlußmasse nachweisen; der Hauptbestandteil dieser Massen wird durch ein hyalines, bei der van Gieson-Färbung gelb tingiertes, plumpes Netzwerk gebildet, das sich' mit der Weigertschen Fibrinmethode intensiv blau färbt. Die der Gefäßwand zunächstliegenden Fibrinbalken verlaufen parallel zu dieser und scheinen ihr nicht fest anzuhaften, da sie sich an 
mehreren Stellen glatt abgelöst haben, ohne daß Reste an der Gefäßwand hängen geblieben wären oder Teile des Pfropfes an der Gefäßwand. Diese wiederum läßt deutlich entzündliche Veränderungen erkennen, viel stärker jedoch an einer kleinen Stelle, wo sie ganz frei zutage liegt. Ein mächtiges Ödem hat hier die Gewebselemente auseinandergedrängt, zahlreiche Leukozyten sind auf der Wanderung durch die Venenwand begriffen. Die Gewebskerne sind teils gequollen, teils ganz zerfallen, auch das elastische Gewebe weist Defekte auf. Sehr deutlich sieht man an einer Anzahl von Stellen ganze Bündel von Leukozyten büschelförmig aus der Gefäßwand ins Lumen treten. Dazwischen finden sich feine Fäserchen, welche zum Teil noch die Fibrinreaktion geben, außerdem sind die ganzen, zuletzt beschriebenen Partien überschwemmt von grampositiven Kokken.

Fall 22. S.-Nr. 928 (1911). Anna Sch., 34 Jahre. Aufnahme 22. 8. 1911, gestorben am 24. 8. 1911 .

Krankengeschichte: Seit etwa 8. 8. 1911 Ohrlaufen rechts mit Kopfschmerzen, Erbrechen. Druckempfindlichkeit des Kopies, Nackensteifigkeit. Am 22. 8. Radikaloperation: Wand der Jugularis miBfarbig, in der Jugularis und im Bulbus jauchige Flüssigkeit. Doppelte Unterbindung der Jugularis. Entfernung der vorderen Sinuswand bis zur Mitte des Sinus transversus. Schüttelfrost bei der Operation. 24. 8. Exitus.

Klinische Diagnose und Notizen: Mittelohrentzündung and Thrombophlebitis.

Anatomische Diagnose: Operative Eröffnung des rechten Proc. mastoideus. Drainage des rechten Sinus sigmoideus. Unterbindung und Eröffnung der Vena jugularis dextra. Eitrige Thrombose des linken Sinus transversus mit ausgedehnter eitriger Basilarmeningitis, hanptsächlich links. Leptomeningitis spinalis purulenta. Septische Milz. Erbsengroßer hämorrhagischer Erweichungsherd an der Unterseite des rechten Schläfenlappens. Alte käsige Spitzentuberkulose mit schiefriger Induration beiderseits. Chronische Miliartuberkulose in beiden Oberlappen, frische Miliartuberkulose im linken Unterlappen. Derbe pleuritische Verwachsungen an beiden Spitzen. Tuberkulose der Hilus- und Bronchialdrüsen. Endokarditis chronica mitralis et chordalis. Schnür* furche der Leber. Alte peritonitische Verwachsungen und Stränge im ganzen Abdomen.

Mikroskopischer Befund: Beide. Sinus transversi sind von gemischten Thromben mit Andeutung von geschichtetem Bau und reichlichem Fibrin verschlossen; an verschiedenen Stellen beginnt eitriger Zerfall.

Fall 23. S.-Nr. 1185 (1911). Pauline A., 48 Jahre. Aufnahme 4. 10. 1911, gestorben am ว. 11. 1911 .

Krankengeschichte: Totaler Prolapsus uteri et vaginae, der in der Charité operiert wurde, seitdem Fieber und stinkender Ausfluß aus den Genitalien. Ödem der Schamlippen, Einschneiden der Klammern der Operationswunde in das Gewebe. 12. 10. Puls klein, 130. 13. 10. rostfarbenes Sputum, Herausnahme der Klammern, Scheiden- und Blasenspülung. Schüttelfrost. 17. 10. Abdomen anfgetrieben, linker Unterschenkel ödematös. Puls 138. 18. 10. Atmung 30 pro Minute. Schleimig-eitriger Auswurf. 19. 10. Puls 140. Scheidenödem geht zurück; untere Harnröhrenschleimhant ist vorgequollen. Ödem der rechten Schamlippe. 21. 10. Puls klein, beschleunigt, unregelmäßig; es besteht zwischen Scheide und Rektum eine gut kirschgroße Kommunikation, es laufen Faeces in die Scheide. 23. 10. Puls 80-90. Von der Rektalschleimhaut lösen sich nekrotische Fetzen ab. 25. 10. Puls unregelmäßig. 31. 10. Benommenheit, Beine stark geschwollen. 3. 11. Puls 140. 5. 11. Exitus.

Klinische Diagnose and Notizen: Myokarditis, Nephritis und Zystitis.

Anatomische Diagnose: Sepsis nach Operation eines Uterusprolapses. Beginnende diffuse eitrige Peritonitis. Septische.Milz. Eitrige Zystitis nnd schwere eitrig-hämorrhagische, zum Teil pseudomembranöse Ureteritis und Pyelitis. Nepbritis mit zahlreichen Ausscheidungsherden, Abszeßchen, septischen Infarkten und Papillarnekrosen. Septische Thrombophlebitis der paravesikalen und Femoralvenen. Große Embolie in beiden Lungen. Bronchopneumonische Herde rechts, alveoläres Emphysem und starke pleuritische Verwachsungen beiderseits. Trübes 
und verfettetes, sehr schlaffes Herz mit beginnender Endocarditis verrucosa mitralis, älterer einer Aortenklappe. Mesaortitis. Hepar lobatum mit mehreren alten Gummata. Hydrosalpinx beiderseits. Operativer Defekt der Portio cervicalis uteri mit Verschluß des Orifizium, Pyometra. Endometritis proliferans. Beginnende Epityphlitis. Verdoppelung des rechten Ureters und Nierenbeckens. Mehrfache Strikturen des linken Ureters. Ödem beider Beine.

Bakteriologische Diagnose: In der Milz Staphylococcus aureus.

Protokoll: Die paravesikalen Venen und vor allem die Vv. femorales sind mit festhaftenden, braunroten, im Zentrum großenteils sehr weichen, hier zum Teil auch gelblich aussehenden Pfröpfen erfüllt. Die Harnblase enthält eine kleine Menge trüber, gelblicher Flüssigkeit, die Schleimhant sieht trübe aus und zeigt im Fundus eine große Anzahl punktförmiger, nicht abwaschbarer Blutpunkte. Zwischen Blase und Uterus kommt man beim Auseinanderziehen der frischen Verklebungen in eine unregelmäßige, buchtige Höhle, die mit trüben, roten, dicklichen Massen erfüllt ist; diese Höhle steht mit der Vagina in weiter Kommunikation. Die Vagina zeigt eine übelriechende, grangrüne, mit ausgedehnten Substanzverlusten versehene Schleimhaut; in ihrem unteren, hinteren Teil führt eine daumendicke Kommunikation ins Rektum. Beim Aufschneiden des Uterus findet sich in ihm etwa ein Teelöffel trübgelber Flüssigkeit, die Schleimhaut ist blaßgelb bis blaßgrau.

Mikroskopischer Befund: Die vorliegenden Thrombusmassen der Vena femoralis sind anscheinend älteren Ursprungs; am Rande zeigen sie eine deutliche Vaskularisation und Entwickling von Bindegewebsfasern, die bei der van Gieson-Färbung schon einen deutlich roten Ton annehmen. Die andern Partien bestehen teils aus zusammengeballten Erythrozyten, von denen manche sich der Fibrinreaktion gegenüber positiv verhalten, zum Teil auch aus wirklichen Fibrinnetzen, die jedoch in körnigem Zerfall begriffen sind. Kerne finden sich nur ganz spärlich, auch die der Achse der Vene zunächst gelegenen Schichten sind nicht von Leukozyten durchsetzt, sondern einfach verflüssigt und eingeschmolzen; hier liegen auch einige spärliche Kokken und - wohl als Verunreinigung zu betrachten - einige grampositive Stäbchen. Die Wand der Vene zeigt nur eine geringfügige zellige Infiltration.

Fall 24. S.-Nr. 1198 (1911). Hermann R., 47 Jahre. Aufnahme 6. 11. 1911, gestorben am 6. 11. 1911.

Krankengeschichte: In der Lehrzeit am linken Ohr Schmerzen und Ohrenlaufen. Wiederanftreten am 4. 11. 1911, am 5. 11. starker Kopfschmerz, mehrmals Erbrechen. Am 6. 11. Verwirrtheit. Schwindel und Kopfschmerz seit den letzten Wochen. Der Patient wird in bewuBtlosem Zustande eingeliefert; keine Nackensteifigkeit. Am 6. 11. Radikaloperation und Labyrinthoperation. Dura enorm gespannt, sie wird gespalten. Hirnpunktion negativ. Abends Exitus.

Temperatur bei der Aufnahme 38,2, sie steigt auf 38,5 .

Klinische Diagnose und Notizen: Eitrige Hirnhautentzündung im Anschluß an chronische Mittelohreiterung.

Anatomische Diagnose: Fitrige Leptomeningitis und Pyocephalus internus nach Operation am linken Felsenbein. Prolaps eines Teils des linken Schläfenlappens durch die Operationsöffnung. Septische Thrombose des Sinus longitudinalis sup., des Sinus transversus rechts und des Sinus rectus. Sehr schlaffes dilatiertes Herz mit Sehnenfleck auf der Vorderfläche des linken Ventrikels. Bronchitis, Tracheitis catarrhalis, Bronchiolitis purulenta. Hyperämie und starkes Ödem beider Lungen. Beiderseits obliterierende Pleuritis. Angina lacunaris, besonders rechts. Kleines Kavernom der Leber.

Bakteriologische Diagnose: Im Eiter Streptokokken.

Protokoll: Im Sinus longitudinalis findet sich ein der Wand stellenweise fest anhaftender, teils bräunlicher, teils gelblicher Pfropf. Der Sinus sigmoideus links enthält nur Blutgerinnsel, der rechte ist leer. Der Sinus transversus rechts enthält ähnliche gelbliche, bröcklige Massen, wie der Sinus sagittalis sup., ebenso der Sinus rectus.

Mikroskopischer Befund: Im ganzen bietet dieser Fall nichts wesentliches, es handelt sich um einen gemischten Thrombus, auf der einen Seite hauptsächlich aus Leukozyten und Fibrin, 
auf der andern aus roten Blutkörperchen zusammengesetzt. Nähere Beziehungen zwischen Inhalt und Wand des Sinus lassen sich nicht nachweisen; nirgends ist es zu einer ausgesprochenen Eiterung gekommen. Auffällig ist vielleicht, daß die Kokken in weit größerer Menge zwischen den Erythrozyten als in den übrigen Teilen des Thrombus zu finden sind.

Fall 25. S.-Nr. 1274 (1911). Elfriede D., 2 Jahre, 1 Monat. Aufnahme 9. 11. 1911, gestorben am 25. 11. 1911.

Krankengeschichte: Am 11. 11. Schwellung links hinter dem Ohr; seit einigen Tagen Fieber; am 11. 11. typische Antrumoperation; in den Warzenzellen Eiter. Sinus nicht freigelegt. 24. 11. Schüttelfrost. 25. 11. Sinusoperation; Sinuswand grau, schmutzig verfärbt, Eiter, Thrombus, Schlitzung der Wand nach unten hin, Unterbindung der Sinus. Exitus am gleichen Tage.

Klinische Diagnose und Notizen: Operierte Sinusthrombose im Anschluß an Mittelohreiterung.

Anatomische Diagnose: Sepsis nach operierter Mittelohreiterung und Sinusthrombose sowie Unterbindung der V. jugularis unter teilweiser Resektion der Klavikula. Septische Thrombose des linken Sinus transversus. Endophlebitis der Vena subclavia sinistra. Septischer Milztumor. Alte tuberkulöse Mesenterialdrüsen. Nebenmilz, starke Anämie.

Protokoll: Die Gegend des rechten Warzenfortsatzes zeigt einen ausgedehnten operativen Defekt des Knochens, durch den man in den linken Sinus transversus hineingelangt. Sinus longitudinalis und die Sinus der linken Seite 0 . V., rechts finden sich im Sinus transversus graubräunliche, zum Teil mehr gelbliche, der Wand fest anhaftende, etwas bröckelige Massen. In der Tiefe der Operationswunde an der linken Halsseite sieht man die eröffnete und bei ihrem Eintritt in die Subklavia unterbundene Vena jugularis. In der V. subclavia sinistra bis zur Axillaris und bis zur V. cava superior findet sich der Innenfläche ziemlich fest anhaftend eine zarte bräunlichrote bis bräunlichgelbe morsche Masse; dicht vor der Einmündung in den rechten Vorhof hört diese Veränderung auf.

Mikroskopischer Befund: Das Bild in diesem Fall wird beherrscht dureh die Erkrankung der Venenwand, die Veränderungen bietet, wie sie bei andern Fällen schon mehrmals beschrieben sind. Hervorzuheben ist nur der Umstand, daß hier an verschiedenen Stellen Leukozyten gerade im Stadium ihres Durchtritts durch die Lamina elastica interna beobachtet werden können. Die Fasern dieser Grenzlamelle sind noch lebhaft färbbar, nur manchmal etwas durch entzündliehes Ödem auseinandergedrängt, ein Verhalten, das die erwähnte Beobachtung wesentlich erleichtert. Die Innenfläche des Gefäßes ist von einer Pseudomembran bedeckt, deren Fibringehalt relativ spärlich ist. Dickere Balken, parallel zur Gefäßwand angeordnet, finden sich nur wenige, dafür mehr feines Faserwerk, das der Innenfläche des Gefäßes fest anhaftet; trotzdem finden sich einige Defekte in der Pseudomembran, und hier liegen dann auch die grampositiven Kokken unmittelbar auf der Gefäßwand, während sie sich sonst nur in und auf dem Häntchen aufhalten.

Fall 26. S.-Nr. 1392 (1911). Frieda M., 13 Jahre. Aufnahme 26. 12. 1911, gestorben am 26. 12. 1911.

Krankengeschichte: Seit Kindheit Ohrenlaufen rechts; am 20. 12. mehrmaliges Erbrechen, Schwindelgefühl und seit diesem Tage täglich ein Schüttelfrost. Am 24. 12. Anschwellung hinter dem rechten Ohr. In der Nacht vom 25. 12. zum 26. 12. Verwirrtheit.

Bei der Aufnahme moribund, baldiger Exitus. Temperatur bei der Aufnahme 42,1 ${ }^{\circ}$.

Klinische Diagnose und Notizen: Chronische eitrige Mittelohrentzündung und subperiostaler AbszeB mit Sepsis.

Anatomische Diagnose: Doppelseitige eitrige Mittelohrentzündung. Chronische eitrige Meningitis, besonders des Kleinhirns. Eitrige Mandelentzündung. Ausgedehnte Phlegmone der Halsmuskulatur mit Findringen in die beidèn Vv. jugulares, rechts stärker als links. Septische Milz. Doppelseitige fibrinöse Pleuritis. Parenchymatöse Trübung der Nieren.

Bakteriologische Diagnose: Streptokokken im Meningealeiter (neben Verunreinigungen). 
Protokoll; Die Intima der Vv. jugulares, welche von der eitrig infiltrierten Halsmuskulatur umgeben sind, ist ganz glatt und grau, nur an einer Stelle finden sich beiderseits ganz feine, rötliche Unebenheiten, diese Veränderung ist rechts etwas ausgesprochener als links.

Mikroskopischer Befund: Außerordentliche, weit verbreitete Fibrinnetze und große Leukozytenmengen in der Gefäßwand bei freiem Lumen lassen erkennen, daß der Krankheitsprozeß ausschließlich in der Substanz des Venenrohrs fortgeschritten ist; das Endothel fehlt fast vollständig. An den Stellen, die makroskopisch als verändert zu erkennen waren, reichen die sonst mehr nach der Adventitia zu lokalisierten Entzündungsprozesse fast bis an die Lamina elastica. interna. Einige Mikroorganismen an der freien Oberfläche dürften sich erst nach der Sektion dort angesiedelt haben (die Organe hatten vor der Konservierung 24 Stunden gelegen); ich entnehme das aus dem Fehlen jeder lokalen Reaktion der Gewebe. In der Adventitia dagegen finden sich dichte Kokkenschwärme in nekrotischem Gewebe, während die weitere Umgebung in der erwähnten Art und Weise verändert ist.

Fall 27. S.-Nr. 65 (1912). Frau G., 33 Jahre. Aufnahme 13. 1. 1912, gestorben am 13. 1. 1912.

Krankengeschichte: Seit 15. 12. Schwellung 1. Hals, am 12. 1. plötzlich Atemnot.

Befund: An der linken Halsseite eine faustgrobe fluktuierende Schwellung. Druckschmerz Atemnot. Puls frequent Temperatur $38^{\circ}$. Exitus.

Klinische Diagnose: Zellgewebsentzündung am Hals.

Anatomische Diagnose: Großer intramuskularer Halsabszeß links. Septische 'Thrombose der linken V. jugularis und des linken Sinus transversus, beginnende Leptomeningitis purulenta. Piaödem. Ödem des Keḩlkopfeingangs, geringe Tracheobronchitis, Hydrothorax einer Seite, septische Milz und schwere parenchymatöse Degeneration der Nieren mit Schrumpfherden. Colitis mucosa. Gestieltes Myofibrom des Uterus. Status menstrualis. Geringe Sklerose d. Aorta.

Bakteriologische Diagnose: Streptokokken in Blut und Eiter.

Protokoll: Die Vena jugularis ist in ihrem obersten Abschnitt erfüllt von einem ziemlich weichen, zum Teil bräunlich-rotem, zum Teil mehr grüngelbem, der Wand ziemlich fest anhaftendem Pfropf.

Mikroskopischer Befund: An den untersuchten Stücken ist das Lumen der Vene frei, die Entzündungsvorgänge haben sich nur in der Gefäßwand abgespielt. Auffällig ist an mehreren Stellen eine leichte, zellreiche Verdickung der Intima. Dicht neben der Vene liegt eine Lymphdrüse mit ausgedehnter Blutresorption und Lymphadenitis catarrhalis.

Fall 28. S.-Nr. 129 (1912). Heinrich V., 4 Jahre. Aufnahme 25. 1. 1912, gestorben am 29. 1. 1912.

Krankengeschichte: Vor 14 Tagen in chirurgischer Poliklinik wegen Halsdrüsen operiert. Vorgestern Blutung aus der Jugularis, seitliche Gefäßnaht. Blutung, Charité.

Befund: Starke Anämie. Verband am Halse rechts sehr stark durchblutet, bei dessen Entfernung starke Blutung. Digitalkompression, dann doppelte Ligatur der Jugularis, deren Wand sehr morsch ist. Jodoformgazetamponade. 29. 1. plötzlich Exitus.

Klinische Diagnose: Herzschwäche nach operierter Halsdrüsentuberkulose. Anämie.

Anatomische Diagnose: Septische Thrombophlebitis der rechten Vena jugularis nach operierter Halsdrüsentuberkulose rechts, partielle Resektion der Vene, septische Infarkte in beiden Lungen, ausgedehntes Emphysem links, beginnendes rechts; Milzschwellung, parenchymatöse Trübung der Nieren und der Leber. Oxyuren im Darm und im Epityphlon, ein Trichozephalus. Magenschleimhautinsel des Ösophagus, schwere Kachexie und Anämie. Zwei Myome am Pylorus.

Protokoll: Am Hals rechts eine vom Unterkieferwinkel nach dem Sternoklavikulargelenk ziehende Operationswunde, die bis tief in die Muskulatur geht, deren Grund mit schmierigen graugelben Massen belegt ist. Die großen Halsgefäße liegen frei, von der Vena jugularis fehlt ein etwa $5 \mathrm{~cm}$ langes Stück, die beiden Stümpfe waren durch Fäden, die sich jedoch gelöst haben und im schmierigen Belag gefunden werden. verschlossen worden. 
Mikroskopischer Befund: Soweit es sich aus den vorliegenden Bildem beurteilen läßt, handelt es sich hier mehr um eine Phlebitis als Thrombophlebitis; die Gefäßwand ist bis weit in die Media hinein vollständig nekrotisch und von so dichten Kokkenschwärmen durchsetzt, wie man sie auch beim Erysipel nur selten sieht. Mit der Weigertschen Fibrinmethode färbt sich ein großer Teil der Mikroorganismen intensiv blau, bei der Gramfärbung verhält sich nur ein Teil von ihnen ausgesprochen positiv. Verschiedentlich ist eine Andeutung von Kettenbildung zu konstatieren. Das Lumen der Vene ist leer; da nun erhebliche Teile der Venenwand fehlen, so kann man nicht mehr feststellen, ob früher vorhandene Thromben- oder Pseudomembranbildungen mit abgestoßen sind oder ob diese zu keiner Zeit vorhanden waren.

Fall 29. S.-Nr. 176 (1912). Clara Sch., 50 Jahre. Aufnahme 4. 1. 1912, gestorben am 10. 2. 1912.

Krankengeschichte: Im 5. Jahr Fall von. Treppe, dadurch Kyphoskoliose. Anfang Oktober Schmerzen in der linken Hüfte, dazu Erbrechen. Schmerzen in den Armen, Schlaflosigkeit.

Befund: Herz, Lungen o. B. Harn: viel EiweiB, hyaline, granulierte Zylinder, Nierenepithelien. 12. 1. Hemiplegia completa dextra und Aphasie, nach 6 Stunden besteht nur noch Schwäche in der rechten Seite. 4 Uhr nachmittags: Jacksonscher Epilepsieanfall, schließlich Utbergreifen auf rechte Seite. Daner: 3 Minuten. 16. 1. feuchte Nekrose an der linken Fubsohle, die Gangrän nimmt zu. 1. 2. Schüttelkrämpfe mit Opisthotonus, die Anfälle folgen sich in kurzen Abständen. 3. 2. Nackenstarre. Somnolenz. 5. 2. Schmerzen am rechten Unterkieferwinkel, dort taubeneigroße, ziemlich feste dolente Schwellung, Rötung. Ödem der Zunge. Epithelnekrose an der Zunge. 6. 2. Die Schwellung wird gespalten und zeigt sich als die mit zahlreichen Abszessen durchsetzte Gl. submaxillaris. Nachts Fieberphantasien. 7. 2. 36,5 ${ }^{\circ}$. 8. 2. $36,5^{\circ}$. Sensorium leidlich frei. 9. 2. Luftmangel. Erneute Inzision am Hals, Spaltung der Faszie: miliare Abszesse, eitrige Infiltration der Sublingualis. 10.2. Zunge sehr stark verdickt, Exitus.

Klinische Diagnose: Nierenentzündung, Sepsis.

Anatomische Diagnose: Schwere parenchymatöse Degeneration der rechten Niere. Atrophie der linken Niere mit zahlreichen Kalkkörperchen. Fitrige Entzündung der rechten Submaxillaris. Halsphlegmone. Phlegmone des hinteren Mediastinum, eitrige Thrombophlebitis der rechten V. jugularis. Septische Lungeninfarkte. Abszeß in der thyreoidea, Ausscheidungsherd der rechten Niere, kleiner Abszeß in der rechten Niere, geringe Hypertrophie des linken Ventrikels. Ovula Nabothii. Piädem, Gehirnödem, schwere Kyphoskoliose. Albuminurische Netzhautherde.

Protokoll: In der Mittellinie des Halses findet sich unter dem Kinn eine bis auf die Muskulatur reichende $3 \mathrm{~cm}$ lange, $i \mathrm{~cm}$ klaffende Operationswunde, an der rechten Halsseite eine zweite ebensolche, die $5-6 \mathrm{~cm}$ lang ist, parallel mit dem Unterkieferrand verläuft und bis an den Zungengrund heranreicht. Beim Abpräparieren der Haut quilit aus Muskulatur und Gewebe dunkelgrüner dicker Eiter. Bei Freilegung der V. jugularis dextra findet man die ganze Halsmuskulatur und das Halsbindegewebe durchsetzt mit zahlreichen, meist umschriebenen, gelbgrünen Eiterherden; der Eiter ist in die Interstitien vorgedrungen bis auf die Körper der Halswirbelsäule. Das Lumen der Vena jugularis ist verlegt durch schmierige graurötliche und rotgrünliche Massen, die der Wand fest ansitzen. Der obere Teil der Jugularis ist leer, nach unten reicht der Verschluß bis zur Zusammenmündung mit der Vena subclavia.

Mikroskopischer Befund: Ein besonderes Interesse bietet dieser Fall dadurch, daß er Pseudomembranbildung und Thrombenablagerung in unmittelbarer Nachbarschaft zeigt; durch die naken räımlichen Beziehungen beider Veränderungen sowie dadurch, daß ihre Entstehung zeitig ungefähr zusammenfallen muß, sind Möglichkeiten zu Vergleichen gegeben, die man nicht ohne weiteres ziehen dürfte, wenn man die beiden Prozesse bei verschiedenen Leichen oder auch nur in verschiedenen Präparaten desselben Falles finden würde. Die Verhältnisse gestalten sich so, daB auf der einen. Seite des Präparats eine ganz typische Pseudomembran liegt, auf der andern 
ein Erythrozytenpfropf, der dann in einen mehr gemischten Thrombus mit undeutlicher Schichtung übergeht; dieser wieder hängt, ohne daß sich eine scharfe Grenze konstatieren ließe, mit der Pseudomembran zusammen durch eine, man könnte sagen, indifferente oder intermediäre Partie, die man ihrem Aussehen nach ohne weiteres weder zu dem einen noch dem andern Gebilde rechnen kann. Schon bei schwacher Vergrößerung fällt auf, daß die Psendomembran der Gefäßwand fest: und unmittelbar anhaftet, während unter der indifferenten Schicht eine schmale, helle Zone zu erkennen ist, die auch noch unter dem Thrombus sichtbar ist, dessen Ende schlieBlich frei in das Venenlumen hineinhängt. Bei stärkerer Vergrößerung stellt sich dieser helle Streifen als gequollene, verdickte Intima dar, Bei der Weigertschen Fürbung erkennt man in all den beschriebenen Partien große Fibrinmengen, die je nach dem Gebilde, dem sie angehören, eine etwas verschiedene Struktur besitzen; in den Thromben herrscht ein mehr baumförmig verästeltes System vor, dann folgen nach der intermediären Zone zu Stellen, wo feine Fäserchen sternartig um intensiv blaugefärbte Körnchen angeordnet sind. Diese Körnchen haben etwa die Größe eines Kokkus, lassen sich aber leicht von solchen unterscheiden. Die indifferente Zone enthält meist plumpe, der Gefäßinnenfläche parallel angeordnete stärkere Balken, die sich auch in die Pseudomembran fortsetzen, hier aber durch zahlreiche, in allen möglichen Richtungen verlaufende Flächen unter sich und mit der Gefäßwand zusammenhängen. Versehiedentlich kann man anfs deutlichste verfolgen, daß eine ganze Anzahl solcher feiner Fasern ein ganzes Stück bis in die Media hineinreichen. Diese selbst ist relativ wenig verändert, nur sind die elastischen Fasern etwas auseinandergedrängt, dagegen haben sich in der Adventitia die schwersten Prozesse abgespielt. GroBe Mengen von Leukozyten, Nekrosen, Kokkenhäufchen und ausgedehnte Netze von geronnener Ödemflüssigkeit; welche auch die Fibrinreaktion geben, ziehen durch die ganze Ausdehnung der Präparate. Ich spreche im Gegensatz zu andern Fällen absichtlich von geronnener Ödemflüssigkeit, da die hier vorliegenden Massen eine etwas hellere Farbe angenommen haben, auch ganz anders angeordnet sind, als die im Venenlumen liegenden Bestandteile, ferner lassen sich keine Beziehungen zwischen den beiden Fadensystemen nachweisen; die Media schiebt sich wie eine Scheidewand dazwischen. Aus demselben Grunde möchte ich es auch nur als einen Zufall betrachten, daß die Pseudomembranbildung gerade da am ausgesprochensten ist, wo in der Adventitia ein größerer AbszeB liegt; ich möchte annehmen, daß beide Veränderungen nicht in Kausalnexus stehen, um so weniger, wenn man die im Lumen des Gefäßes vorhandenen Kokken genauer beobachtet. Wo die Gefäßwand frei liegt, haben sie sich auf ihr angesiedelt, sobald aber die Pseudomembranbildung beginnt, finden sie sich nur an deren Oberfäche. Ganz besonders interessant ist eine kleine Stelle, wo die Membran sich abgehoben hat; hier liegen Kokken unter ihr auf der nackten Venenwand, dicht daneben hat aber schon wieder die Bildung einer neuen, kleineren Pseudomembran eingesetzt, welche die Mikroorganismen wieder an ihrer Oberfäche trägt, sie also gewissermaßen von der Gefäßwand mit abgehoben hat. Ich möchte aus diesen Gründen die Bildung der Pseudomembran auf die Anwesenheit der Kokken im Lumen, nicht auf die Krankheitsprozesse in der Adventitia zurückführen. Die Kokken sind rundliche, grampositive Gebilde, meist paarweise angeordnet, doch konnte ich ihre Natur aus dem mikroskopischen Bilde nicht mit Sicherheit feststellen.

Um eine möglichst klare Übersicht des vorhandenen Materials zu gewinnen, habe ich versucht, eine Einteilung nach den im mikroskopischen Bilde am meisten hervorstechenden Merkmalen zu treffen; wenn ich mir auch keinen Augenblick verhehle, daß eine wirklich scharfe Abgrenzung der einzelnen Fälle voneinander nicht durchführbar ist, schon wegen der oft außerordentlich mannigfaltigen Befunde, die ein und dieselbe Vene an verschiedenen Stellen uns bietet, so denke ich doch, daß sich drei einigermaßen zwanglos abzugrenzende Typen ergeben, wenn wir die Beobachtungen mit und ohne Pseudomembran und die ohne jeden GefäBinhalt gesondert betrachten. 
Demnach nehmen wir als erste Gruppe heraus die Fälle, in welchen die Erkrankung der Venenwand, die Phlebitis, am meisten imponiert; es handelt sich dạ um die Nummern 5, 10, 26, 27, bei denen größere Inhaltsmassen im Lumen des Gefäßes nicht nachweisbar sind. Auch den Fall $28 \mathrm{muß}$ ich notgedrungen hier unterbringen, da die allzuweit fortgeschrittene Zerstörung kein Urteil mehr über Vorhandensein und Art des Veneninhalts gestattet.

An zweiter Stelle der Zahl nach folgen die Beobachtungen, wo sich mit Sicherheit eine deutliche Pseudomembranbildung nachweisen läbt; es sind dies die Nummern 1, 2, 3, 11, 12, 15, 16, 20, 25 und 29. Den etwas zweifelhaften Befund bei Nr. 4 habe ich in die letzte Gruppe verwiesen, da ich die Möglichleit nicht ausschließen kann, daß das gefundene Gebilde doch ein Thrombus ist. Dagegen habe ich mich bei der Beobachtung Nr. 20 nach reiflicher Überlegung zu der Diagnose Pseudomembran entschlossen aus Gründen, die ich weiter unten ausführen werde.

Zur letzten, größten Abteilung gehören alle anderen Fälle - 14 an der Zahl -, deren Charakteristikum im alleinigen Auftreten deutlicher. Thromben gegeben ist. Es lassen sich hier wieder verschiedene Untergruppen abgrenzen, je nachdem die Gefäßwand verändert ist oder nicht, ob eine Organisation aufgetreten ist oder nicht, ob die Zerfallserscheinungen mehr am Rand oder mehr in der Mitte des Thrombus fortschreiten.

Ehe ich an eine kurze Besprechung der letztgenannten Fälle gehe - sie machen $48,3 \%$ der Gesamtzahl aus --, darf ich noch einmal auf die weiter oben auseinandergesetzten Gründe hinweisen, die mich hindern, Venen mit einfachen Thromben ohne Anzeichen einer Infektion, obwohl Bakterien vorhanden sind, in den Bereich der vorliegenden Arbeit zu ziehen. Blutpfröpfe mit wirklich schöner Schichtung der einzelnen Blutelemente habe ich relativ wenig gesehen, allerdings wurde auf diesen Punkt bei der Auswahl des Materials keine Rücksicht genommen. Wie die Protokolle besagen, finden sich meist nur Andeutungen eines korallenstockartigen Aufbaus; häufig auch finden sich die einzelnen Blutelemente regellos durcheinander liegend, wie wir das vom Schwanzteil der gewöhnlichen Thromben her kennen. Ob diese letztgenannten Bilder nun als der Ausdruck einer einfachen mechanischen Stagnation bei Verschluß des Gefäßes durch einen obturierenden Pfropf aufzufassen sind, oder ob andere Einwirkungen - etwa durch Toxine erhöhte Gerinnbarkeit des Blutes - eine Rolle spielen, mag unerörtert bleiben. Auf jeden Fall aber können wir feststellen, daß der Fibringehalt unserer Präparate im allgemeinen erheblich größer ist als wir bei den blanden Pfröpfen zu sehen gewohnt sind; und zwar scheint mir die Abscheidung des Fibrins in einem gewissen Zusammenhang zu stehen mit der später erfolgenden eitrigen Einschmelzung des Thrombus. Solange die Mikroorganismen und mit ihnen die Leukozyten noch nicht ihre zerstörende Wirkung entfaltet haben, finden wir dem blanden Thrombus entsprechende Fibrinmengen; beim Vorruicken der Zerfallszone wird immer mehr von dieser Substanz sichtbar, die dann schließlich in den Endstadien der Zerstörung mit aufgelöst und 
färberisch nicht mehr darstellbar wird. (Siehe auch die Protokolle der Tierversuche.)

Wenn ich vom Fortschreiten der Eiterungsprozesse in den Thrombusmassen spreche, so setze ich selbstverständlich ihr Auftreten als etwas primäres voraus; über die Ursachen ihres Entstehens und darüber, ob sie wirklich die erste Erscheinung dessen sind, was wir unter dem Begriffe der Thrombophlebitis septica zusammenfassen, wird noch unten zu sprechen sein. Offenbar gibt es verschiedene Wege, auf denen ein einmal vorhandener Pfropf infiziert und zerstört werden kann; einmal sehen wir, wie es z. B. in der einen Schnittserie von Fall 7 erfolgt ist, Kokken in einem sonst ganz normalen, blanden Pfropf liegen. Hier muß also zur Zeit der Entstehung der Ablagerung aus dem Blut schon eine Bakteriämie bestanden haben, die Kokken schlugen sich eben mit den anderen in der Blutflüssigkeit suspendierten Teilchen zusammen nieder. Wenn nicht schon ganz leichte entzündliche Veränderungen beständen (abgesehen davon, daß die anderen Präparate das Vorhandensein einer schweren Thrombophlebitis beweisen), könnte man für den vorliegenden Fall an ein zufälliges Zusammentreffen einer gewöhnlichen, nicht infektiösen Thrombose mit einer Bakteriämie denken, also ein Krankheitsbild, das von dieser Besprechung auszuschalten wäre. Nun, hier scheint aber wirklich die Blutpfropfbildung in Kausalnexus mit der Anwesenheit der Kokken zu stehen, und der Thrombus verfällt der unmittelbaren Einwirkung der Mikroorganismen und wird von ihnen vernichtet wie ein schon normalerweise vorhandenes Körpergewebe.

Anders bei der Mehrzahl der Fälle in dieser Gruppe. Wie der Augenschein uns lehrt, handelt es sich um primär ganz kokkenfreie aseptische Thromben; mag deren Aufbau deutlicher oder weniger klar sein, stets vermißt man auf weite Strecken hin die Vikroorganismen. Auch glaube ich, das verschiedentlich gefundene Einsetzen organisatorischer Vorgänge in dem Sinne verwerten zu dürfen, daß hier an Ort und Stelle die pyogenen Keime noch nicht zur Wirkung gelangt sein können.

Es ist ja dieser Umstand kein absolut sicherer Beweis für die unschuldige. Natur der Pfröpfe, doch kann ich mir nicht vorstellen, daß sich derartig komplizierte produktiv-entzïndliche Vorgänge wie die Organisation an einem Gewebe abspielen können, das schon unmittelbar dem destruierenden Einfluß der Kokken unterworfen ist. Diese beginnende Vaskularisation ist manchmal noch ganz frisch, aber doch genügend deutlich und darf natürlich nicht verwechselt werden mit den Resten früherer Thromben, die als derbe bindegewebige Streifen mit relativ spärlichen Gefäßen gleichfalls in mehreren Fällen gesehen wurden.

Die Randzone mit den weiten und zarten Gefäßchen der frischen Organisation und den schmalen maschenartigen Septen der noch restierenden Thrombussubstanz bietet nun dem Vordringen der pathogenen Keime nur geringe Hindernisse, und wir können beobachten, wie Kokken, Eiterung und Nekrose sich gerade diese Zone des schwächsten Widerstandes zum Weiterschreiten ausgesucht haben (Fall 4, $6,7,8,9)$. Schon dieser Umstand läßt erkennen, daß dem Blutpfropf eine gewisse 
Schutzwirkung gegen die Angriffe der Mikroorganismen zu eigen sein muß, doch ganz besonders deutlich geht dies aus einer anderen Beobachtung hervor (Fall 4 und 27). Die Gefäßwand ist an den Stellen viel stärker geschädigt, die ganz offen den Einwirkungen der Spaltpilze preisgegeben sind als an solchen Partien, welche von Thrombusteilchen bedeckt sind.

Während in den bisher beschriebenen Fällen der vordringenden Zerstörung gewissermaßen der Weg gewiesen ist, bedarf es einer kurzen Erklärung, warum sie fast noch häufiger die zentralen Partien des Thrombus aufsucht (Nr. 6, 9, 13, $14,17,18,19,21,22,23,24)$. Diese Aufgabe ist um so mißlicher, als man in den meisten untersuchten Schnitten eben nur die noch vorhandenen Zerfallsprodukte sieht und infolgedessen nicht mehr entscheiden kann, ob hier nicht nach Ablagerung des wandständigen Thrombus noch ein kleines Lumen übrig geblieben ist; das einen, wenn auch geringen Blutstrom und damit die Heranführung frisch infektiösen Materials (septischer Embolus oder Kokkenhaufen) gestattete. Andererseits kann man sich vorstellen, daß nach Bildung der röhrenförmigen ersten Ablagerung sich hauptsächlich nur noch die Erythrozyten in der Mitte ansammeln konnten -manche Bilder sprechen in der Tat für diese Annahme -, die den Einfliissen der Giftstoffe schneller unterlagen als die sonstigen Bestandteile des Thrombus. An dieser Stelle möchte ich in Parenthese bemerken, daß ich die positive Fibrinreaktion an roten Blutkörperchen, wie sie von Löwit, v. Bardeleben und Katzenstein mehr oder weniger bestimmt angegeben worden ist, mehrfach bestätigen konnte; um einfache Fehler in der Färbetechnik kann es sich also wohl kaum handeln, auch möchte ich hervorheben, daß diese Erscheinung sich stets nur an einzelnen Stellen in einigen Blöcken feststellen ließ, wie auf einer Anzahl von Serienschnitten kontrolliert wurde. Ob jedoch diese abnorme Farbreaktion als Charakteristikum eines der vollständigen Auflösung vorangehenden Degenerationsstadiums zu betrachten ist, wage ich an der Hand meines Materials nicht zu entscheiden.

Ich glaube, in diesen Erörterungen nachgewiesen zu haben, daß die eigentliche Thrombenbildung nicht unter der direkten Einwirkung der pathogenen Keime stattfindet, sondern ihrem Auftreten örtlich und zeitlich gewissermaßen voraneilt und einer Art Fernwirkung der Kokken zu verdanken sein muß, um schließlich erst nach Einwanderung der Mikroorganismen ihrer Zerstörungskraft zum Opfer zu fallen. Interessant ist es, daß Talke, Stenger und Haymann ${ }^{26}$ auf Grund ihrer experimentellen Untersuchungen zu denselben Schlïssen gekommen sind, die ich ganz unabhängig davon aus der Beobachtung des menschlichen Materials ziehen zu müssen glaube.

Auf die Fälle der ersten Gruppe, die der reinen Phlebitis, will ich an dieser Stelle nicht näher eingehen, da sie unten noch mit einigen Worten erwähnt werden sollen; sie machen nur 17,2\% der Gesamtzahl aus.

Die Beobachtung Nr. 20 habe ich nach reiflicher Überlegung in die der Zahl nach zweitgrößte Abteilung gerechnet, indem ich mich zu der Diagnose Pseudo- 
membran entschlossen habe. Das fragliche Gebilde ähnelt bei den gewöhnlichen Färbemethoden so sehr einem Exsudathäutchen und andererseits so wenig den thrombotischen Ablagerungen, daß mich das Fehlen von größeren Fibrinmengen, die wir als Hauptcharakteristikum der Pseudomembran betrachten, aufs äußerste überraschte. Ich glaube mich hier zu der Annahme berechtigt, daß es sich um ein Stadium der Entzündung handelt, in dem das Fibrin aufgelöst wird oder wenigstens seine Färbbarkeit nach der Weigertschen Methode verloren hat; ich schließe das besonders daraus, daß noch einige schwach tingierte Partikel gefunden wurden. Abgesehen von diesem Umstand bestärkt mich auch der Nachweis von weit in die Pseudomembran versprengten Elastikaresten in meinem Verdacht, ganz ähnlich, wie wir es im Fall 16 gesehen haben, wo gar kein Zweifel an der exsudativ-entzündlichen Natur des Gefäßinhalts besteht.

So einfach sich diese Erscheinung erklären läßt, wenn man sich vorstellt, daß die durch nekrotisierende Vorgänge gelösten Teilchen von elastischen Fasern durch den von der Peripherie nach der Achse der Vene erfolgenden Exsudatstrom verlagert und abgehoben sind, so schwierig würde eine befriedigende Lösung der Frage sein, wenn man eine thrombotische Natur der besprochenen Gebilde voraussetzt. Soll man sich vorstellen, daß der hypothetische Thrombus gewissermaßen wie ein maligner Tumor zwischen die Elemente der Venenwand vordringt, sie auseinanderzerrt und verschiebt? Die einzige Möglichkeit, sich ein derartiges Verhalten von Ablagerungen aus dem Blutstrom zu erklären, wäre die, daß durch die vorrückenden pathogenen Keime und Leukozyten die Zerstörung der Gefäßwand erfolgt wäre und dann die einzelnen Elemente des vorbeifließenden Blutes sich zwischen den gelockerten Fetzen angesiedelt hätten; doch auch diese Theorie ist hinfällig, da eine nennenswerte Eiterung noch nicht besteht und die gefundenen Mikroorganismen nicht in der Wandsubstanz, sondern auf der freien Oberfläche des Häutchens liegen.

In allen übrigen neun Fällen gelang mir der Nachweis, daß die Fibrinfäden der Pseudomembran ihren Ursprung in der Wand der Vene nehmen. A priori sollte man annehmen, daß dies Verhalten stets ganz leicht aufzufinden sein müßte; ich war überrascht, daß ich oft längere Zeit, manchmal sogar mit Ölimmersion nach beweisenden Stellen suchen mußte. Offenbar beansprucht die Fibringerinnung einen gewissen Platz, sie tritt stets erst ein, wenn sie einen Hohlraum oder ganz lockeres Gewebe erreicht hat. Sie fehlt immer in der kompakten Media, kann sich aber einstellen, wenn diese durch Eiterung oder förmliche Abszeßbildung aufgelockert ist. Wir vermissen sie selten in dem zarten, an Saftspalten reichen perivaskulären Gewebe, ganz besonders günstige Umstände aber trifft sie, sobald das Exsudat die freie Innenfläche des Gefäßes erreicht hat. Vielleicht spielt für den letzteren Fall auch die Berührung mit dem strömenden Blut eine gewisse Rolle $\left(O \operatorname{rth}^{50}\right)$. Wenn auch die oberflächliche pseudomembranöse Entzündung dadurch charakterisiert ist, daß die ausgeschwitzten Massen auf dem Gewebe, nicht mehr in ihm zu finden sind, so müßte man doch häufiger feine Fortsätze der Fibrinfasern 
bis in ihre Geburtsstätte, die Substanz des Venenrohrs, hinein verfolgen können, wenn nicht im allgemeinen die dichte Lamina elastica interna das Fibrinnetz nach der Peripherie zu scharf abschnitte, etwa wie die Glashaut der Trachea bei der Diphtherie dieses Organs. Sobald man aber kleine Lücken in der elastischen Lamelle findet - mögen diese nun physiologischer Natur sein oder ihre Existenz der destruierenden Entzündung verdanken -, trifft man auf die gesuchten Bilder. Gegen ein aktives Eindringen der Fäserchen in die Bestandteile der Venenwand vom Lumen her sprechen dieselben Gründe, die ich bei der Besprechung des Falles 16 gegen ein derartiges Verhalten sonstiger Thrombusbestandteile angeführt habe.

Als einen weiteren Beweis, der die Diagnose Pseudomembran zu stiutzen geeignet ist, nenne ich den Zustand der Gefäßwand, der namentlich in den Fällen 1 und 2 sehr charakteristisch ist. Wir finden die stärksten exsudativ-entzündlichen Veränderungen des Gefäßrohrs an den Stellen, die eine Pseudomembran hervorgebracht haben, geringere oder keine dort, wo das Häutchen fehlt. Natürlich liegt der Einwand nahe, es handle sich hier doch um Thrombenteile, die sich eben nur an den entzündlich veränderten Partien der Gefäßwand hätten ansiedeln können. Wenn wir aber nach den Erregern der Entzündung suchen, so finden. wir sie nicht etwa in der Wand der Blutader, sondern auf der freien Oberfläche der Exsudatschicht. Ich wüßte wirklich nicht, wie man sich diese Bilder anders erklären soll als durch die Annahme, daß die Spaltpilze vom Lumen her die Wand der Blutader attackiert und zu einer entzündlichen Ausschwitzung gereizt haben, von der sie dann mit in die Höhe und von der gefährdeten Gefäßwand abgehoben sind. Diese gesamten Erscheinungen passen ja auch aufs beste zu allem, was wir sonst von der pseudomembranösen Entzündung überhaupt wissen, und demonstrieren uns zugleich den Zweck, den diese Reaktion des menschlichen Körpers ganz allgemein hat, nämlich den Schutz angegriffener Gewebe gegen schädliche Reize versehiedener Art; gleichgültig ist es dabei, ob man den springenden Punkt dieser Abwehrvorrichtung mehr in der mechanischen Fortschaffung der Noxen oder mehr in dem Erscheinen chemischer Abwehrkörper in der Exsudatflüssigkeit erblicken will. Als besonders schöne Beispiele für das Gesagte führe ich die Beobachtungen 1, 2 und 3 an, die jedesmal zeigen, daß die rein exsudative Wandentzïndung stets da am stärksten ist, wo auch schon die Pseudomembranen liegen, daß aber die Nekrose, die Zerstörung des Wandgewebes da mehr in den Vordergrund tritt, wo sie bloß und ungedeckt den Mikroorganismen preisgegeben ist. Gerade der letzt zitierte Fall ist wohl geeignet, den Verdacht, es könne sich trotz alledem um Reste von Thromben handeln, ad absurdum zu führen; denn wenn einmal die Wandentzündung ohne weiteres zur Thrombenbildung disponiert, so ist gar nicht einzusehen, warum die Blutbestandteile sich nur an den leichter entzündeten Strecken ablagern sollen und nicht auch da, wo schon die ersten Zeichen der beginnenden Destruktion sichtbar werden. Man sollte doch meinen, daß diese viel stärker aufgerauhten Stellen den Bedingungen der mechanischen Blutpfropfbildung eher entsprächen, während das Fehlẹn einer Pseudomembran, eines entzündlichen 
Produkts in einer Zone der stärksten regressiven Störung nicht verwunderlich sein kann. Nur nebenbei sei bemerkt, daß eine Exsudatschicht auch einmal einer wenig oder gar nicht veränderten Stelle des Venenrohrs anliegen kann (Fall 1); diese Erscheinung läßt sich leicht erklären, denn analoge Beobachtungen bei der Rachen- und besonders der Tonsillardiphtherie lehren uns, daß die aus entzündetem Gewebe stammende, zunächst noch flüssige Ausschwitzung auf die im Augenblick der Untersuchung noch nicht erkrankte Nachbarschaft hinüberlaufen und dort erstarren kann.

Wenn mir nach diesen Untersuchungen an menschlichem Leichenmaterial und den daraus gezogenen Schlüssen ein Zweifel daran kaum noch möglich erscheint, daß bei der Thrombophlebitis septica Pseudomembranen auftreten können, und zwar keineswegs selten, so schien mir doch auch ein experimenteller, gewissermaßen mathematischer Beweis für die Richtigkeit meiner Behauptung dringend erwünscht. Ich habe zu diesem Zweck Tierversuche angestellt, muß aber gleich voranschicken, daß diese aus äußeren Gründen, namentlich wegen Mangels an Hunden geeigneter Größe, recht dürftig ausgefallen sind und wegen der verschiedenen Komplikationen, die sich dabei herausgestellt haben, nicht ganz meinen Erwartungen entsprechen.

Wenn auch die Ausschwitzung gerinnbarer Massen keineswegs ein Charakteristikum spezifischer Gewebe ist und daher die oberflächliche pseudomembranöse Entzündung überall dort statthaben können müßte, wo dem Exsudat eine freie Oberfläche erreichbar ist, so könnte man es doch als fraglich ansehen, ob als solche auch die Innenfläche einer Vene funktionieren könnte; es sollte nun mit möglichster Sicherheit entschieden werden, daß nicht alles im Lumen einer Blutader gefundene Fibrin dem Blutstrom entstammen müsse, sondern auch von der Venenwand produziert sein könne. Zu diesem Zweck mußte einmal alles in einem bestimmten Gefäßabschnitt enthaltene Blut entfernt, zum anderen die Ader selbst zu einer entzündlichen Reaktion gereizt werden. Die Anordnung der Versuche wurde folgendermaßen getroffen: Schonende Freilegung der Vena femoralis bei einem Hunde und Unterbindung an zwei Stellen, doch su, daß möglichst kein Seitenast in die Hauptbahn zwischen den beiden Ligaturen einmündete. Durch zwei feine, unmittelbar neben den. Fäden eingestochene Kanülen wurde die eingeschlossene Blutmenge entfernt, indem auf die peripher gelegene eine mit physiologischer Kochsalzlösung gefüllte Rekordspritze gesetzt und so lange injiziert wurde, bis die Flüssigkeit aus der zentralen Nadel klar ablief. Sobald die Vene nun wieder kollabiert war, wurde unmittelbar peripher neben der zentral gelegenen Hohlnadel eine dritte Unterbindung gelegt und diese Kanüle entfernt. Schließlich wurde durch die untere, noch in dem Gefäß steckende Nadel eine Aufschwemmung von Staphylokokken in 0,8 prozentiger NaCl-Lösung eingespritzt, bis das abgebundene Stück wieder ungefähr das Volumen der blutgefüllten Ader erreicht hatte. Nachdem nun nochmals dicht zentral von der peripherischen Kanüle eine Unterbindung gelegt worden war, restierte ein völlig von der Umgebung und von dem übrigen 
Blutstrom abgeschlossenes, mit einer Bakterienemulsion gefülltes und von seinem ursprünglichen Inhalt befreites Venenstück. Die Technik dieser ganzen Operation ist nicht ganz einfach, denn einmal mußte, um einwandsfreie Resultate zu zeitigen, eine Stelle der Vene gewählt werden, welche frei von Nebenästen war, doch sollte das ausgeschaltete Stück wegen der vierfachen Ligatur eine gewisse Länge haben, um nicht zu winzig zu werden, zwei Bedingungen, die in einem gewissen Gegensatz zueinander stehen. Dabei durfte das Gefäß auch nicht allzu weit aus seinem Lager herauspräpariert werden, um trotz der Kompression der Vasa vasorum durch die ober- und unterhalb fest zugeschnürten Seidenfäden eine gewisse Ernährungsmöglichkeit der Venenwand zu gewährleisten, von der die Produktion der gerinnbaren Flüssigkeit doch offenbar abhängig ist. Diese drei Schwierigkeiten im Verein mit der Knappheit brauchbaren Hundematerials - ich konnte nur an drei Gefäßen

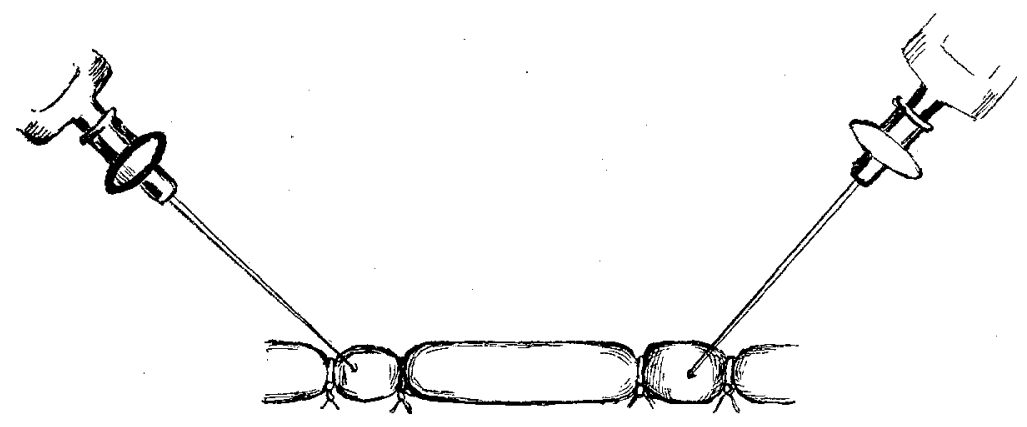

Fig. 1.

Zeigt die Versuchsanordnung für die Infektion der Venenwand von innen aus, insbesondere die Lage der Ligaturen und der Kanülen zueinander. Das zwischen den beiden mittleren Ligaturen liegende Venenstück ist frei von Blut und enthält nur die Kokkenemulsion.

die beschriebenen Versuche anstellen - lassen mich auf die Wiedergabe der genaueren Versuchsprotokolle verzichten, ich teile daher nur ganz kurz die Resultate mit. Bei dem ersten Experiment war augenscheinlich die Dauer des Versuchs (2 Stunden) zu kurz gewählt, auch scheint die Blutversorgung der Venenwand nicht einwandsfrei gewesen zu sein, wenigstens findet sich in dieser keine Spur einer Entzündung, keine Eiterkörperchen, keine Andeutung einer Fibrinausschwitzung; die Kokken liegen in einer dichten Schicht, stellenweise auch in größeren Haufen auf der Innenfläche der Ader, deren Endothel meist abgestoßen ist. Schmale Streifen mit mangelhafter Kernfärbung lassen erkennen, daß die Bakterien nicht ganz wirkungslos geblieben sind. Bei dem zweiten Hund wurden beide Schenkelvenen behandelt und die Dauer des Versuchs auf 40 Stunden ausgedehnt. Trotzdem ist auf der rechten Seite wieder nur eine minimale Reaktion eingetreten, bestehend in einer erheblichen Endotheldesquamation und einer geringen kleinzelligen Infiltration der Adventitia. Auf dieser Seite war nur eine kleine Menge Kokken injiziert worden, auch haben diese in der Kochsalzlösung an Lebensfähigkeit eingebüßt; 
ein großer Teil von ihnen ist nach Gram gar nicht oder nur noch ganz schwach färbbar. Etwas besser haben sie sich auf der linken Seite erhalten, da hier kleine Mengen von Blut in dem abgebundenen Gefäßstïck zurückgebieben sind und so ist es hier zu ganz erheblichen Entzündungserscheinungen gekommen, vor allen Dingen aber durch den Umstand, daß auch die in die Umgebung des Gefäßes geratenen Bakterien - eine solche Verunreinigung der umliegenden Gewebe ist ja bei der gewählten Versuchsanordnung kaum je zu vermeiden - Zeit und Gelegenheit gefunden haben, ihre verderbliche Wirkung zu entfalten. Es ist infolgedessen zu einer Abszeßbildung im perivaskulären Gewebe gekommen, und diese Eiteransammlung hat an einer Stelle die Venenwand völlig durchbrochen, so daß das Lumen eröffnet ist. In der weiteren Umgebung des Abszesses ist die Substanz des Gefäßes von zahllosen Leukozyten durchsetzt und nicht nur hier, sondern auch noch in weiterer Entfernung von dem Zentrum der eingeschmolzenen Partien findet man auf der Intima streifenförmige Auflagerungen, welche aus abgestoßenen Endothelien, Leukozyten, Kokken und Fibrin bestehen. Dessen Fasern sind zart, der Innenfläche der Elastica interna parallel angeordnet, zum Teil erscheinen sie aber auch als kurze plumpe, netzartig verästelte Balken, die sich manchmal bis zwischen die aufgefaserten Wandelemente hinein verfolgen lassen. Wenn diese Gebilde auch keineswegs eine schöne, typisch gebaute Pseudomembran repräsentieren, so ähneln sie doch einer solchen in den Grundprinzipien ganz zweifellos und beweisen vor allen Dingen, daß nach Ausschaltung des Blutes noch Fibrin im Lumen eines Gefäßes auftreten kann. Betonen möchte ich noch, daß die Fasersubstanz im vorliegenden Fall nicht etwa mit dem eindringenden Abszeß in die Vene gelaufen ist, sondern wirklich der Gefäßwand entstammt an Stellen, wo diese noch in ihrer Kontinuität erhalten ist. Auch die erwähnten Blutreste haben nichts damit zu tnn, denn sie liegen meist in der Mitte des Lumens in Haufen zusammengeballt, während die fibrinhaltigen Bestandteile fast ausschließlich am Rande gefunden werden.

Wenn die Ergebnisse dieser Versuche auch keineswegs voll befriedigend sind, so hat doch der letzte Befund das gezeigt, was bewiesen werden sollte; es wäre vielleicht nicht aussichtslos, diese Experimente systematisch, eventuell unter gewissen Modifikationen fortzusetzen.

Nach dem bisher Gesagten glaube ich also behaupten zu dürfen, daß eine Pseudomembranbildung bei der septischen Thrombophlebitis theoretisch möglich ist und nach meinen mikroskopischen Protokollen gar nicht so selten in praxi vorkommt; es drängt sich daher die Frage auf, ob ihr Auftreten nur einen unwesentlichen, mehr zufälligen Befund darstellt, oder ob diese Exsudationserscheinungen einen wichtigen, integrierenden Anteil haben an dem ganzen komplizierten Prozeß der infektiösen Thrombose. Gegen eine reine Zufälligkeit spricht meines Erachtens deutlich genug die relativ hohe Zahl von positiven Beobachtungen bei dem durch Sektionen gewonnenen Material, das nach den Auseinandersetzungen in der Einleitung nicht gerade günstig für meine Untersuchungen war; ein Prozentsatz von 
34,5 (zehnmal Pseudomembranen gefunden unter 29 Beobachtungen) ist zu hoch, um diese Erklärung einigermaßen plausibel erscheinen zu lassen. Schließen wir demnach ein rein akzidentelles Zusammentreffen aus, so bliebe zu untersuchen, von welchen Bedingungen das Auftreten der Pseudomembranen abhängig ist.

Am nächsten liegt es da wohl, an die verschiedenartige Natur der gefundenen Mikroorganismen zu denken; es ist ja das Zustandekommen einer exsudativfibrinösen Entzündung keine absolut spezifische Reaktion des animalischen Körpers auf einen bestimmten Krankheitserreger, ja es können auch chemische Reize als auslösende Momente in Betracht kommen, wie z. B. die Veränderungen der Darmschleimhaut bei der Quecksilber- und Lysolvergiftung zeigen, doch ist andererseits nicht zu leugnen, daß die Körpergewebe auf manche pathogenen Keime mehr mit dieser, auf andere Arten mehr mit jener Form der Abwehr antworten. Staphylokokken und Streptokokken, die exquisit pyogenen Keime, rufen mehr Nekrose und Eiterung hervor, Diphtheriebazillen und die Erreger der Pneumonie disponieren im allgemeinen mehr zur fibrinösen Entzündung; gerade den Pneumokokken, die wir ja oft genug auch als wirkliche Eitererreger kennengelernt haben, schreibt Weichselbaum (zitiert nach v. Kahlden ${ }^{30}$ ) in den von ihnen gesetzten Metastasen ein besonders fibrinreiches Exsudat zu. Ich erinnere auch an das Bild der Pneumokokkenperitonitis, die dem erfahrenen Chirurgen schon aus der Art der Exsudatflüssigkeit eine ziemlich sichere Diagnose des zugrunde liegenden Erregers gestattet. Allerdings ergibt die bakteriologische Untersuchung des Leichenmaterials keine ganz sicheren Resultate. Bis auf wenige Ausnahmen wurden von allen beschriebenen Fällen Kulturen aus dem Herzblut und der Milz angelegt, und da, wo die Ergebnisse der bakteriologisehen Züichtung mit denen der mikroskopischen Betrachtung im Einklang stehen, liegen die Verhältnisse klar. In einem jedoch nicht ganz geringen Bruchteil meines Materials (Nr. 5, 6, 11 z. B.) zeigen sich Differenzen zwischen dem kulturellen und dem histologischen Befund; ich glaube allerdings nicht fehlzugehen, wenn ich dem letzteren die größere Bedeutung beilege und annehme, daß der primären Infektion mit Eiterkokken die Ansiedelung der Koli- bzw. Pyozyaneusstäbchen gefolgt ist, die dann auf den Nährböden die zuerst eingedrungenen Keime überwuchert haben. Dagegen ist es bei einer Reihe von Mischinfektionen vollkommen unmöglich, eine Entscheidung darüber zu treffen, welche Kokkengattung zuerst und hauptsächlich ihre Wirkung entfaltet hat (siehe gerade Fall 6), oder dort, wo das Kulturverfahren versagt hat, die Spezies der festgestellten Bazillen allein aus dem mikroskopischen Bilde genauer zu identifizieren. Ich bin mir demnach vollkommen klar darüber, daß der Versuch, das geschilderte Material nach seinen bakteriologischen Eigenheiten einzuteilen, nicht bis zu einem befriedigenden Ende durchführbar ist, wenn ich mich auch bemüht habe, durch Vergleich meiner Diagnosen mit den Notizen über den Ausgangspunkt und Verlauf der Infektion, sowie auch mit den verschiedentlich intra vitam gelungenen Kulturen zu möglichst sicheren Annahmen zo kommen. Versuchen wir unter Ausschaltung der ganz unklaren Fälle und den erwähnten Vor- 
behalten eine Statistik über die Erreger bei den einzelnen Gruppen der Thrombophlebitis aufzustellen, so finden wir bei den Formen mit Pseudomembranbildung zwar relativ häufig Pneumokokken vertreten (zweimal allein, einmal gemeinsam mit Staphylokokken, einmal zweifelhaft, ob Pneumo- oder Streptokokken und einmal Diplokokken nicht ganz sicherer Natur), doch fehlen andererseits Fälle mit Pseudomembranbildung nur auf Grund einer Strepto- oder Staphylokokkenerkrankung nicht (zweimal sicher diese Erreger, dreimal Kokken, die aller Wahrscheinlichkeit nach keine Pneumokokken sind). Auf der anderen Linie - Thrombophlebitis ohne Pseudomembran - sind diese letztgenannten Keime nur einmal, und dazu nicht einmal ganz sicher genannt, dagegen überwiegen dementsprechend die anderen Spaltpilze. Wegen der Unsicherheit unserer Prämissen glaube ich jedoch aus diesem Zahlenverhältnis keine absolut bindenden Schlüsse auf etwaige Beziehungen zwischen der Spezies der gefundenen Mikroorganismen und dem Auftreten oder Fehlen exsudativer Prozesse ziehen zu dürfen; dazu erscheint mir meine ganze Beobachtungsreihe überhaupt zu klein. Schon geringe Zufälligkeiten können hier zu erheblichen Irrtümern führen; so finden wir zum Beispiel in der Gruppe mit Pseudomembranbildung allein drei vom infizierten Mittelohr bzw. von der vereiterten Stirnhöhle ausgehende Thrombophlebitiden; daß sich bei einem derartigen Ursprung häufiger Pneumokokken finden als bei den zahlreichen Fällen von puerperaler Infektion, welche sonst das Hauptkontingent unseres Materials stellen, ist klar. Jedenfalls kann ich mich nicht zu der Ansicht entschließen, daß die von den pneumatischen Räumen des Schädels ausgehenden Venenentzündungen deshalb häufiger mit Pseudomembranbildung einhergingen, weil sie besonders häufig durch Pneumokokken verursacht werden. Wenn wir demnach also vielleicht der Pneumokokkenerkrankung im Sinne Weichselbaums bis zu einem gewissen Grade eine erhöhte Disposition zur exsudativen Entzündungsform nicht absprechen wollen, so ist diese doch keineswegs auf derartige Mikroorganismen beschränkt, sondern auch Strepto- oder Staphylokokken können schöne und typische Pseudomembranen produzieren (siehe allein Fall 16).

Dann habe ich Vergleiche angestellt, um zu sehen, ob sich Relationen nachweisen ließen zwischen dem Gesamtzustande der Kranken und der uns interessierenden Abart der Thrombophlebitis; namentlich konnte man daran denken, daß kräftige Patienten in jüngerem Lebensalter, die ja überhaupt auf jede Form eines äußeren Reizes heftiger zu reagieren pflegen, auch eher zu einer fibrinösen Ausschwitzung neigen würden. Irgend ein greifbares Resultat war nicht zu ermitteln. Ebenso gering war der Erfolg als ich den einzelnen Unterabteilungen meiner Fälle die Aufzeichnungen über die Höhe und die Charakteristika der Temperaturkurven gegenüberstellte; Art des Fiebers und histologischer Befund ließen keine Parallele zueinander ziehen.

Schließlich hatte ich gehofft, daß der primäre Sitz der Entzündungserreger innerhalb oder außerhalb des Venenrohrs - mir einen Fingerzeig geben könnte für die Beantwortung der gestellten Frage; aus verschiedenen Gründen läßt sich 
auch nach diesem Gesichtspunkt eine befriedigende Scheidung der Beobachtungen nicht durchführen. Einmal finden sich in einer ganz beträchtlichen Anzahl von Fällen Kokken sowohl innen wie außen, manchmal auch in der Wand der Vene; auffallend ist es immerhin, daß in allen Präparaten mit Pseudomembranbildung der Angriff der Kokken an der untersuchten Stelle wenigstens, soweit man aus den mikroskopischen Bildern einen Schluß ziehen darf, in der Hauptsache vom Lumen erfolgt zu sein scheint. Ein solcher Zusammenhang wäre ja auch ganz einleuchtend, wenn wir an die gewöhnlichen Bedingungen denken, unter denen ein gerinnbares fibrinöses Entzündungsprodukt sich einzustellen pflegt. Vollkommen befriedigend würde diese'Erklärung jedoch erst dann sein, wenn bei den übrigen, den pseudomembranfreien Fällen die Kokken nicht gleichfalls häufig gentig im Lumen lägen, wenn ferner der Nachweis gelänge, daß bei Einwirkung von Yikroorganismen aus der Umgebung eine exsudative Entzündung ins Lumen der Vene nicht stattfände.

Es liegt auf der Hand, daß diese Forderung am besten zu erfüllen ist durch geeignete Tierversuche, daher war mir das Studium der sehr genauen Arbeit von Talke für diesen Punkt außerordentlich interessant, der gerade die gewünschten Bedingungen seiner experimentellen Arbeit über infektiöse Thrombose zugrunde gelegt hatte. An die unverletzte Außenseite einer freigelegten Blutader wurden Bröckel von Staphylokokkenkulturen gelegt, die Wunde vernäht und die Tiere nach 9 bis 74 Stunden getötet. Nun lehren die sehr eingehenden mikroskopischen Protokolle, daß Talke meistens bei den erzielten Thromben eine zentrale und eine Randpartie voneinander differenzieren konnte; fast bei jedem Versuch wird dieser marginale Teil des Blutpfropfs als etwas besonderes hervorgehoben, und zwar als eine feinkörnige, helle, detritusartige Masse, welche mehr oder weniger Fibrin enthält. So heißt es z. B. in der Beschreibung des Falles 12: „Die Vena femoralis enthält einen adhärenten, wandständigen Thrombus, der als vollständiger Wandbelag erscheint. Der Thrombus ist in seinen Randpartien hell, weiter nach innen sind rote Auflagerungen vorhanden; die Randpartien sind ungemein fein gekörnelt, haben sich blaßrosa gefärbt." Nach dem Gesamteindruck, den ich mir aus den verschiedenen Protokollen über diese Bestandteile bilden mußte, hätte ich kaum daran gezweifelt, daß es sich hier um reguläre Pseudomembranen handelte, wenn nicht an mehreren Stellen wieder betont wäre, dậ sich in dieser Randzone auch Erythrozyten, Reste von solchen und Blutplättchen in größerer Menge gefunden hätten, also etwas, was nicht zu dieser Auffassung stimmte. Dagegen ersehien mir das Vorliegen einer Pseudomembran in den Versuchen 8 und 13 absolut sicher, denn hier heißt es: „Die Trennung von Thrombus und Gefäßwand, welche in ihren innersten Schichten, von geronnenem, fibrinhaltigem Exsudat durchsetzt ist, ist einwandfrei nicht möglich und kann nur willkürlich gemacht werden." "In dem letzteren (dem Thrombus) nämlich sind mit dem Protoplasma der Endothelzellen verschmolzene und von ihm den Ausgang nehmende Fibrinbälkchen und Fäden, die sich bis in die tieferen Lagen der Intima hinein fort- 
setzen, in großer Menge vorhanden." Wenn ich hinzufüge, daß die beschriebenen Randschichten der Gefäßinnenfläche so fest anhafteten, daß sie bei der Schrumpfung der Präparate im Alkohol an der Venenwand, nicht an den zentralen Thrombusteilen haften blieben, daß sie ferner sich vorzugsweise dort fanden, wo das Endothel fehlte und die Entzündungserscheinungen der Gefäßwand besonders ausgeprägt waren, so mußte ich doch wieder annehmen, daß die gefundenen Randschichten weniger durch Ablagerungen aus dem Blut denn vielmehr als ein Produkt der entzündeten Gefäßwand zu betrachten seien. Auch Talke (nach ihm auch Stenger, Haymann und Zurhelle) kommt zu dem Schluß, daß aus der erkrankten Gefäßwand Gewebsflüssigkeit austreten müsse, allerdings mehr auf Grund theoretischer Erwägungen, während er auf den histologischen Nachweis dieser Erscheinung weniger Wert gelegt hat. Die beschriebenen Massen stammen seiner Ansicht nach nur aus dem Blut und sind dort durch die austretende Flüssigkeit fixiert, während ich a priori in diesen Gebilden zum großen Teil das Exsudat selbst erblicken zu müssen glaubte. Um einigermaßen klar zu sehen, stellte ich unter den von Talke gegebenen Bedingungen gleichfalls einige Tierversuche an, die sich allerdings aus den oben angedeuteten Gründen nur auf das allerdiurftigste beschränken mußten. Die Einwirkung der verimpften Bakterien ließ ich aus besonderen Gründen in einem Fall etwas kürzer andauern als Talke.

Versuch I. Kleiner Spitz. Die Vena femoralis wird ganz vorsichtig freigelegt und durch zwei sehr behutsam unter dem Gefäß durchgeführte, aber vollkommen lose gelassene Fäden eine kleine Strecke markiert; zwischen den beiden Seidenfädchen wird ein Agarbröckel mit vriulenten Staphylokokken an die Venenwand gelegt, dann die Wunde dicht genäht. Bei der Sektion des 'Tieres, das nach 27 Stunden getötet wurde, zeigte sich der Wert der eingelegten Fadenstïcke; es wäre sonst unmöglich gewesen, in dem weithin eitrig-sulzig infiltrierten Gewebe die genaue Stelle der Impfung wiederzufinden. Das lebenswarm exzidierte Stück wurde in der üblichen Weise verarbeitet.

Mikroskopischer Befund: Im ersten Block sieht man die durch die Infektion gesetzte Entzündung noch ganz auf die eine Seite der Vene lokalisiert, sie hat hier im perivaskulären Gewebe und der Adventitia eine Eiteransammlung und ein dichtmaschiges Netz von Fibrin erzeugt; in der Media finden sich nur vereinzelte Fibrinnester, dagegen zahllose Leukozyten, welche größtenteils dem Lumen des GefäBes zustreben. Muskulatur und Bindegewebe sind etwas gequollen, die elastischen Fasern noch gut erhalten. Das Endothel befindet sich im Stadium lebhaftester Proliferation; es hat sich reihenweise abgestoßen und sitzt der Außenseite eines hier ursprünglich. anhaftenden wandständigen Thrombus an, doch hat sich nach dessen Abhebung auf der Innenfläche der Gefäßwand schon wieder ein fast vollständiger Saum von gequollenen Endothelien gebildet, zwsichen denen sich reichliche Leukozyten durchdrängen. Die Abhebung des Blutpfropfs muß intra vitam erfolgt sein, da sich zwischen ihm und Intima rote Blutkörperchen eingesehwemmt finden. Der Thrombus besteht aus feinkörnigen Massen, bei van Gieson-Färbung gelblich tingiert, und enthält reichliche Netze knorrigen und körnigen Fibrins, das in einzelnen Haufen angeordnet ist, ferner anch eine ganze Menge Leukozyten, zum Teil im Stadium des Zerfalls; eine ausgesprochene Schichtung besteht nicht. Verschiedentlich steht der Thrombus noch in Kontakt mit der Innenfläche des GefäBes, und zwar durch Vermittelung von hellen, fast homogen aussehenden Bestandteilen, in denen hie und da noch Erythrozyten oder Reste von solchen zu erkennen sind. Eine ausgesprochene Eigenfarbe nehmen diese Massen bei den gewöhniichen Methoden nicht mehr an; es findet sieh aber neben einzelnen Leukozyten und Endothelien ein ungeheuer feines Fibrinmaschenwerk, das mit dem des Thrombus in keinem unmittelbaren $\mathrm{Zu}$ - 
sammenhang steht. An einzelnen Punkten sind etwas stärkere der Venenwand parallele Balken zu erkennen, deren Verbindung mit den elastischen Fasern und den noch haftenden Endothelzellen sehr innig ist, ja stellenweise kann man. Fäserehen bis zwischen diese Elemente der Wand hinein verfolgen.

An den übrigen Teilen der Venenzirkumferenz sind die gesamten Erscheinungen viel weniger ausgesprochen, einige Leukozyten finden sich in der Wand, doch ist auch hier schon das Endothel in lebhafter Wucherung begriffen. Der zweite Block bietet insofern kein Interesse, als von Fibrin überhaupt kaum noch etwas nachzuweisen ist; die ganze Vene ist in einen wohlausgebildeten Abszeß eingebettet, der Thrombus besteht aus regellos zusammengeballten Erythrozyten mit außergewöhnlich reichlichen, meist stark zerfallenen Eiterkörperchen.

In keinem der Präparate konnte ich Kokken im Thrombus nachweisen.

Versuch II. Kaum mittelgroßer, ziemlich fetter Pintscher. Beide Venae femorales werden freigelegt und in üblieher Weise behandelt. Tötung schon nach 6 Stunden. Beiderseits ist das ganze Gefäßbündel in sulzig infiltrierte Gewebsmassen eingebettet und wird, um eventuelle postmortale Gerinnungsprodukte sicher auszuschalten in einem Schälchen mit physiologischer Kochsalzlösung ansgespültt.

Mikroskopischer Befund: Rechts: Die Veränderungen in der Umgebung und in der Wand der Vene sind qualitativ dieselben wie bei dem vorigen Tier, wenn sie auch deren Intensität bei weitem nicht erreichen. Beherrscht wird das Bild von einem sehr schön geschichteten obturierenden Thrombus, dessen Randzone sich fest an die Gefäßwand geheftet hat und bei der Schrumpfung des ganzen Präparats an dieser hängen geblieben ist. Diese Schicht enthält reichlich Fibrin, und zwar in ziemlich gleichmäßiger Verteilung, während in den zentralen Teilen der Fibringehalt der Schichtenbildung entsprechend erheblichen Schwankungen unterworfen ist. Die charakteristische periphere Partie haftet mit Hilfe feinster Fäserchen fest an den Resten der ihres Endothels beraubten Intima; fehlt an einzelnen Stellen eine besonders kenntliche Randzone, so bexühren sich zwar die Bestandteile des gewöhnlichen Thrombus mit der Gefäßwand, doch sind die Beziehungen zwischen beiden Substanzen lange nicht so innig wie in den Regionen der deutlich differenzierten Rindenschicht.

Links hat scheinbar eine kleine Verletzung der Vene stattgefunden, da trotz der kurzen Versuchsdauer die sehr heftige Eiterung fast direkt in den sonst ganz schön geschichteten Thrombus übergeht. Die Randzone ist in hervorragender Weise ausgesprochen; nur an einigen kurzen Strecken enthält sie Erythrozyten und deren Trümmer, im übrigen gleicht sie namentlich bei der van Gieson-Färbung ganz auffallend einer wirklichen Pseudomembran. Bemerkenswerterweise enthält jedoch dieses Gebilde keine Spur von Fibrin.

In den untersuchten Schnitten fanden sich nirgends im Lumen des Gefäßes Kokken.

Versuch III. Es handelt sich hier um die Arteria femoralis des einen zur ersten Versuchsreihe benutzten Hundes, die infolge des Vorbeifließens der Bakterienemulsion denselben Einwirkungen ausgesetzt war wie die Venen in dieser zweiten Gruppe; nach Talke spielen sich ja die Erscheinungen der infektiösen Thrombose an Arterien und Venen in gleicher Weise ab. Tötung des Hundes nach 40 Stunden und Arfertigung der Präparate in gewöhnlicher Art.

In der Wand der Arterie hat sich ein ziemlich großer AbszeB entwickelt, der in den ersten Schnitten noch nicht völlig in das Lumen des Gefäßes eingebrochen ist; in den später folgenden Präparaten läßt sich jedoch konstatieren, daß er den obturierenden, einigermaßen gut geschichteten Thrombus erreicht hat. In der nächsten Nachbarschaft der Eiterung fehlt das Endothel vollständig, in der weiteren Umgebung ist es in lebhafter Desquamation begriffen. Der Blutpfropf hat sich zum großen Teil von der Innenfläche der Arterie, teilweise unter Mitnahme von Endothelfetzen abgehoben, ein festerer Zusammenhang besteht eigentlich nur in der Gegend des Abszesses; hier ist eine deutlich ausgesprochene Randzone zu erkennen, welche zum Teil Erythrozyten enthält, an andern Stellen jedoch wieder das reine Bild einer Psendomembran bietet.

Die kräftige Arterienwand ist erheblich aufgelockert und enthält ein dichtes Netz von plumpen, 
intensiv gefärbten Fibrinbalken, und zwar namentlich in den äußersten Partien der Eiterung, wo einerseits die Elemente der kompakten Media auseinandergedrängt sind, wo andrerseits die Einwirkung der Leukozyten noch nicht stark genug gewesen ist, um die geronnenen Massen aufzulösen oder wenigstens ihre Färbbarkeit zu vernichten. Dies dicke Fibrinnetz geht nun an verschiedenen Stellen, besonders zu beiden Seiten des Abszesses unmittelbar in ganz gewaltige, blau gefärbte hyaline Balken über, welche ihrer Lage nach der genannten Randschicht entsprechen; mehrfach sind dickere und zartere Fasern zu sehen, welche über die Lamina elastica hinweg die beịden Fibrinnetze geradezu in eins verwandeln. Diese kräftigen Bestandteile der peripherischen Zone - es handelt sich hier wirklich um Balken - lockern sich allmählich nach dem Zentrum des Lumens zu auf und gehen ohne scharfe Grenze in das Maschenwerk des Blutpfropfs über.

Daß im vorliegenden Fall der Thrombus Kokken enthielt, ist nach dem Gesagten nicht wunderbar.

Ziehen wir kurz das Fazit unserer Nachforschungen, so können wir im allgemeinen vollkommen die vorzüglichen Beobachtungen Talkes bestätigen. Daß bei der von außen nach innen fortschreitenden exsudativen Entzündung - Phlebitis oder auch Lymphangitis der Gefäßwand im Sinne Koesters-, deren Existenz nach den weiteren Arbeiten Ebelings, Wlassows, Stengers und Zurhelles nicht bestritten werden kann, das Exsudat schließlich einmal das Lamen der Vene erreichen und dort sichtbar werden muB, ist ja klar und schon in den Experimenten Talkes deutlich zum Ausdruck gebracht, sobald die Versuchsdauer genügend lange gewählt wurde; entsprechend verliefen auch die Veränderungen bei meinem vierten Hund. Ob man diesem Vorgang den Namen einer tiefen pseudomembranösen Entzündung zubilligen will, ist in gewissem Grade Geschmackssache; der konstatierte anatomische Befund hat zweifellos große Ähnlichkeit mit den Erscheinungen dieses Prozesses, wenn wir auch für gewöhnlich annehmen, daß die Infektion nicht aus der Tiefe der Gewebe, sondern von der freien Oberfläche, in unserem Fall also von der Intima der Vene aus erfolgt.

Was bedeuten nun aber die hellen Randschichten, die schon in den ersten Stadien der Erkrankung sichtbar werden? Talke hält sie im großen und ganzen für zusammengesinterte Blutplättchen und Erythrozyten und deren Trümmer und hat auch schon der Ansicht Raum gegeben, daß diese Elemente durch austretende Gewebsflüssigkeit zum Haften gebracht seien. Ich muß ihm in dieser Hinsicht völlig beipflichten, möchte mich aber doch dahin aussprechen, dabj dieses von der Venenwand produzierte Exsudat räumlich eine viel größere Rolle spielt als ihm von Talke zugestanden wird, mit anderen Worten, daß diese Randzone zu einem nicht unerheblichen Teile aus der geronnenen entzündlichen Flüssigkeit besteht. Einmal müssen wir uns daran erinnern, daß die Koagulation günstigere Bedingungen vorzufinden scheint, sobald dem Exsudat ein größerer freier Raum zur Verfügung steht, daß ein solches also im Lumen des Gefäßes vielleicht schon sichtbar ist, ehe wir es in dem straffen Gewebe des Venenrohrs erkennen können. Ferner glaube ich sagen zu dürfen, daß das Verhalten des Fibrins uns zwingt, den Ursprung eines wesentlichen Teiles der hellen Massen in der Venenwand zu suchen; da seine Fasern, wie die Experimente von längerer Dauer uns lehren, in die Schichten der Intima und Media hineinreichen, muß es aus dieser Gegend 
stammen; nur ist es verwunderlich, daß die fragliche Randzone in den frühesten Stadien der Versuche scheinbar kein Fibrin enthält. Ich sage scheinbar, denn unser sicherstes Kriterium, die Weigertsche Methode, läßt uns die Fasersubstanz vermissen; später fällt die Farbreaktion positiv aus. Sollen wir nun annehmen, daß erst jetzt aus der Gefäßwand Fibrin zwischen die festgeklebten Blutbestandteile hineingewachsen ist? Ist es da nicht viel einleuchtender sich vorzustellen, daß es schon gleich zu Anfang ins Lumen vorgedrungen ist und seine Färbbarkeit nach Weigert erst nach Ablauf einer gewissen Zeitspanne erlangt hat? Finden wir doch hier genug Massen, die sehr wohl Fibrin sein können, deren feine Fäserchen aber bei den gewöhnlichen Tinktionen zwischen den in großer Zahl abgelagerten, in allen möglichen Stadien des Zerfalls begriffenen Blutelementen nicht als solches erkannt werden; wie schwer eine Differentialdiagnose in dieser Beziehung sein kann, ist ja schon mehrfach angedeutet worden.

Bei einem kurzen Überblick auf das bisher Gesagte können wir als feststehend betrachten, daß das Entstehen einer wirklichen Pseudomembran von der Lokalisation der Krankheitserreger abhängig ist, das heißt also, der toxische Reiz muß von der Innenfläche auf die Vene gewirkt haben. In diesem Satz fassen wir den Begriff Pseudomembran ganz streng, nicht nur in anatomischer Hinsicht, sondern auch nach der Art ihrer Entstehung. Wollen wir weniger rigoros vorgehen und mit dem Wort Pseudomembran jedwedes geronnene oder gerinnbare Exsudat verstehen, so ist die getroffene Scheidung nach dem Prinzip, ob die Kokken innen oder außen liegen, nicht durchführbar, da eine entzündliche Ausschwitzung aus der Gefäßwand bei jeder der beiden Arten von Thrombophlebitis septica nachweisbar ist.

Endlich dürfte es nicht ohne Interesse sein, wenn wir noch einige Vergleiche zwischen der Krankheitsdauer der untersuchten Fälle und der Eigenart der zugehörigen histologischen Bilder zu ziehen versuchen. Die hierfür notwendigen Unterlagen ließen sich dank der Liebenswürdigkeit der einzelnen Kliniken fast stets mit der notwendigen Genauigkeit beschaffen, wenn natürlich auch in keinem einzigen Falle das Einsetzen der Thrombophlebitis zeitlich mit vollkommener Sicherheit festgelegt werden kann. In einigen Nummern der Beobachtungsreihe habe ich mich mit ziemlich rohen Schätzungen begnügen müssen, doch glaube ich mich möglichster Objektivität befleißigt zu haben; so nahm ich bei Fall 27 eine Krankheitsdauer von 10 Tagen, bei Fall 24 eine solche von nur 14 Tagen an, wie wir sehen werden, ziemlich ungünstige Zahlen für unsere Erörterungen. Teilen wir unser Material wieder in die drei anatomisch voneinander verschiedenen Gruppen ein, in die der reinen Phlebitis, in die der Thrombophlebitis mit und ohne Pseudomembranbildung, so können wir die mittlere Zahl der Krankheitstage für die erste Abteilung auf 6,8, für die zweite auf 9,8 und für die letzte auf 29 Tage berechnen. Wir sehen also, daß die Dauer der Krankheit in der dritten Gruppe ganz erheblich länger ist, ja die kleinste Zahl, die ich hier ermittelt habe (14 Tage) überragt noch erheblich den Durchschnitt der Fälle mit Pseudomembranbildung; 
weniger scharf ist die Abgrenzung zwischen den beiden ersten Abteilungen, indem bei Pseudomembranbildung mehrere Fälle gefunden wurden, die nach dreimal 24 Stunden tötlich verliefen. Immerhin ist jedoch zu bemerken, daß der Verlauf bei der reinen Phlebitis im Durchschnitt kürzer zu sein pflegt, als wenn es zur Bildung eines Exsudathäutchens und einer Thrombose gekommen ist. So einleuchtend diese Zahlen auf den ersten Blick aussehen mögen, allzuviel Bedeutung möchte ich ihnen nicht beilegen, da die Durchschnittsziffer in der dritten Abteilung durch einige Fälle mit extrem langer Dauer in die Höhe getrieben ist (siehe Fall 14 und 19). Dabei ist es klar, daß hier Pseudomembranen a priori gar nicht zu erwarten sind, da sie nach Einsetzen der organisatorischen Veränderungen nicht mehr als solche kenntlich sein dürften; auch kann man sich vorstellen, daß es sich hier ursprünglich gar nicht um eine septische Thrombophlebitis gehandelt hat, sondern um eine schon länger bestehende blande Thrombose, die einer interkurrenten Infektion nachträglich zum Opfer gefallen ist. Scheiden wir aber derartige Fälle aus, so können wir bald keine Grenze mehr ziehen, ob wir diese oder jene Beobachtung statistisch noch verwerten dürfen, und die Ziffern der einzelnen Unterabteilungen nähern sich dann immer mehr. Alles in allem genommen, können wir uns jedoch dem Eindruck nicht entziehen, daß gewisse Beziehungen zwischen dem klinischen Verlauf und den geschilderten histologischen kennzeichnenden Befunden bestehen müssen. Ich habe bisher immer nur von der Dauer des Krankheitsablaufs gesprochen und mich jedes Urteils uiber die Schwere und die Bösartigkeit der infektiösen Thrombose enthalten; so nahe es liegt, diese beiden Begriffe ohne weiteres zu ịdentifizieren, wir müssen uns stets vor Augen halten, daß der Eintritt des Todes nicht allein von der Menge und der Virulenz der eingedrungenen Bakterien abhängig ist; viel entscheidender kann hier die Lokalisation der Erkrankung werden, man denke nur an die Hirnsinusthrombose nach einer Infektion der pneumatischen Räume des Schädels; auch die metastatischen eitrigen Prozesse spielen eine gewichtige Rolle für den Eintritt des Todes. Es ist doch klar, daß ein metastatischer Hirnabszeß oder eine eitrige Meningitis bei einer an sich nicht allzu schweren Thrombophlebitis schneller zu einem ungünstigen Ausgang führen wird als eine sonst ziemlich stürmische Infektion einer Extremitätenvene, die ohne derartige akut lebensbedrohenden Komplikationen verläuft. Wollen wir auch noch diesen Gesichtspunkt als Einteilungsprinzip unseres Materials einführen, so verlieren die erhaltenen Zahlen wegen ihrer absoluten Kleinheit jeden Wert.

Einige Worte wären noch zu sagen über den Wert, den wir der Exsudatbildung auf der Venenwand bei der Thrombophlebitis septica beilegen diurfen. Die Aufgabe der Pseudomembran an Ort und Stelle, nämlich den lokalen Schutz der bedrohten Gefäßwand vor der unmittelbaren Einwirkung pathogener Lebewesen, hatten wir oben schon erwähnt. Gegen die Allgemeinerkrankung nun, die Überschwemmung des Blutes mit pyogenen Kokken, sucht sich der Körper durch Ausschaltung des Kreislaufs in der befallenen Region mit Hilfe throm- 
botischer Prozesse zu schützen. Ist nun die Thrombose eine ganz unmittelbare Folge der an oder in der Vene liegenden Kokken? Für den ersteren Fall kann man diese Frage nach den Talkeschen und meinen Versuchen ohne weiteres mit nein beantworten, wir müssen uns vielmehr vorstellen, daß es die aus der Gefäßwand austretende gerinnbare Flüssigkeit ist, welche die vorbeiströmenden Blutbestandteile zum Haften bringt. Ganz so bestimmt können wir uns nicht aussprechen über die Reihenfolge und Wertigkeit der Vorgänge, wenn die Erkrankung einer Vene von ihrer Innenfläche aus zustande kommt; diese Unsicherheit rührt daher, daß wir diesen Modus der Infektion im Experiment nicht mit der notwendigen Sicherheit nachahmen können, daß das Leichenmaterial uns andererseits keine befriedigende Lösung bietet, da wir nie sicher sind, ob wir für unsere Präparate wirklich die Stelle der primären Infektion gewonnen haben oder ein erst sekundär erkranktes.Stückchen; auch konnten wir uns ja nicht in jedem Falle ganz darauf festlegen, ob die Hauptveränderungen, die gefunden wurden, mehr durch die zentral oder mehr durch die peripher gelegenen Mikroorganismen bedingt waren. Stellen wir dem jedoch gegenüber, daß es mir gelungen ist, auf experimentellem Wege wenigstens eine Fibrinabsonderung åus der Wand eines Gefäßes, wenn auch keine typische Pseudomembran zu erzeugen, und zwar durch intravenös gelagerte Kokken, daß es ferner ganz überwiegend derartig angeordnete Kleinlebewesen waren, die unter den Sektionspräparaten zur Pseudomembranbildung geführt hatten, und daß schließlich mehrfach festgestellt werden konnte, wie sich auf einem solchen Häutchen der Thrombus angesiedelt hatte, so glaube ich, allerdings mit aller Reserve, aussagen zu dürfen, daß auch bei diesem Infektionsmodus die Phlebitis den primären, die Thrombose nur den sekundären Anteil der gesamten Erscheinung darstellt. So brauchen wir auch bei der Thrombophlebitis septica nach keiner besonderen Ursache für die Blutpfropfbildung zu suchen, es sind im Grunde genommen dieselben Bedingungen, welchen auch die einfache aseptische Thrombose ihre Entstehung verdankt. An Veränderungen der Gefäßwand fehlt es bei der Bildung der Exsudatschichten wahrlich nicht, und auch der Blutstrom dürfte nicht ohne Wirbelbildung und Änderung seiner Geschwindigkeit an der rauhen Oberfläche der Gerinnungsmasse vorbeistreichen. Nicht ausgeschlossen erscheint es jedoch, daß neben diesen vorwiegend mechanischen Momenten auch chemische Vorgänge im Sinne Talkes statthaben; vielleicht darf man die oft vermißte Schichtung der Thromben, die nur regellose Ablagerung der einzelnen im Blute suspendierten Teilchen in diesem Sinne verwerten. Wie schon betont, stelle ich diese Theorie nur mit allem Vorbehalt auf, da sich ihre Richtigkeit nicht für jeden einzelnen Fall mit Sicherheit beweisen läßt, immerhin darf ich wohl annehmen, daß ihr ein hoher Grad von Wahrscheinlichkeit innewohnt; jedenfalls habe ich für die umgekehrte Anschauung, daß die Blutpfropfbildung die erste Erscheinung, die Exsudation aus der Venenwand nur eine Folge hiervon sei, nirgends einen Anhalt gefunden.

Wenn wir so das aus der Substanz des Venenrohrs stammende Entzündungs- 
produkt als das vermittelnde Bindeglied zwischen dem Auftreten der Kokken und dem Einsetzen der Thrombose betrachten, so läßt sich auch bis zu einem gewissen Grade das Zustandekommen der reinen Phlebitis ohne Verstopfung des Aderlumens erklären; wäre die Ablagerung der Blutbestandteile eine unmittelbare Folge der von den Bakterien ausgehenden Reize, so wäre gar nicht zu verstehen, warum es manchmal trotz der zahlreichen gefundenen Mikroorganismen nicht zur Thrombenbildung gekommen ist. Setzen wir als Bedingung hierfür jedoch erst das Eindringen von Exsudat in das Gefäßrohr voraus, so ist die Frage sofort gelöst, denn in den fraglichen Fällen ist ein Gerinnungsprodukt an dieser Stelle noch nicht nachweisbar; ohne weitergehende Schlüsse ziehen zu wollen, müssen wir uns doch vergegenwärtigen, daß die Krankheitsdauer bei der reinen Venenwandentzündung stets auffallend kurz angegeben wurde.

Um von vornherein Mißverständnissen zu begegnen, stelle ich noch einmal fest, daß diese ganze Theorie sich nur auf die Stelle der primären Infektion bezieht, da, wo aller Wahrseheinlichkeit nach der erste Angriff der pathogenen Keime erfolgte; denn diese Partie ist es allein, welche unsere Kenntnis der infektiösen Thrombose fördern kanh, mag sie im einzelnen Fall eine längere oder kürzere Ausdehnung zeigen. Ist es erst einmal zu einem völligen oder fast vollständigen Verschluß des GefäBrohrs gekommen, so kann der Thrombus schnell über den Wirkungsbereich der Spaltpilze hinauswachsen und den von ihnen direkt gesetzten Veränderungen vorauseilen; so wäre dann in einer bestimmten Entfernung von dem ursprünglichen Infektionsherd der Thrombus scheinbar etwas primäres, aber nur scheinbar, denn seine eigentliche Ursache liegt ja an anderer Stelle. Wir haben oben gesehen, daß solche Bilder wirklich beobachtet werden, und daß schließlich die vorrückenden Bakterien ihren Weg in diese Blutpfröpfe zu finden wissen. Ich möchte glauben, daß die nicht genügende Beachtung dieser Umstände mit das ihrige dazu beigetragen hat, daß die Ansichten über die infektiöse Thrombophlebitis sich noch so vielfach widersprechen.

\section{Schlußzusammenfassung:}

I. In einer nicht unerheblichen Anzahl von Thrombophlebitisfällen (etwa $1 / 3$ der untersuchten) läßt sich die Bildung von oberflächlichen Pseudomembranen auf der Innenseite der Venenwand nachweisen.

II. Es konnte aus den mikroskopischen Bildern festgestellt werden, daß diese Häutchen wirklich aus der Substanz des Venenrohrs stammende Exsudatmassen sind, daß es sich nicht etwa um atypisch gebaute Thrombenteilchen handelt; experimentell konnte wenigstens der Beweis erbracht werden, daß das Gewebe der Venenwand überhaupt die Fähigkeit besitzt, eine fibrinhaltige Flüssigkeit in die Gefäßlichtung auszuschwitzen.

IIT. Die Pseudomembranbildung ist kein zufälliger Nebenbefund, sondern ein integrierender Bestandteil des gesamten Komplexes von Erscheinungen, den wir mit dem Namen Thrombophlebitis septica bezeichnen. 
IV. Thr Auftreten hängt vor allem davon ab, daß die Krankheitserreger die Venenwand vom Lumen aus angreifen; liegen diese an der Außenseite des Gefäßes, so wurde eine typische Pseudomembran stets vermißt; gewisse Zusammenhänge lassen sich vielleicht auch mit der Spezies der Keime, auch mit der Dauer der Krankheit konstruieren.

V. Eine fibrinreiche Exsudation aus der Wandsubstanz der Ader fehlt auch dann nicht, wenn zuerst ihre Außenfläche von den Bakterien erreicht wird, sie ist jedoch ihrer Entstehung nach etwas anders zu bewerten wie die eigentliche Pseudomembran.

VI. Mögen die Keime liegen wie sie wollen, in jedem Fall dürfte das Exsudat vor dem Eintreten der Thrombose das Lumen erreichen und die letzte Ursache für die Ablagerungen der Blutelemente darstellen.

\section{Erklärung der Abbildungen auf Taf. IV.}

Fig. 1. Fall 2. S.-Nr. 1256 (1909). Elastika - van Gieson. A. Kokken. B. Pseudomembran. C. Lamina elast. int. D. Venenwand.

Fig. 2. Dasselbe Präparat wie Fig. 1. Elastika - van Gieson. Zeigt rechts typische Pseudomembran, die nach links nur allmählich in einen in Organisation befindlichen Thrombus übergeht.

Fig. 3. Fall 16. S.-Nr. 583 (1910). Hämatoxylin. - Rote Elastika-Fibrinfärbung. Zeigt, daß die Fibrinfäden der Pseudomembran zum Teil ihren Ursprung in der Venenwand unter der Lamina elast. int. nehmen. A. Pseudomembran. B. Lamina elast. int. C. Venenwand. D. Die tief in die Wand reichenden Fibrinfasern.

\section{Literatur.}

1. Arnold, Zur Morphologie der intravaskulären Gerinnung und Pfropfbildung. Virch. Arch. Bd. 155. - 2. As ehoff, Lehrbuch der Pathologischen Anatomie. - 3. Derselbe, Über den Aufbau der menschlichen Thromben und das Vorkommen von Plättchen in den blutbildenden Organen. Virch. Arch. Bd. 130. - 4. Derselbe, Thrombose und Embolie. Verh. d. Ges. D. Naturforscher u. Ärzte. Karlsruhe 1911. - 5. Derselbe, Über den Aufbau des Thrombus. D. med. Wschr. 1912, Nr. 44. - 6. Derselbe, Thrombose und Sandbankbildung. Zieglers Beitr. Bd. 52. 7. v. Bardeleben, Streptokokkus und Thrombose. Arch. f. Gyn. Bd. 83. -- 7a. Beneke in Krehl-Marchand, Handb. d. allg. Path. II, 2, S. 225. - 8. Bizzozero, Über einen neuen Formbestandteil des Blutes und dessen Rolle bei der Thrombose und Blutgerinnung. Virch. Arch. Bd. 90. - 9. Brücke, Über die Ursache der Gerinnung des Blutes. Virch. Arch. Bd. 12. 10. Bubnoff, Über Organisation des Thrombus. Vireh. Arch. Bd. 44. - 11. De la Camp, Thrombose und Embolie. Verh. d. Ges. D. Naturforseher u. Ärzte. Karlsruhe 1911. - 12. Duffek, Untersuchungen über septische Thrombosen. Arch. f. Gyn. Bd. 96. - 13. Ebeling, Über Phlebitis. Diss. Bonn, 1880. - 14. Eberth und Schimmelbuseh, Die Thrombose nach Versuchen und Leichenbefunden. Stuttgart 1888. - 15. Die selb en, Experimentelle Untersuchungen über Thrombose. Virch. Arch. Bd. 103. - 16. Dieselben, Die Entstehung von Thromben in größeren Gefäßen von Süugetieren. Virch. Arch. Bd. 103. - 17. Dieselben, Experimentelle Untersuchungen über Thrombose. Virch. Arch. Bd, 105. - 18. Fischer, Krankheiten der Lymphgefäße, Lymphdrüsen und Blutgefäße. D. Chir., Lief. 4, 24 a, 1901. - 19. Ders elb e, Entzündung, Sklerose und Erweiterung der Venen. Zieglers Beitr. Bd. 27. - 20. Fischer und Levy, Über pathologische Anatomie und Bakteriologie der Lymphangitis der Extremitäten. D. Ztschr. f. Chir. Bd. 36. - 21. Freud weiler, Experimentelle Phlebitis. Virch. Arch. Bd. 141. - 22. Gussenbauer, Sephthämie, Pyohämie und Pyosephthämie. D. Chir., Lief. 4, 1882. - 23. Gutschy, 
है
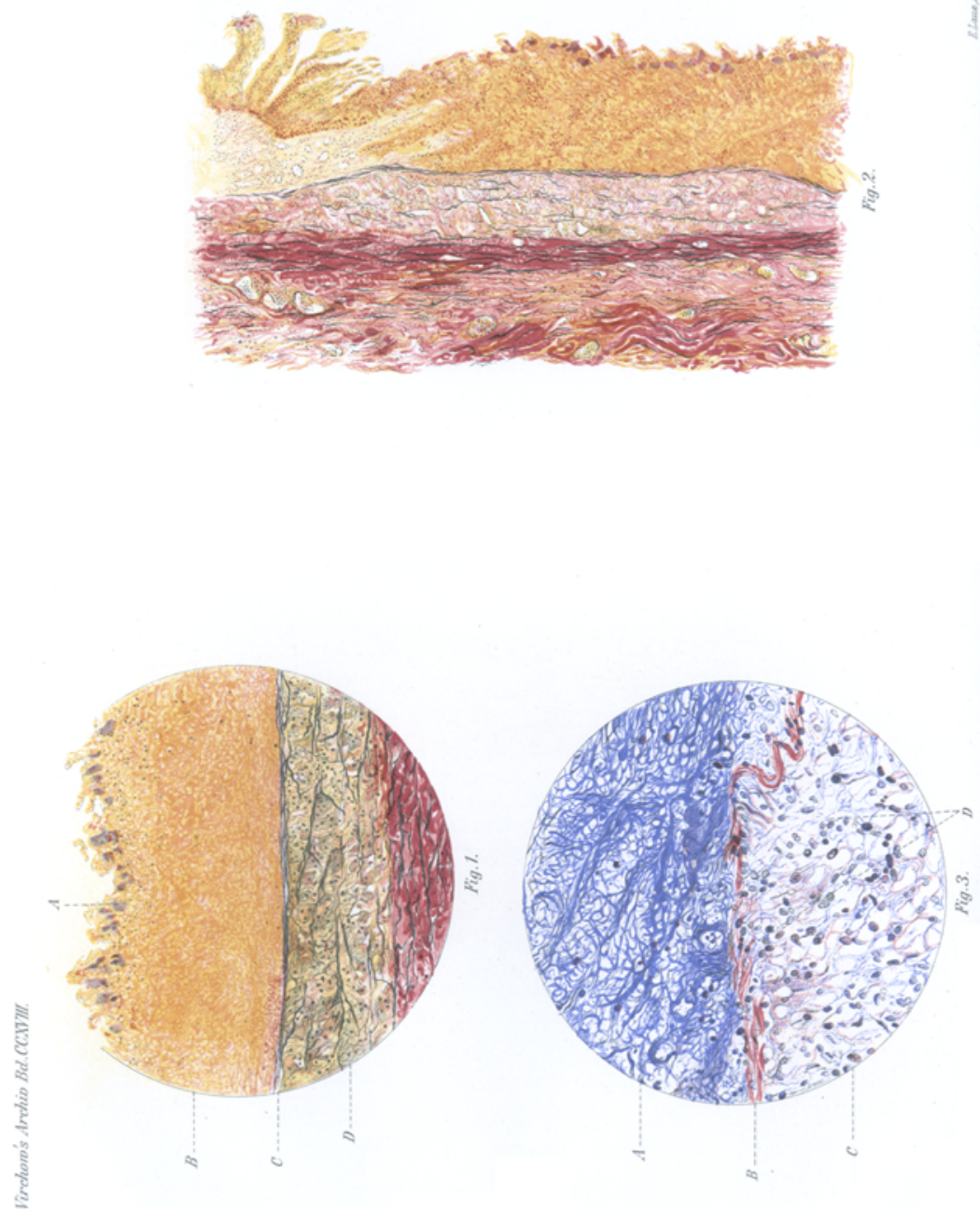
Zur Morphologie der Blutgerinnung und der Thrombose. Zieglers Beitr. Bd. 34. - 24. Hauser, Ein Beitrag zur Lehre von der pathologischen Fibringerinnung. D. Arch. f. klin. Med. Bd. 50. 25. Derselbe, Zur Frage der Thrombose. Virch. Arch. Bd. 213. - 26. Haymann, Experimentelle Untersuchungen über die Genese der otogenen Pyämie. Müneh. med. Wschr. 1910, Nr. 44. 27. Hohnfeld, Über die Histogenese der durch Staphylokokkusinvasion hervorgerufenen Bindegewebsabszesse. Zieglers Beitr. Bd. 3. - 28. Hunter, Transact. of the soc. for the improvement of med. and chir. knowledge. 1793. - 29. Derselbe, Abhandlung über Blut, Entzündung and SchuBwunden, ins Deutsche übertragen von Dr. Fz. BraniB, Berlin 1850. - 30. v. Kahlden, Über Septikämie und Pyämie. Ztlbl. f. Path. Bd. 13. - 31. Katzenstein, Über Venenthrombose und hämorrhagische Enzephalitis im Anschluf an bakteriologisch-anatomische Untersuchungen bei Sinusthrombosen. Münch. med. Wschr. 1911, S. 1853. - 32. Kaufmann, Lehrbuch der speziellen pathologischen Anatomie. - 33. Kelling, Studien über Thrombo-Embolie. Langenbecks Arch. Bd. 91. - 34. Koester, Über die Struktur der Gefäßwände und die Entzündung der Venen. Berl. klin. Wschr. 1875. - 35. Kus s ma, Über Aufbau und Entstehung der toxisehen Thrombose und deren Bedeutung. Zieglers Beitr. Bd. 55. - 36. Jaknowski, Ein Beitrag zur Kenntnis der Venenthrombósen infektiösen Ursprungs. Ztlbl. f. Bakt. Bd. 25. - 37. Derselbe, Über die Mitwirkung der Mikroorganismen beim Entstehen der Venenthrombose. Ztlbl, f. Bakt. Bd. 28. - 38. Laker, Studien über die Blutscheibchen und den angeblichen Zerfall der weiben Blutkörperchen bei der Blutgerinnung. Sitzungsbericht der Kgl. Akademie der Wissensehaften. Zitiert nach Lubarsch u. a. Virch. Arch. Bd. 116. - 39. Lebert, Krankheiten der Blut- und Lymphgefäße. Handb. d. spez. Path. u. Thex., redigiert von Radolf Virchow, Erlangen 1855. 40. Le u tert, Über die otitische Pyämie. Arch. f. Ohrenheilk. Bd. 41. - 41. Loeb, Vergleichende Untersuchungen über die Thrombose. Virch. Arch. Bd. 185. - 42. Löwit, Beobachtung der Zirkulation beim Warmblüter. Arch. f. exp. Path. u. Pharmak. Bd. 23. - 43. Derselbe, Weitere Beobachtungen über Blutplättchen und Thrombose. Ebenda Bd. 24. - 44. Labarsch, Handbuch der allgemeinen Pathologie. - 45. Merkel, Die Beteiligung der Gefäßwand an der Organisation des Thrombus mit besonderer Berücksichtigung des Endothels. Hab.-Schr. Erlangen 1903. - 46. Moty, Sind die postoperativen Thrombophlebitiden septischer Natur? Semaine med. 1912, Nr. 21. Ref. im Ztlbl. f. Chir. - 47. Oestreich, Lehrbuch der allgemeinen Pathologie. - 48. Orth, Lehrbuch der speziellen pathologischen Anatomie. - 49. Derselbe, Pathologisch-anatomische Diagnostik. - 50. Derselbe, Über Phlebitis exsudativa. Berl. klin. Wschr. 1914, Nr. 9, - 51. Ribbert, Lehrbuch der allgemeinen Pathologie und pathologisehen Anatomie. 52. Derselbe, Über die Thrombose. D. med. Wschr. 1912, Nr. 34. - 53. Derselbe, Über den Aufbau der Thromben. D. med. Wschr. 1912, Nr. 48. - 54. Derselbe, Weitere Beiträge zur Thrombose. D. med. Wschr. 1914, Nr. 2. - 55. Rieder, Beiträge zur Histologie und pathologischen Anatomie der Lymphgefäße und Venen. Ztlbl. f. Path. Bd. 9. - 56. Rokitansky, Lehrbuch der speziellen pathologischen Anatomie. - 57. Rost, Über den Aufbau und die Oberflächenzeichnung der Leichengerinnsel. Zieglers Beitr. Bd. 52. - 58. v. Schrötter, Erkrankungen der Gefä:Be. Nothnagels spez. Path. u. Ther. - 59. Schwallbe, Allgemeine Pathologie. - 60. Derselbe, Die Morphologie des Thrombus und die Blutplättchen. Zieglers Beitr. Suppl.-Bd. 7. 61. Stenger, Untersuchungen über die Entstehung der otitischen Hirnsinusthrombose. Verh. d. D. Otol. Ges. 1904, Bd. 13. - 62. Talke, Experimenteller Beitrag zur Kenntnis der infektiösen Thrombose. Bruns Beitr. Bd. 36. - 63. Virchow, Gesammelte Abhandlungen. - 64. Weigert, Über Kroup und Diphtheritis. Virch. Arch. Bd. 70 u. 72. - 65. Wlassow, Untersuchungen iiber die histologischen Vorgänge bej der Gerinnung und Thrombose mit besonderer Berücksichtigung der Entstehung der Blutplättchen. Zieglers Beitr. Bd. 15. - 66. Yatsushiro, Experimentelle Untersuchungen über die Thrombosenfrage nebst Angabe einer einfachen Methode zur Koagulationsbestimmung des Blutes. D. Ztschr. $f$. Chir. Bd. 125. - 67. Zahn, Untersuchungen über Thrombose. Bildung der Thromben. Virch. Arch. Bd. 62. - 68. Zenker, Über intravaskuläre Fibringerinnung bei der Thrombose. Zieglers Beitr. Bd. 17. - 69. Ziegler, Lehrbuch der allgemeinen Pathologie und pathologischen Anatomie. - 70. Derselbe, Venenentzündung in Eulenburgs Realenzyklopädie. - 71. Zurhelle, Experimentelle Untersuchungen über die Beziehungen der Infektion und der Fibringerinnung zur Thrombosenbildung im strömenden Blut. Zieglers Beitr. Bd. 47. 